Portland State University

PDXScholar

\title{
Identifying and Building on Strengths of Children With Serious Emotional Disturbances
}

Michael Orval Taylor

Portland State University

Follow this and additional works at: https://pdxscholar.library.pdx.edu/open_access_etds

Part of the Child Psychology Commons, Developmental Psychology Commons, and the Social Work Commons

Let us know how access to this document benefits you.

\section{Recommended Citation}

Taylor, Michael Orval, "Identifying and Building on Strengths of Children With Serious Emotional Disturbances" (2002). Dissertations and Theses. Paper 2873.

https://doi.org/10.15760/etd.2867

This Dissertation is brought to you for free and open access. It has been accepted for inclusion in Dissertations and Theses by an authorized administrator of PDXScholar. Please contact us if we can make this document more accessible: pdxscholar@pdx.edu. 
IDENTIFYING AND BUILDING ON STRENGTHS OF CHILDREN WITH SERIOUS EMOTIONAL DISTURBANCES

by

MICHAEL ORVAL TAYLOR

A dissertation submitted in partial fulfillment of the requirements for the degree of

DOCTOR OF PHILOSOPHY

in

SOCIAL WORK AND SOCIAL RESEARCH

Portland State University

2002 


\section{DISSERTATION APPROVAL}

The abstract and dissertation of Michael Orval Taylor for the Doctor of Philosophy in Social Work and Social Research were presented November 7, 2002, and accepted by the dissertation committee and the doctoral program.

COMMITTEE APPROVALS:

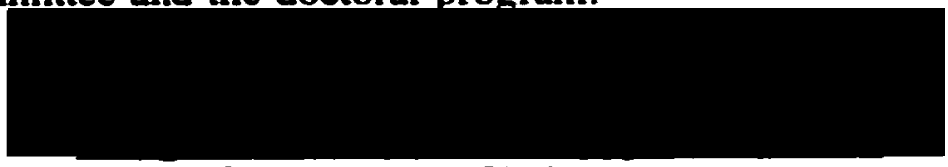

Sandra C. Anderson, Chair

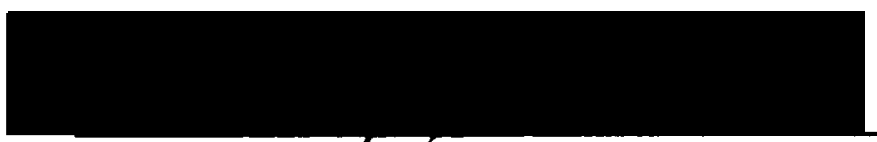

Eileen M. Brenhan

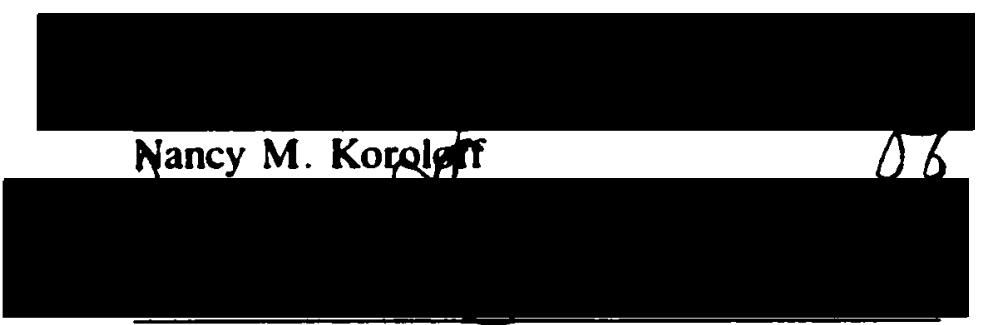

Matthew J. Modrcin

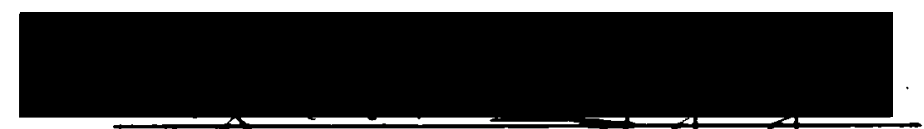

Elizabeth Wosley-George

Representative of the Office of

Graduate Studies

DOCTORAL PROGRAM APPROVAL:

Barbara J. Friesen

Graduate School of Social Work 


\begin{abstract}
An abstract of the dissertation of Michael Orval Taylor for the Doctor of Philosophy in Social Work and Social Research presented November 7, 2002.
\end{abstract}

Title: Identifying and Building on Strengths of Children with Serious Emotional Disturbances

The aim of this study is to explore strengths assessments and the participation of parents in assessment of strengths and functioning of their children challenged by serious emotional disorders. The children in this study have a high level of exposure to mental illness, domestic violence and substance abuse in their biological families. These children are living with family members or foster families in the community, with the majority at continuing risk of placement outside of their homes and communities due to serious emotional and behavioral problems.

The research questions investigated are the concordance of families and professionals in assessment of strengths, differences in assessment of strengths, problems in specific domains of functioning, and relationships of characteristics of the child with recognition of strengths by the parent and professional. 
This study uses data collected from families of children with serious emotional disorders receiving services through community-based wraparound services supported by the mental health services program for children $\# 5$ HSS SM52297 funded by the Center for Mental Health Services, Substance Abuse and Mental Health Administration. The dissertation research presents a secondary analysis of a portion of the evaluation data collected for that demonstration.

Eighty-five children were assessed by the parent and professional using the Behavioral and Emotional Rating Scale (BERS), the Achenbach Child Behavior Checklist (CBCL), and the Child and Adolescent Functioning Scale (CAFAS). It was found that families provided significant and unique information regarding their children. A repeated measures analysis of the strengths scores revealed significant differences in the assessment of strengths by the parent and professional raters in domains of intrapersonal strengths, affective strengths and family involvement. The findings support the use of the strengths measure by multiple informants to provide unique information regarding the child's strengths and functioning. 


\section{ACKNOWLEDGMENTS}

I wish to acknowledge the consistent mentoring provided to me by Sandra Anderson and Eileen Brennan during this research project and for sharing their standards for writing and data analysis with me. To Barbara Friesen and Nancy Koroloff for their leadership in advancing family empowerment and to Matt Modrcin and Michael Epstein for their unique contributions to recognizing strengths in children and adults.

This dissertation is dedicated to my son Daniel. who has demonstrated great strengths and to my life partner, Linda Marshall, who lives and works from the strengths perspective daily. 
TABLE OF CONTENTS

PAGE

ACKNOWLEDGMENTS $\ldots \ldots \ldots \ldots \ldots \ldots$ ii

LIST OF TABLES $\ldots \ldots \ldots \ldots \ldots \ldots \ldots \ldots \ldots \ldots$

LIST OF FIGURES $\ldots \ldots \ldots \ldots \ldots \ldots \ldots \ldots \ldots$ vii

\section{CHAPTER}

I SYSTEMIC AND INDIVIDUAL INTERVENTIONS FOR CHILDREN WITH EMOTIONAL AND BEHAVIORAL.

DISORDERS $\ldots \ldots \ldots \ldots \ldots \ldots \ldots$

Introduction $\ldots \ldots \ldots \ldots \ldots \ldots$

Mental Disorders in Children $\ldots \ldots \ldots \ldots \ldots$

Clinical Practice Research

Systems of Care for Children with Serious

Emotional Disorders

Supporting and Sustaining Systems of Care

Wraparound Practice Model

Identifying Strengths

Family Participation

Significance of the Study $\ldots \ldots \ldots \ldots \ldots \ldots$

Aims of the Study $\ldots \ldots \ldots \ldots \ldots \ldots \ldots \ldots$

II CONCEPTUAL FRAMEWORK AND RESEARCH

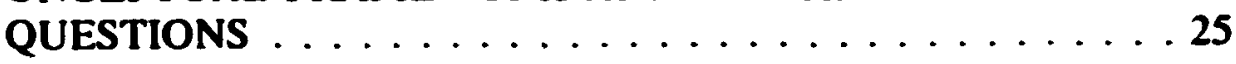

Conceptual Framework $\ldots \ldots \ldots \ldots \ldots \ldots$

Practice Constructs 
Research Questions . . . . . . . . . . . . 31

Research Question 1

Research Question 2

Research Question 3

Research Question 4

Research Question 5

Research Question 6

Research Question 7

III METHODS .................... 39

Context of the Study . . . . . . . . . . . 40

Implementation of a Wraparound Approach . . . . . 45

Participants and Procedures . . . . . . . . . 46

National Evaluation

Local Evaluation

Target Population/Sample for the Study

Recruitment and Selection

Data Collection Procedures . . . . . . . . . . 50

Instrumentation $\ldots \ldots \ldots \ldots \ldots \ldots \ldots \ldots$

Descriptive Information Questionnaire (DIQ)

Child Behavior Checklist (CBCL)

Child and Adolescent Functional Assessment Scale (CAFAS)

Behavioral and Emotional Rating Scale (BERS)

IV $\quad$ RESULTS $\ldots \ldots \ldots \ldots \ldots \ldots \ldots \ldots \ldots$

Child and Family Characteristics $\ldots \ldots \ldots \ldots \ldots 6$

Identification of Strengths $\ldots \ldots \ldots \ldots 7$

Agreement on Ratings of Strengths

Differences on Strengths Ratings

Comparing Strengths and Deficits Ratings 
Relationship of Child Characteristics and Assessed Strengths

v DISCUSSION $\ldots \ldots \ldots \ldots \ldots \ldots \ldots \ldots \ldots \ldots$

Identification of Strengths $\ldots \ldots \ldots \ldots 2$

Concordance of Family and Care Coordinator

Differences in Assessment of Strengths

Relationships to Strengths and Deficits Scores

Relationships of Scores of Problems and Strengths

Limitations of the Study $\ldots \ldots \ldots \ldots$. . . . . 88

Suggestions for Future Research $\ldots \ldots \ldots \ldots \ldots \ldots$

Implications for Practice $\ldots \ldots \ldots \ldots \ldots$. $\ldots \ldots$

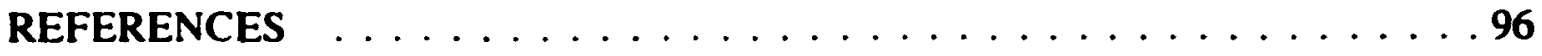

APPENDICES

A HUMAN SUBJECTS REVIEW AND APPROVAL . . . . 115

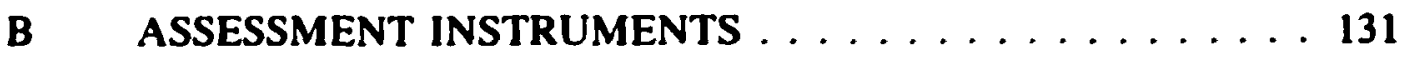




\section{LIST OF TABLES}

1. Child and Family Characteristics ...............63

2. Family Characteristics and Family Risk Factors ..... . . . . 64

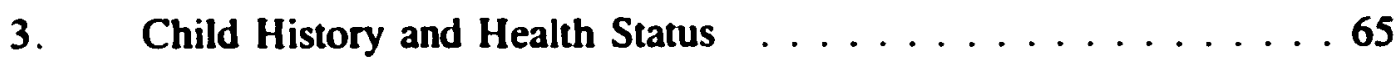

4. Scores on Standardized Instruments at Admission . . . . . . . 66

5. Mean Scores of Parent and Therapist Standard BERS

Subscale Scores ....................68

6. Concordance Among the Five BERS Subscales for Parent and Therapist ..................... 70

7. Repeated Measures Analysis of Variance of BERS Subscale Scores . . . . . . . . . . . . . . . . . . 72

8. BERS Subscale Score Mean Difference Between Parent and and Therapist Ratings .................. 74

9. Correlations Between Child Behavioral Checklist (CBCL) Scores and Child and Adolescent Functional Assessment Scale (CAFAS) Scores . . . . . . . . . . . . . . . . . 77

10. Summary of Regression Analysis for Variables Predicting Strengths Scores .................... 79 


\section{LIST OF FIGURES}

$\begin{array}{lll}\text { FIGURE } & \text { PAGE }\end{array}$

1. Conceptual Practice Model and Practice Constructs . . . . . . 27

2. Scale Main Effects $\ldots \ldots \ldots \ldots \ldots \ldots \ldots \ldots$

3. Rater by Scale Interaction Effects $\ldots \ldots \ldots \ldots \ldots \ldots$ 


\title{
CHAPTER I
}

\section{SYSTEMIC AND INDIVIDUAL INTERVENTIONS FOR CHILDREN WITH EMOTIONAL AND BEHAVIORAL DISORDERS}

\author{
Introduction
}

Mental and emotional disorders in children and adolescents touch at least one in ten children - and just one in five of those children receives treatment, as documented in the recent report on Mental Health by the United States Surgeon General (U.S. Department of Health and Human Services, 1999). Mental health care available to families challenged with children suffering from serious emotional disturbances has been historically fragmented, restrictive, and categorical. Many families lack access to the right level of treatment for their children in the community. This lack of sufficient services can exacerbate the development of more severe disorders. Mental health treatment and services provided to these children and their families must be better coordinated and integrated with other elements of the health care, education, and social service system.

Social workers and other helping professionals have relied too long on a deficit-based approach in practice emphasizing pathology over strengths. This approach serves to stigmatize families and their children. This study explores 
practice methods that instill hope for these children and families through involvement of families and professionals in assessing strengths of the child.

Jane Knitzer's (1982) groundbreaking work, Unclaimed Children, gave heed to the harm done to children and families poorly served due to service disorganization. Knitzer's study highlighted a systemically ineffectual delivery of services that contributed to isolation, harbored unmet needs, and favored institutional care. Her work asserted that mental health treatment services did not minimize or eliminate existing problems, but exacerbated them. Her published investigation became a rallying point for reform efforts.

This need for increased collaboration at the systems level has been well established, supported by Knitzer's (1982) work and others advocating for systems reforms (Stroul \& Friedman, 1986). To address this need, federal funding has supported initiatives to develop and enhance child centered, family-focused systems of care in local communities. According to Stroul and Friedman (1986), a system of care is based on multi-agency collaboration that is responsive to the individual child and the unique cultural needs of the family. Essential elements of a system of care include: strength-based service planning; coordinated agency efforts; and family voice, access, and ownership streams. These features serve to build systems that are responsible and accountable to children and families challenged by complex and enduring social, behavioral and emotional problems. Under this collaborative system of care, Knitzer's "unclaimed children" are embraced as the entire community's children. 
While current research provides support for the successful implementation of systems changes and practice improvements (Friedman \& Burns, 1996; Rosenblatt, 1998; Whitbeck, Kimball, Olsen, Lonner, \& McKenna, 1993), the relationship between systems level changes and practice methods for children and families remains unclear. Additional research is needed to refine the interventions and assess fidelity of practice to selected values and principles (Epstein, 1999b; Lourie, Stroul, \& Friedman, 1998).

This study identifies some key practice constructs of the system of care philosophy and explores these through the use of standardized instruments. In the study, the Behavioral and Emotional Rating Scale (BERS; Epstein \& Sharma, 1998) is used to identify strengths and to explore agreement between professionals and family members on assessment of strengths. Traditional child assessment instruments appraising behavior problems and functional deficits are also utilized to explore the extent of agreement and differences regarding both strengths and functioning of the child. Practice constructs being explored are the identification of strengths and participation of family members in assessing the child's strengths and needs. These constructs are posited as key practice elements associated with improved services for children with serious emotional disorders (Cowger, 1994; McCammon, Spencer, \& Friesen, 2001).

Social work researchers have raised practice challenges inherent in implementing a strengths perspective and increasing collaboration between families and professionals to increase productive partnerships and mutuality (Collins \& 
Collins, 1990; Saleeby, 1996; Weick, Rapp, Sullivan, \& Kisthardt, 1989). The process of assessing strengths including the perspectives of both the family and professional are investigated through this study. Saleeby (1996) provides a context for the importance of focusing on strengths:

The impetus for the evolution of a more strengths-based view of social work practice comes from the awareness that U.S. culture and helping professions are saturated with psychosocial approaches based on individual, family and community pathology, deficits, problems, abnormality, victimization and disorder. (p. 226)

A strengths perspective challenges the dominant deficit-oriented approach to assessment, evidences a belief in the dignity, worth, and capabilities of the individual, and challenges the reliance of professional authority as the dominant voice in assessment and diagnosis (Weick, Rapp, Sullivan, \& Kisthardt, 1989).

The following review of literature and research addresses the prevalence of mental health disorders in children and practice improvements in systems of care; including strengths-based assessment and family participation in assessment and care planning. The aim of this study is to explore recognition of strengths by families and professionals and explore participation of families with practitioners regarding those strengths. The assessment of strengths and functioning from the perspectives of both the family and professional are examined to determine relationships can be predicted between a child's behavior problems, functional level, age and gender and the recognition of strengths. The purpose of this study is to increase our understanding of methods to assess and build upon strengths of children living with behavioral and emotional challenges. 
Mental Disorders in Children

Mental disorders appear in families of all social classes and backgrounds, although children with physical problems, family history of mental and addictive disorders, poverty and caregiver neglect are at higher risk. The manifestation of mental disorders in children derives from a complex mix of individual development and constitutional factors. This complexity requires clinicians and researchers to attend to multi-determinant etiology encompassing biological, social, and psychological factors in assessment and treatment planning.

The 1999 U.S. Department of Health and Human Services report of the Surgeon General on children and mental health, citing results of the MECA Study (Methodology for Epidemiology of Mental Disorders in Children and Adolescents), reports a prevalence estimate of $21 \%$ of U.S. children ages 9-17 with a diagnosable mental or emotional disorder. These findings reveal a serious statistic: one in five children and adolescents experience symptoms of a mental or emotional disorder, with $5 \%$ suffering from an extreme functional impairment. The incidence of specific disorders, by diagnostic categories resulting in at least a mild level of impairment includes anxiety disorders (13\%); mood disorders (6.2\%); disruptive disorders (10.3\%); and substance abuse disorders (2\%) (Shaffer et al., 1996; U.S. Department of Health and Human Services, 1999).

A range of treatments exists for many mental disorders in children and emerging research explores effectiveness of these treatments. Though traditional 
practice models have relied on the etiology of these disorders being negative environmental influences, there is an increasing consensus that constitutional factors have pronounced influences on many disorders. Disorders such as autism, childhood schizophrenia, attention-deficit disorders, and mood disorders have only recently been accepted as predominantly biologic in origin (Jensen, 1999; U.S. Department of Health and Human Services, 1999; Weissman, Warner, Wickramaratne, Moreau, \& Olfson, 1997). Research on neurobiology challenges a provincial overemphasis on family dynamics as the source of serious emotional disorders. However, these traditional models of practice based on pathology and blaming the family are rooted deeply in our professional cultures and practices (Ryan, 1976, Saleeby, 1996).

\section{Clinical Practice Research}

Research verifies the importance of a multi-determinant model in assessment and treatment that includes biologic (genetic and environmental), social (familial and societal), and psychological (developmental and interpersonal) influences. Controlled studies of treatment interventions, primarily limited to outpatient treatments in research settings, demonstrate that improvements in functioning are consistently greater in groups receiving treatment and that multimodal treatment leads to better outcomes (U.S. Department of Health and Human Services, 1999). Research on children's mental disorders and treatment are summarized in the Surgeon General's report which emphasizes the need for more 
extensive study of optimal treatment practices, especially for children with the most severe disorders.

Current research does not adequately address a range of interventions for the most seriously disordered children. Clinical practices studied in much of the current research is most often designed around a particular service modality, outpatient therapy, and are usually tested in controlled research settings (Rosenblatt, 1998). Rosenblatt suggested that the study of interventions focus at the services level, examining specifics of therapist or caseworker interactions with children, their families, and community support systems. As multi-level services include a number of interventions across community and clinic settings, this requires a capacity to describe and measure the interventions beyond those conducted via clinical trials research in outpatient settings. This inquiry requires methods relevant to emerging practices, methods derived from the experience of program evaluation and formative research methods (Patton, 1994; Tyson, 1992). Studies on outcomes of intensive community-based treatments, though limited in number, have supported positive benefits of these comprehensive interventions (Heflinger, Northrup, Sonnichsen, \& Brannan, 1998; Kutash \& Rivera, 1996; Rosenblatt, 1998).

Research focusing on benefits of residential treatment for children and adolescents has been sparse, though these settings account for up to one-half of the dollars spent on treatment for children (Burns, 1991). Burns and others (Weller, Cook, Hendren, \& Woolston, 1995) have expressed concern regarding the lack of 
data on outcomes for hospital and residential treatment settings, as these are the most expensive and intrusive treatment options for children. Rising admissions to inpatient psychiatric settings during the 1980s and 1990s were not supported by evidence of increased clinical need or social benefit. Concerns have been raised about this lack of data for residential and hospital treatments including admission criteria; cost-benefit ratio; risks inherent in removal from the home and community; difficulty of reintegration into the family; and potential for victimization by residential treatment center staff (Friedman \& Street, 1985; Greenbaum et al., 1998). Knitzer (1982) initially raised these concerns in the early 1980s, focusing on the excessive and inappropriate use of psychiatric hospitals and reliance on residential treatment for children and adolescents. These concerns support the need for investigation of emerging practices in community-based systems of care for children as alternatives to institutional treatment.

The need for more empirical data regarding community-based treatment supports this investigation of key practice constructs of these evolving systems of care. This study focuses on two practice constructs: using a strengths-based assessment and exploring family participation in assessment of both strengths and functioning of their child. Strengths identification and participation of families in assessment are posited as essential components of community-based treatment for children and adolescents living in their own families and communities. These constructs are components of a practice model described as wraparound services 
provided to children with serious emotional disorders through coordinated systems of care.

\section{Systems of Care for Children with Serious Emotional Disorders}

Evaluations of services provided to targeted children with severe mental/ emotional disorders have produced a body of research on implementation of systems of care endeavoring to link outcomes with practice improvements. These studies have documented changes in service delivery as well as improved child outcomes in functioning and behavior (Center for Mental Health Services, 1999). This literature has increased understanding of some key elements of communitybased and integrated services for children, implementing the principles first articulated in Child and Adolescent Services Systems Principles (CASSP) and later referred to as systems of care (Stroul \& Friedman, 1986). Much of this literature has focused on implementation and measurement of systems-level and practice changes (Center for Mental Health Services, 1997, 1999). Research provides evidence of successful implementation of the system of care approach through practice improvements including: (a) increased access, voice, and ownership by families and consumers (Whitbeck et al., 1993); (b) involvement of key individuals in developing community wraparound plans (VanDenBerg, 1990); and (c) engagement of the family as a collaborator in the use of a strengths-based approach (Malysiak, 1998). 
Findings of positive outcomes for children served by systems of care comes from a number of sources related to these efforts and has been increasing (Center for Mental Health Services, 1999; Stroul, 1993). Functional improvements for children in family life, school success, and reduction of juvenile arrests has been reported in several studies. Data from California's experience in pioneering system reform efforts identified a specific target population and a mission to keep children "in school, at home and out of trouble" (Rosenblatt, 1993, p. 275). Interagency coordination and collaboration along with requirements that services be community based and culturally competent are key elements in this system. In assessing the system's success in achieving its goals, Rosenblatt and his colleagues found a reduction in out-of-home placement, cost savings through placement avoidance, improved school performance, increased school attendance, and a reduction in juvenile justice recidivism (Jordan \& Hernandez, 1990; Rosenblatt, 1993). The cost containment data for California is compelling and has been substantiated by data from Vermont (Bruns, Burchard, \& Yoe, 1995) as well as Wisconsin and Hawaii (Foster, Kelsch, Kamradt, Sosna, \& Young, 2001).

Data from the SAMHSA Child Mental Health Initiative programs have been positive, especially regarding the impact on quality of life for families. Significant improvements in child and family functioning have teen associated with practice changes and systems' interventions (Farmer 1996). The Milwaukee "25 Kids Project" focuses on a group of children who have experienced multiple challenges in their lives, including residential treatment, and whose care has been particularly 
costly. As a result of the Milwaukee project, the majority of these adolescents have returned to their communities, many to live with their families. Many returned to school and have avoided contact with the juvenile justice system (Center for Mental Health Services, 1999; Kamradt, 1996).

Systems of care initiatives have not received universally positive evaluations. Research conducted on the Fort Bragg demonstration project and in Stark County, Ohio found no differences in children's outcomes for those enrolled in systems of care versus those receiving usual services (Bickman, 1996b; Bickman, Summerfelt, Firth, \& Douglas, 1997). These findings have been challenged on the basis that the Fort Bragg project did not establish fidelity to the theory and practices of systems of care (Friedman \& Burns, 1996). The Bickman studies underscore the need for increased empirical evidence about both the practices that constitute system of care interventions and the connection between practice changes and child and family outcomes.

\section{Supporting and Sustaining Systems of Care}

Intensive services for children with serious emotional disturbances remains primarily managed and funded by the public sector, which has been dependent on the identification of a categorical need under educational or mental health criteria and funding. The continued prevalence of categorical services is rooted in the financing mechanisms codified in special education law and Medicaid regulations. These categorical restrictions can limit access to flexible funding needed to support 
community-based practices. Barriers to flexible funding and individualized service delivery continue to impede the full implementation of system of care values (Malekoff, 2000). Expenditures for residential and hospital care still exceed those for community and family-based treatments. There is a lack of evidence of effectiveness of these more restrictive traditional interventions (Burns, Hoagwood, \& Maultsby, 1998).

Implementation of mental health managed care in the public sector provides new opportunities to focus on improved access, practice innovations, and flexible services. The success of mental health managed care for children is closely related to the level of community and family involvement in implementation, quality assurance and public oversight of contract performance (Pires, Stroul, \& Armstrong, 2000).

The impact of managed care initiatives differs greatly by state and community, most often related to the parameters of the managed care contracts. Managed care entities are widely varied in their goals depending on whether they are profit or service driven. The managed care business model can result in either an emphasis on limiting care to increase profit or improving flexibility to achieve positive outcomes. Incentives often do not align at the systems and services levels, resulting in categorical services such as residential care receiving higher levels of reimbursement than intensive community-based care (Foster et al., 2001).

Creating service delivery systems capable of meeting the needs of these children and families requires a sustainable infrastructure to deliver and support 
these services (Stroul \& Friedman, 1996). This drives the call for systematic research addressing demonstrations of services integration in mental health, education, and human services that goes beyond descriptions of systems reforms to evaluation of practice changes raised repeatedly in the literature on developing systems of care. Research on practice changes resulting from expanded and alternative structure of service delivery technologies at the systems, program, and services level is needed to link essential practice elements to long-term successes for these children and their families (Friedman, 1997; Knapp, 1995; Rosenblatt, 1998).

The focus of this dissertation research is to study some key practice constructs of a practice model advocated in the literature on system of care: identification of strengths and exploring participation of families in assessment. The implementation of these practice constructs are posited to optimize the match between the needs of the child and family and services through identification of strengths of the child and involvement of the family in conducting the assessment and implementing a plan of care.

\section{Wraparound Practice Model}

Wraparound is a collaborative practice model, derived from ecological systems theory, which defines a process of implementing individualized, comprehensive services for youth with complicated serious emotional disturbances. The wraparound approach emphasizes meeting the individualized needs of the child 
in the least restrictive setting (Malysiak, 1997). Wraparound practices were advanced by John VanDenBerg (1990), initially through the Alaska Youth Initiative, and by other innovators in North Carolina, Florida, Illinois, and Vermont (Behar, 1985; Burchard \& Clarke, 1990; Dennis, 1992; VanDenBerg \& Grealish, 1996). Wraparound practice principles are being actively adopted across the country as a model for meeting the needs of children requiring an array of community services and natural supports to achieve positive outcomes. To increase healthy functioning, the natural ecology of the child including the family, community, and service systems, is engaged to support the strengths and individualized needs of the child and family. Principles of wraparound practice include voice and choice for the child and family, compassion, and flexibility (Franz, 2000). The wraparound process focuses on engaging families and community supports in a process of developing an individualized plan based on individual and family strengths and needs in multiple life domains (McGinty, McCammon, \& Koeppen, 2001).

Essential practice elements of wraparound include: (a) individualized services, (b) strengths-based perspective and use of natural supports, (c) development of a support team for the child and family, (d) services that are community-based, (e) a collaborative stance between families and professionals, (f) flexible funding and services, (g) outcome-based services, and (h) family voice and choice of services (Burchard, 1998). Wraparound emphasizes a collaborative approach between service providers and families that provides families with 
supports and services in the community to maintain their children at home and in school. The wraparound practice model is designed to support families in providing care and treatment at home in lieu of institutional treatment (Burns, Hoagwood, \& Maultsby; i998). VanDenBerg and Grealish (1996) emphasized wraparound must include collaborative child and family teams that create and implement individualized support and plans of care and availability of sufficient funding to meet the needs identified in the plan of care. This approach relies upon the child and family as members of a team coming together to listen and to agree on a plan of action. Successful implementation of wraparound requires a funding infrastructure that includes shared and flexible funding and services necessary to support this practice. Malysiak (1998) reported that a key to positive outcomes is the active engagement of the family as collaborators in the process and the use of a strength-based ecologically oriented approach. Traditional methods of providing services have been described as fragmented, costly, overly restrictive and often disruptive in requiring placement that is outside the child's home and community (Hernandez \& Hodges, 1996; Sosna, 1999).

This dissertation research explores key constructs of the wraparound practice model - the recognition of strengths and involvement of the family in assessment of the child's strengths and needs. 


\section{Identifying Strengths}

The process of mental health assessment, with its embedded bias toward illness and dysfunction and pressure to collect data on pathology, can have a profound negative effect on the client (Graybeal, 2001). Key to a change in perspective is engaging clients and families in a way that builds on their strengths, recognizing that the most challenged children and stressed families have competencies, strengths, and resources (Epstein, 1999b). Saleeby (1996) articulated how an emphasis on pathology has permeated our field of practice and may be antithetical to social work values; reliance on categorical funding and service delivery "silos" perpetuate this deficit-oriented service delivery system.

Embracing a strengths-based perspective has been posited to: (a) lead to more positive engagement of children and families; (b) identify for the child, family, and professionals what is going well in the child's life; (c) remind professionals of the competencies that can become the basis for future growth; and, (d) establish positive expectations for the child (Epstein, 1999b). Strengths-based intervention and case management approaches have been evaluated as useful for adults with serious mental disorders (Modrcin, 1988) and have been postulated as an essential component in promoting positive outcomes for children (Epstein \& Sharma, 1998).

Traditional practice approaches have emphasized problem-focused care planning that is driven by services reimbursement, emphasis on medical diagnosis, and professional and facility licensing. Unlike a deficit approach, with well- 
entrenched assumptions about human functioning, a strengths-based approach to service provision for high-needs children and adolescents has gained recognition and support (Brun \& Rapp, 2001; Graybeal, 2001). A focus on assessment of strengths has commanded increasing attention in the literature on education (Nelson \& Pearson, 1991), mental health (Stroul \& Friedman, 1996), child welfare (Saleeby, 1992), and family services (Dunst, Trivette, \& Deal, 1994).

Fostering strengths in children with serious emotional disturbances builds upon research identifying critical factors present in resilient children. These factors are caring relationships, consistent expectations from a caring adult with capacity to build on strengths, and opportunities for child and family participation (Benard, 1996). Important sources of strength are cultural and personal stories, narratives and lore (Saleeby, 1996), as well as the "survivor's pride" of surviving abuse and trauma (Wolin \& Wolin, 1993). These strengths are often evident in youth and their families who are coping with and surviving mental illness.

Resiliency research challenges traditional concepts about child development; positing that childhood trauma most inevitably leads to adult psychopathology (Bernard, 1993; Garmezy, 1994) and that social conditions viewed as toxic usually lead to problems in everyday functioning of children, families, and communities (Rutter, 1979; Rutter \& Sandberg, 1992).

Strengths-based assessment can facilitate the engagement of the family in services, particularly when a child has a history of unsuccessful placements or services (Courneyer \& Johnson, 1991). Strengths-based assessment from multiple 
perspectives supports discourse regarding strengths of the child and is theorized in this study to promote family-professional collaboration in recognizing and building upon strengths.

A primary aim of this study is exploring use of a strengths assessment. Adoption of a strengths perspective is examined through use of the Behavioral and Emotional Rating Scale (BERS) completed by the family and professional.

\section{Family Participation}

In comparison with families of children with physical disabilities and developmental disorders, families of children with serious emotional disabilities (SED) have reported a higher level of personal and family stress (Friesen, 1989). Stigma and blame continue to center on families of these children, based on theoretical approaches dominated by pathology and attribution of problems to individual deficits or family dysfunction (DeChillo, Koren, \& Mezera, 1996). The complexity and intensity of challenges facing children with SED and their families have become increasingly well documented. These include a fragmented service delivery system, inadequate insurance coverage for home and community-based care, and difficulty with access to flexible and individualized services. The lag between the recognition of this need and the provision of a systemic response to that need has had a negative impact on these children and their families, resulting in greater stress for and isolation of the family and negative outcomes for the child (Stroul, 1996). 
Family involvement is an increasingly recognized value, and family members have assumed administrative and advocacy positions within government and treatment agencies (Koroloff, Friesen, Reilly, \& Rinkin, 1996). Familycentered service delivery is accepted as a value, but has not been fully realized or adequately measured at the services level. Changed attitudes toward families and clinical practices that are inclusive of family voice require professionals to hear and heed family input (Allen \& Petr, 1995; Tannen, 1991). Involvement of families as full partners in creating a plan for their children is critical to success of that plan. A partnership between parents and professionals is one in which both parties join to determine and meet information and service needs (Heflinger \& Bickman, 1996). Essential components of this partnership are: (a) shared power and decision-making, (b) open communication regarding the child's needs in conjunction with shared information about the services systems' strengths and limitations, (c) practical assistance and improved access to services, and (d) readiness of the provider or system to alter services based on feedback from families (Simpson, Koroloff, Friesen, \& Gac, 1999). Factors supporting increased involvement of families in assessment and care planning include growth of consumer awareness, research evidence discrediting family dynamics as the primary etiology of mental illness in children, and evidence that social support and family empowerment can lead to improved outcomes (DeChillo, Koren, \& Mezera, 1996; Koroloff, Friesen, Reilly, \& Rinkin, 1996). 
Increased family support has been associated with a higher level of initiation of mental health services (Elliott, Koroloff, Koren, \& Friesen, 1998), membership and involvement in parent support groups (Singh, Curtis, Wechsler, Ellis, \& Cohen, 1997), participation in systems reform efforts (Koroloff, Friesen, Reilly, \& Rinkin, 1996), and increased satisfaction and empowerment (Singh, Wechsler, \& Curtis, 2000).

Participation in assessment and care planning endorses families of children with serious emotional disorders as experts regarding their children. Family participation also supports a principle of democratic participation and exercise of client and family rights (Heflinger \& Bickman, 1996). Social work has codified self-determination in its practice values. Nevertheless, mental health professionals from social work and other disciplines have contradicted these values in striving for professional role identity, increased reimbursement, and personal status. These factors serve to distance professional helpers from families of children with serious emotional disorders (Johnson, Cournoyer, \& Fisher, 1994). Examples of exclusion of families are still evident in practice: requiring families to stay in the waiting room while their children receive treatment; isolation of children receiving residential treatment from their families; and pejorative use of diagnostic labels for parents.

Increasing family participation requires rapport between families and professionals in planning, providing, and delivering services and demands changing the balance of power and control between professionals and families (Collins \& 
Collins, 1990). Implicit in increasing participation is the expectation that no one person is the expert with the answers to all the issues or problems being presented. Relationships between mental health professionals and families should include conveying a caring and non-blaming attitude, sharing of information, recognizing the family as a key resource, and acknowledging limits to professional authority through sharing responsibility and power (Franz, 1999).

\section{Significance of the Study}

Essential to evaluating family participation is the collection and analysis of data indicating the degree to which key participants were adequately involved in the process and agreed upon an assessment and care plan. Previous studies have raised questions regarding whether or not families were truly engaged as collaborators in the assessment and service planning and as contributors to the wraparound process itself (Friedman \& Burns, 1996). The youth served by this project have many challenges based on their individual histories and biologic vulnerability. This study adds to the body of research through analysis of assessments of strengths by families and service providers, and by exploring agreement and difference between families and professionals on standardized measures.

It is a significant finding that families do endorse higher ratings of strengths of their children, given the context of their own challenges. The findings support the use of diverse perceptions of strengths and functioning, proposed in the 
conceptual model, to enhance communication and engagement. Shared assessment provides significant information and the findings indicate that families possess unique information about their children not otherwise available to the therapist. The data provided through use of strengths assessment makes a unique contribution to the assessment.

\section{Aims of the Study}

The first aim is to evaluate the adoption of a strengths perspective through use of strengths-based assessment by the family and professional. Exploring the involvement of the family in assessment of the strengths of their child during the initiation of services is a practice construct under investigation.

The second aim is to explore participation of the family in assessments of the child's strength and needs. Areas of concordance and difference between families and professionals will be explored through analysis of scores on instruments assessing both strengths and needs of the child from the family and professional perspectives.

The final aim is to study the recognition of strengths by both family and provider in rela: : nship to characteristics of the child including behavior problems, functional level, age, and gender. This aim explores the associations of strengthsbased assessment with a child's characteristics to determine the effect of these characteristics on perceptions of strengths. 
These research aims focus on the recognition of strengths across multiple domains and extent of agreement between family members and helping professionals extending previous research studying the implementation of wraparound services (Clark, Lee, Prange, \& McDonald, 1996; Sosna, 1999; VanDenBerg, 1992). Prior studies provide support for increased access, voice, and ownership by families as associated with improved outcomes. Whitbeck verified the importance of families having the right to inclusion in decision-making processes, children and families feeling heard and listened to at all points in the process, and child and family having input to agree to any plan involving them (Whitbeck, Kimball, Olson, Lonner, \& McKenna, 1993).

The focus of this investigation is exploring components of a conceptual model through the use of valid and reliable assessments of strengths and needs by both the family and professional. The data analyzed in this study have been obtained from consenting family members and professionals at the time of enrollment in intensive community-based services. The data used in this study include: (a) the child and family history collected by the care coordinator by interview via the Description Information Questionnaire (DIQ), (b) behavior and functional problems as assessed by the care coordinator through the Child and Adolescent Functional Assessment Scale (CAFAS; Hodges \& Wong, 1996), (c) the parent's view of behavior problems as reported on the Child Behavior Checklist (CBCL; Achenbach, 1991); and the assessment of strengths through the Behavioral and Emotional Rating Scale (BERS; Epstein \& Sharma, 1998). The methods of data collection and instruments used are fully described in Chapter III. 
This exploration of these practice constructs investigates the values and principles of system of care reforms in practice. This study focuses on the use of a strengths-based assessment and the involvement of the family in that assessment: Strengths Assessment

- Family and professional both identify strengths,

- Recognition of a child's strengths,

- Formal assessment of strengths by family and professional.

Family involvement in assessment of both strengths and functioning is being explored to study the level of agreement and difference between assessments and providers by parents and professionals. While this study does not directly measure the quantity or quality of family participation, the aim of the research is to explore the family's participation in assessment through completing assessments of strengths and behavior problems.

Family Participation in Assessment

- Family and professionals assess strengths and functioning during initiation of services,

- Concordance between family and provider on assessment of strengths,

- Agreement between family and professional on severity of problems and functional challenges of the child.

Child characteristics, including age, gender, behavior problems and functioning will be explored to determine if these characteristics might predict a higher or lower strengths score by the family or professional. 


\section{CHAPTER II}

\section{CONCEPTUAL FRAMEWORK AND RESEARCH QUESTIONS}

\section{Conceptual Framework}

The research aims and conceptual practice model under investigation evolved from review of research on systems of care and the wraparound practice model. The questions are investigated in the context of a community-based demonstration project for high-needs children and their families. This project embraces a strengths perspective and supports family participation through a wraparound process. This research can lead to more advanced study investigating if the system of care philosophy is associated with improved clinical practices and ultimately to better outcomes for children and families.

Practice constructs described in this chapter reflect some key elements of the wraparound practice model, principally strengths assessment and family participation. These practice constructs are explored to investigate application of strengths assessment from the perspectives of the professional and family. This dissertation provides empirical analysis of assessment data as a method of investigating a strengths perspective for children with serious emotional and behavioral disorders and examining the participation of the family in the assessment process. 
This study of the recognition of strengths by the family and professional extends the work of Friedman, Friedman, and Leone who compared strengths assessments from the perspectives of parents and teachers and investigated differences in strengths ratings based on grade level (Friedman, Friedman, \& Leone, 2002; Friedman, Leone, \& Friedman, 1999). The relationship of gender, age, behavior problems, history, and functional level to the identification of strengths are also explored. The conceptual model being investigated also extends previous research on systems of care values and wraparound practice principles. Practice constructs under investigation in this study extend previous research supporting family inclusion in assessment and identification of strengths by both the family and professional, with the goal of increasing conversation about strengths to decrease a sole focus on problems and deficits (Cowger, 1994; Rapp \& Wintersteen, 1989; Saleeby, 1992).

From this systemic view, an important principle is that a strengths perspective is included in the assessment, not which participant brings the information. Parent-professional partnership is complex and multidimensional and includes the parent perspective, professional perspective, the parent-professional interaction, and the systemic/societal context. Components of these multidimensional transactions are being explored in this dissertation through exploration of assessment data from both parent and professional.

As illustrated in the conceptual practice model in Figure 1, optimal longterm outcomes for these children include: (a) improved clinical status; (b) 


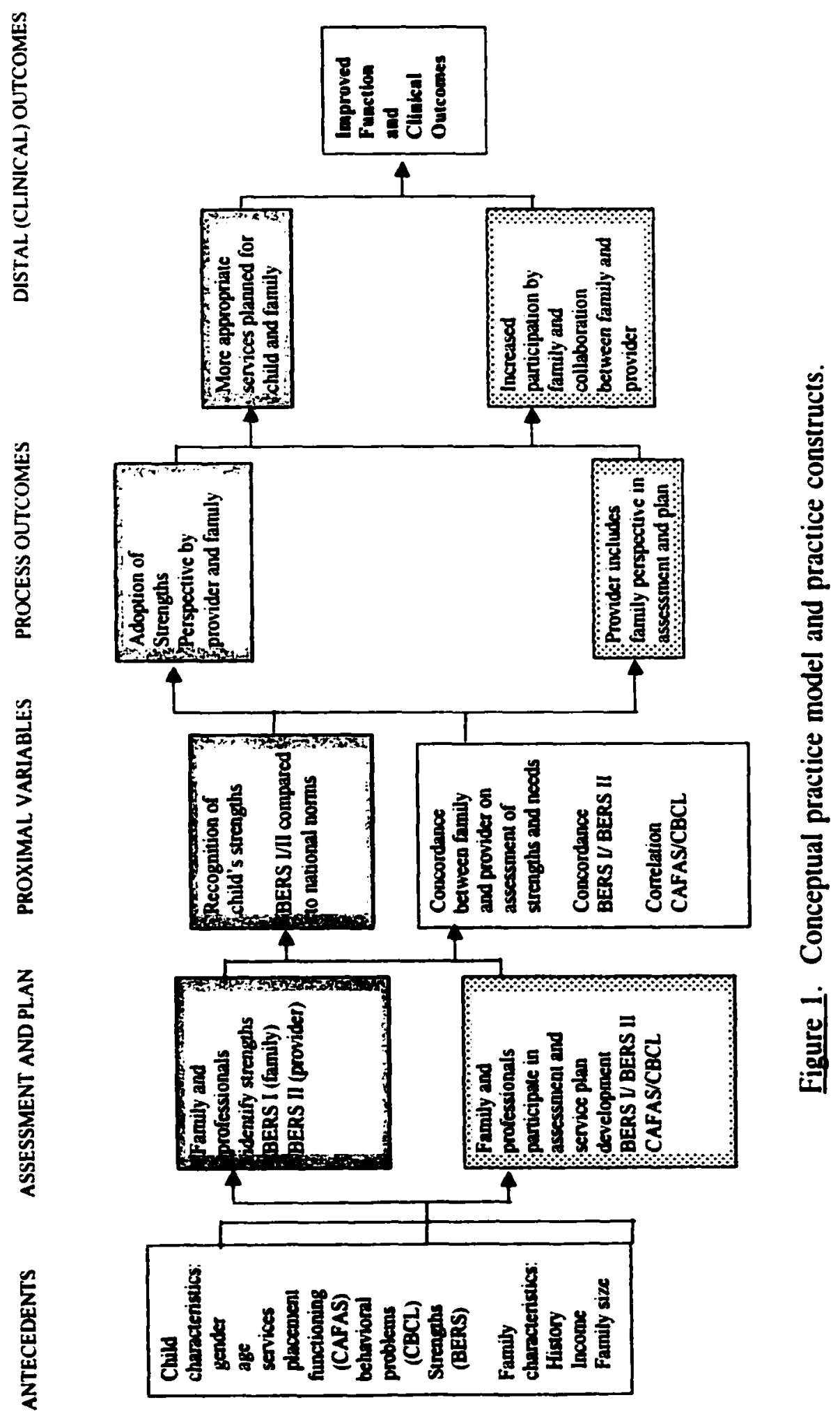


functional improvements; (c) increased life satisfaction, safety and welfare of the child; and (d) attachment to a caring adult (Bickman, 1987; Friedman \& Burns, 1996; Rosenblatt, 1998; Whitbeck et al., 1993). Practice changes posited as linked with these outcomes are being explored through measurement of strengthsidentification and participation of both family members and professionals in the assessment. This dissertation explores the practice constructs of this conceptual model that have been associated with positive long-term outcomes in longitudinal studies (Center for Mental Health Services, 1999).

\section{Practice Constructs}

The aim of this study is to explore practice constructs through an analysis of measurements of functioning, behavior, and strengths of the child from two perspectives. The study explores the identification of strengths by the parent and professional, and family participation in assessment. Concordance between family and professional assessments and relationships between recognition of strengths and behavioral and functional problems from the perspective of the parent and the professional are analyzed to investigate the constructs. The associations between strengths identification, functional and behavioral assessments of the child by families and professionals, and child characteristics will be studied to determine the effects of these factors on perceptions of strengths.

This study follows others (Burchard \& Clarke, 1990; Courneyer \& Johnson, 1991; Foster et al., 2001) evaluating the impact of systemic changes in the 
interaction between parents and professionals on the manner in which individual children and families are served. This study uses valid and reliable measurements of strengths, problems, and functional level based on scores provided by parents and professionals on standardized instruments. Data collected may be useful to refine the conceptual practice model through precise measurement of the practice constructs as recommended by Patton (1997). Utilizing the BERS instrument to independently measure assessments by the family and professional extends previous research that compared strengths scores from parents and teachers (Friedman, Leone, \& Friedman, 1999) and builds on studies comparing BERS scores with established measures of behavioral and functional problems (Nordness \& Epstein, 2000). It is proposed that using the BERS instrument with the focus on strengths will support family participation in assessment through the data collection process and sharing this data with the family.

The instruments used in this study are briefly introduced below and referenced in Figure 1. The instruments and their administration are fully described in Chapter III.

The Descriptive Information Questionnaire (DIQ) is a 37-item inventory that gathers child and family demographic information, risk factors, family composition, referral source, and previous service history. Responses collected with the DIQ are used to provide descriptive data and evaluate predictor variables. The DIQ has no subscales or scoring conventions (Center for Mental Health Services, 1998b). 
The Behavioral and Emotional Rating Scale (BERS) completed by the parent or legal guardian provides strengths assessment from the family and is used to examine both the level of strengths identification and agreement with professionals' assessment. The BERS is an empirically derived scale assessed to be valid and reliable to report strengths across the domains of Interpersonal Strength (IS), Family Involvement (FI), Intrapersonal Strength (IaS), School Functioning (SF) and Affective Strength (AS) (Epstein \& Sharma, 1998). The BERS strengths assessment is also completed by the therapist during the assessment period allowing a study of differences in strengths identification from the perspectives of the therapist and the family (Epstein \& Sharma, 1998).

The Achenbach (1991) Child Behavior Checklist (CBCL) is an extensively used parent completed assessment of behavioral and emotional problems used in this study to explore parents' identification of behavioral problems and to study the parents' assessment of both strengths and behavioral problems.

The Child and Adolescent Functional Assessment Scale (CAFAS) completed by the therapist/care coordinator is a widely used instrument to assess functional problems on eight scales assessing: role performance at school, home and community; interpersonal behavior, mood and emotions; thinking problems; and substance abuse issues (Hodges \& Wong, 1996). A therapist or care coordinator familiar with the functioning of the child completes this assessment or responses to items may be collected from the parent in a structured interview. In this study, the therapists' assessment of functional level of child is the score used to explore 
agreement between families and professionals in identification of functional problems and needs of the child.

\section{Research Questions}

This dissertation explores two practice constructs of the wraparound practice model being implemented in an intensive community services demonstration for children with serious emotional disturbances (SED) in Clackamas County, Oregon. The research questions explore constructs of this practice model: (a) identifying strengths and (b) involvement of both families and professionals in assessments of strengths and functioning of the child. The following questions explore the relationships of these practice constructs through an analysis of empirical data gathered with norm-referenced instruments from professionals' and caregivers' assessments.

The first aim of this dissertation is to measure the adoption of a strengths perspective by a professional working with the child and the family. Professionals have been increasingly exposed to training on adopting a strengths perspective. Previous research suggests that families may more readily identify strengths of their child than professionals (Collins \& Collins, 1990). Outcomes expected for participants in this sample are that both parents and professionals will identify strengths, but in different domains, based on previous research by Friedman, Leone, and Friedman (1999). An a priori prediction is that therapists may identify more strengths in specific domains emphasized in professional training, such as the 
affective domains. It is predicted that professionals may notice and report strengths in these domains at a higher level than parents, predicated on results of a study in which teachers reported higher levels of strengths in school functioning and interpersonal strengths compared to parents (Friedman, Leone, \& Friedman, 1999).

\section{Research Question 1}

Are there differences between families' and professionals' assessment of strengths and the national norms for children with serious emotional disturbances?

This question compares the mean BERS scores in each domain to the normative data published by Epstein and Sharma (1998). It was anticipated that the sample of children with SED in this study would score at or below the national means for a clinical population of children with emotional and behavioral disturbances.

The second aim for this research is to explore family participation through the analysis of assessment data provided by parents and professionals at the initiation of wraparound services. The ratings on the domains of strengths measured by BERS subscales are addressed by the following two questions.

\section{Research Question 2}

Is there agreement in BERS subscale ratings by families and professionals regarding strengths of the child across multiple domains? 
This question examines concordance between ratings on the five subscales of the BERS measuring strengths in behavioral and affective domains. The relationships compare the Parent rating in each domain (subscale) and the Therapist rating on each subscale. Exploration of this question addresses both aims of this dissertation - the adoption of a strengths perspective and exploring family participation in assessment. Therapist ratings may be a product of communication between families and professionals during the assessment period, as the therapist/care coordinator gains information from listening to the parent during this assessment period, as well as from direct interaction with the child. Areas of lower correlation or substantial differences on subscale scores may represent areas in which one rater may have different information based on more extended observation or rater bias. In a previous study teachers had higher strengths scores than parents in school functioning and interpersonal domains perhaps due to more extensive exposure or more informed observations (Friedman, Leone, \& Friedman, 1999). Family-professional transactions, represented by concordance or differences in the strengths domains scores, is investigated through this analysis as a foundation for increasing family participation through dissussion of assessment data. This study of aggregated data as well as review of individual scores in interaction between families and professionals present opportunities for increasing family participation through comparing ratings.

Strengths assessment scores may be used to assess changes in the individual child's functioning, and provide opportunities for discourse between the family and 
professional on agreement or difference on observed strengths. A periodic review of strengths scores can also be used to increase participation of youth by reviewing with them the strengths scores from individuals who have observed their progress. A youth self-report scale is under development that may provide opportunities for comparisons between the youth's self perception and those of adult caretakers and professionals (Epstein, 2002).

\section{Research Question 3}

What are the differences between families' and professionals' ratings of strengths across the domains measured by the BERS?

This question examines differences in mean standard strength scores reported by the family and professional in the five separate domains. The Behavioral and Emotional Rating Scale is a strengths-based instrument that provides an opportunity to obtain information from multiple sources, particularly adults closest to the child. In the case of children with SED, identifying and discussing strengths is a component of the wraparound model and including data representing diverse perceptions, especially that of the family, increases family participation in assessment of strengths. Professionals or parents may see competencies in areas not recognized by the other and exploring the consistencies and differences in the BERS scores provides more data for discussion on the individual level. Analysis of aggregated scores, the focus of this study, provides the opportunity for patterns of difference to emerge from the data. 
The following two questions further explore the first aim, adoption of a strengths perspective, through exploration of the relationship of identification of strengths and assessments of behavioral problems and functional impairments by parents and professionals.

\section{Research Question 4}

What is the relationship between behavioral and emotional strengths and functional impairments as reported by the therapist?

A negative correlation between the BERS and CAFAS scores might be expected as a higher CAFAS score represents more severe functional problems. Conversely, therapists may show systematic bias toward lower functioning youth and observe and report a higher level of strengths reflecting the youth's ability to cope with behavioral and emotional challenges.

\section{$\underline{\text { Research Question } 5}$}

What is the relationship between behavioral and emotional strengths and behavior problems as reported by the parent?

An inverse relationship is expected in the parents scores on the BERS and CBCL given the construction of the scales, the BERS assessing strengths and the CBCL behavioral problems. However, the effect of the child dealing with a serious disability may support a systematic bias in which parents perceive higher strengths in their children who are suffering from more serious emotional disorders as reported by Wolin and Wolin (1993) in their studies of resilience. 
The following question continues the investigation of the second aim of this dissertation - exploring the participation of the family in assessment of both strengths and needs of the child.

\section{Research Question 6}

What is the relationship between behavioral problems as reported by the parent and the functional problems as reported by the therapist?

This question builds on the use of two raters and two scales to support multiaxial assessment utilizing two measurements of functional problems as recommended by Achenbach (1993). Through examination of the level of functioning assessed by the therapist on the CAFAS and behavior problems as assessed by the parents on the CBCL a more complete picture of areas of agreement on the needs of the child can be determined. This extends previous research by Phillips (1999) in which he used these two instruments to explore differences and concordance of assessments between foster parents and caseworkers.

The analysis of the areas of agreement and of lack of concordance offer the opportunity for increased discourse and participation by the family in determining areas for focus of care. Analysis of correlation across this sample provides data to explore patterns of perceptions from parents and professionals. The use of this data in this manner is proposed in the conceptual model to be associated with improved outcomes through increased participation of the family in assessment. 
Gathering and reporting these scores can be used to evaluate implementation of the model. Repeated measures of these assessments on an individual basis would provide ongoing opportunity for dialogue between families' and professionals' regarding progress of individual children through examination of changes in functional deficit and behavior problem scores but is beyond the scope of this study.

The third aim is to examine the recognition of strengths in relationship to other characteristics of the child.

\section{Research Question 7}

What are the relationships between recognition of strengths and child characteristics from the perspective of the family and professional?

Parents of SED children stressed by their behavioral problems may identify strengths in different domains than professionals or may identify fewer strengths related to their level of stress in managing the child's behavior problems. Conversely, though the severity of the child's behavior is associated with higher stress, other variables in the family environment may moderate the impact and may in fact contribute to enrichment of the parenting experience (Yatchmenoff et al., 1998). The effect of independent characteristics of the child such as age, gender, behavior problems and functioning is explored through this analysis, understanding that parent characteristics described in previous research may moderate the parent's perception of strengths of their child. 
Exploration of the recognition of strengths by professionals and families in relationship to gender, age or functional level will probe for any systematic bias in identifying strengths based on group membership. This extends research that explored the differences between counselors and teachers when using the BERS at different grade levels (Friedman, Friedman, \& Leone, 2002), with an expectation that families or professionals may have patterns of strengths identification predicted by age, gender or functional impairment. Exploration of the relationships of subscale scores on these instruments explores predictive values in support of the research aim of understanding the differences of perceptions of strengths and problems from the perspectives of family members and professionals. 


\section{CHAPTER III}

\section{METHODS}

This dissertation uses data collected from families of children with serious emotional disorders (SED) receiving services through the Clackamas Partnership located in Clackamas County, Oregon, supported by the mental health services program for children \#5 HS5 SM52297 funded by the Center for Mental Health Services, Substance Abuse and Mental Health Administration. This dissertation research presents a secondary analysis of a portion of the evaluation data collected for that demonstration.

The primary goals for Center for Mental Health Services (CMHS) funded Comprehensive Mental Health Services Programs consist of: (a) integrated funding streams; (b) a unified governance structure; (c) family partnerships in all aspects of the system and in care of their children; (d) a single, financially sustainable system; (e) interagency involvement; (f) a stateilocal relationship, outcome based evaluation; and $(\mathrm{g})$ the creation of a genuine managed care model (Center for Mental Health Services, 1998c). 


\section{Context of the Study}

The Clackamas Partnership, a collaborative entity of families, child welfare, education, health, mental health, juvenile justice, and private providers, provides community-based care for children and their families who are faced with complex and enduring mental health challenges. Based on the values and principles initially articulated by the Child and Adolescent Service System Program (CASSP) and in response to the Guidance for Applicants (GFA) for the Child Mental Health Initiative, the Clackamas Partnership and Clackamas County Mental Health Center implemented the following programs and services:

- Integrated services around the strengths and needs of families through the creation of Child and Family Teams. Care coordinators authorize and provide flexible services to identified children and their families through an enhanced service array of community-based mental health and non-mental health services to a clearly defined target population - those most at risk for out-of-home placement.

- Improved access to intensive services through outreach, opening a number of pathways to services, and empowering local families to recruit other families into services.

- Blended funds across agencies to provide the necessary resources for community-based services. Contributing to this effort are private and 
public intensive service providers and schools who have redirected resources from intensive and residential services to community services.

- Coordination with the Oregon Health Plan, the state-managed care plan, to provide community services for the children and families who need the most intensive services.

- Providing training and technical assistance and on-going supervision for care coordinators and staff of partner agencies to increase skills in collaboration and clinically appropriate, family-centered services.

- Staffing an evaluation team in collaboration with Portland State University's Regional Research Institute and Research and Training Center to implement national and local evaluation, to ensure that data are used to inform all decision-making processes concerning children and families, interventions, and governance (McCormack \& Taylor, 1998).

The Clackamas Partnership has built upon efforts in mental health, child welfare, juvenile justice, and special education to provide a model to bring together uncoordinated efforts at the level of system, program and practice and to move those efforts to a sustainable level. Clackamas Partnership combined elements of the current reforms in mental health, child welfare, and juvenile justice and education, offering a demonstration for state and local agencies of the compatibility and portability of these efforts.

Key to the sustainability of these changes has been the development of a collaborative governance structure supported by leadership theory and research and 
ongoing local consultation and training. Children's mental health research has stressed the importance of local governance for achieving change that is owned by a community and is implemented in a democratic fashion (Hodges, Nesman, \& Hernandez, 1999). Within the leadership literature, collaborative governance is tied to emerging ideas about authority, such as creativity, systems thinking, risk, and vision (Senge, 1994). The principles of collaborative leadership have been endorsed by a local Partnership Council of agencies and community members.

Family involvement is one of the central tenets of the system of care and has been a focus of the Partnership. Systems of care have moved from familyfocused to family-centered entities in response to advocacy from parents. Through measuring the significance of family access, voice. and ownership, researchers have discovered family involvement yields positive functional outcomes for children and increases in satisfaction and empowerment in families (Whitbeck et al., 1993). The Partnership contracted with the Oregon Family Support Network to lead these efforts.

The Clackamas Partnership is supported by a foundation of shared decisionmaking and collaboration among the key child-serving agencies in the county. The Partnership has matured through the introduction of blended funding and collaborative services. Clackamas County Mental Health Center (CCMHC), through its Mental Health Organization (MHO), brought new and flexible resources from the Oregon Health Plan to the county for eligible residents along with managed care business practices, including shared responsibility and risk. 
Without interagency collaboration, it is impossible to have a system of care. In the case of children with serious emotional disturbances and their families, the "silo" approach to funding and organizing children's mental health services is a disaster because children have multiple needs and challenges and if they are treated in a compartmentalized way that negates their complexity (Franz \& Miles, 1994).

The Clackamas Partnership has established Interagency Treatment Planning for high needs families that supports the family as central in the process of planning for their child. The interagency case review structure focuses on children and adolescents for whom regular agency-based services are not sufficient to support their placement at home and for whom there is often a need for residential or hospital treatment. The interagency case review team includes discussion of intensified local efforts in lieu of residential placement.

Clackamas County, the State Department of Human Services (DHS) and Local Collaborating Agencies through the Partnership Council endorsed core values in building a collaborative approach to mental health services for children and families. The first is that a system of care must be child and family centered with the individual needs of the child and family dictating the provision of services. Second, the service delivery system and infrastructure must be community-based and culturally competent, and the delivery of services, along with management and decision-making authority, must rest at the local level.

The creation of a responsive managed care model for children with SED has been a priority for the State of Oregon. Historically, the steep rise in the costs 
of health care and the increased utilization of inpatient treatment for children, particularly adolescents, created the context for the introduction of managed behavioral health care in the 1980 s. The introduction of managed mental health care in the private sector has led to even greater reliance on the public safety net for children, adolescents, and adults with serious emotional disturbances (Mechanic, 1993). The implementation of managed care contracting for Medicaidfunded programs has raised concerns regarding the effects on systems of care for children who have been served by a continuum of outpatient and intensive services primarily funded and delivered in the public sector (Pires, Stroul, \& Armstrong, 2000). Clackamas County is a local Mental Health Organization for mental health services under the Oregon Health Plan. As a locally operated and state-contracted entity, Clackamas County is integrating systems of care values within the context of managed care. The infrastructure of public mental health services available to children and families in the target community has benefitted from the risk-based, capitated funding methodology of the Oregon Health plan. Clackamas County Mental Health and the Partnership have integrated efficiency in delivery of core "medically necessary" services and supported "reinvestment" of savings from acute hospital care into more flexible intervention efforts with children and families. These reinvested resources have allowed the Partnership to develop creative community-based alternatives to hospitalization and to expand crisis intervention services (Taylor, 2002). 
The goal is for the Clackamas Partnership to sustain a "system of care," with a fully developed infrastructure, and a matching service delivery model. Since this system is built on the existing Oregon Health Plan demonstration, Clackamas County Mental Health and the Partnership are uniquely situated to serve as a model for managed care entities providing services to children with serious emotional disturbances, and their families.

\section{Implementation of a Wraparound Approach}

In order to create an integrated service system with individualized service planning at its core, the Clackamas Partnership embraced a wraparound approach. Essential to this approach is recognition of family access, voice, and ownership as keys to making the system thrive and produce positive outcomes. Drawing on recent wraparound training methods, direct services staff of the Partnership engaged in an intensive process of learning with families how best to create a plan. The training stressed the imperative of strength-based, culturally-competent approaches to all facets of care. Each child and family were asked to form, and were aided in the process of creating, a team. This team provided the family and child with the kinds of supports and services necessary to help them meet their needs. The wraparound plan is documented in the child's record, matched to strengths, and enacted. 
Participants and Procedures

This dissertation utilizes secondary data from the evaluation of the Clackamas County Partnership entitled "An evaluation of the Clackamas County Partnership's System of Care" approved by the Human Subjects Committee of Portland State University (see Appendix A). Michael Taylor, the investigator for this dissertation study, served as Project Director for the Partnership Project from its inception in September 1998 through June 2002. This study examines baseline data of children and families referred for Partnership intensive care coordination services from mental health, child welfare, juvenile justice, and education.

The data were collected as part of a national and local evaluation study for the demonstration site. The Regional Research Institute at Portland State University was retained through a contract with Clackamas County to conduct an evaluation of the Clackamas Partnership. MACRO International, a consulting company located in Atlanta, Georgia, holds the federal contract for implementation of the national evaluator of all 63 communities funded by CMHS (see Appendix A). These data were aggregated and client confidentiality was protected. Families were asked to participate in the local and national evaluation study through a signed consent approved by the Portland State University Human Subjects Committee, and in no case were children denied services if the parent did not consent to participate in the evaluation. 
This secondary analysis integrates a descriptive study of the population, including empirical measures of strengths and problems, with an exploratory design investigating the practice constructs. This study was developed to describe relationships between variables measured at baseline and designed to integrate with the continuing local evaluation of this demonstration.

Cross-sectional data were collected at the time of enrollment and were used to examine the defined practice constructs and their relationships to assess characteristics of the practice model under investigation. With complex multimodal interventions, competing explanations cannot be accounted for and it was not possible to establish causality. An analysis of the logic underlying this practice model requires that constructs are specified, measured, and validated. This research is intended to inform the development of intensive community-based programs through exploring two of the program's practice constructs.

The data for this study were collected from responses by care coordinators and families on instruments that measure: (a) referral patterns and demographics, the Descriptive Information Questionnaire (DIQ); (b) perception of strengths, the Behavioral and Emotional Rating Scale (BERS); (c) functional status, the Child and Adolescent Function Assessment Scale (CAFAS); and (d) symptoms and problems, the Child Behavior Checklist (CBCL). 
National Evaluation

The Clackamas Partnership participates in the national evaluation required by the Center for Mental Health Service. MACRO International conducts the national evaluation. Local participation includes: staffing the evaluation team; training data collectors, including consent processes; data collection; data cleaning; data storage; data transmission; local data analysis; and data reports. Data analysis and management is contracted with the Regional Research Institute at Portland State University, Portland, Oregon (see Appendix A).

\section{Local Evaluation}

The local evaluation plan for the Clackamas Partnership was derived from questions posed by families and collaborating agencies. Data for the National and Local evaluation provided the source of data for secondary analysis for this dissertation. Local evaluation questions were brought forward throughout the conceptualization of the project. This study of implementation of strengths assessment and wraparound practice constructs will be made available to the evaluation team to further refine the implementation of the project goals and refine the local evaluation.

\section{Target Population/Sample for the Study}

Consisting of the children and families with the most complex and enduring needs, the target population represents the most severely needy $5 \%$ of the 8,000 children in Clackamas County with emotional disorders who may require mental 
health treatment and special education services. Based on national studies of the incidence of serious disorders, the annual target population for intensive services provided by the Partnership is estimated to be $\mathbf{4 0 0}$ children per year (U.S. Department of Health and Human Services, 1999). The children in the sample represents about one-quarter of the population estimated in need of this level of care. Children and families seeking assistance from Clackamas County public agencies, through the Interagency Service Planning Committee, are the targeted population for this initiative. This target population includes children and adolescents with serious mental health concerns who need intensive treatment services and are at risk of residential or hospital treatment, or who are returning to the community from residential or hospital care. When a child is in substitute care, every effort is made to include the biological parents in the service plan (McCormack \& Taylor, 1998).

\section{Recruitment and Selection}

Priority for inclusion in the program focused on the children with the most serious mental health challenges and requiring intensive treatment services based on criteria developed by the Partnership. Children with serious mental and emotional disorders constitute a vulnerable population protected through integration of clinical supervision throughout the service system, full inclusion of families, and careful evaluation of outcomes. Children and families are referred from various community agencies including Services to Children and Families (SCF), Juvenile 
Department, Oregon Youth Authority (OYA), schools, residential treatment centers, hospitals and other community partners. The Interagency Treatment Planning Committee (ITPC) serves as the initial access point for services. Child and family teams are created and entry into the Partnership is initiated through the ITPC meetings. Participation in the program is voluntary and only through the consent of the parent or legal guardian. Recruitment occurs through program announcements sent to all child serving agencies, school districts, and support and advocacy groups, such as the Oregon Family Support Network.

\section{Data Collection Procedures}

The data were gathered via standardized interview protocols. Training was provided for purposes of standardization, the local site evaluator and contracted evaluation consultants from Portland State University assured consistency of data collection methods through supervision of staff and evaluation associates, family members hired to interview families. Training included explanations of standardized instruments and their consistent use to collect data in an interview format. For instance, the Behavioral and Emotional Rating Scale (BERS) was discussed to describe its characteristics, why it was used, and how it would be helpful in the provision of services. With this knowledge, data collectors could, in turn, discuss pertinent issues with families and include families in the evaluation. Families often feel no connection to data collection and are often not given a clear 
sense of why they are providing information. This data collection method was designed to reduce the problems related by families participating in the evaluation.

In the case of the Child and Adolescent Functional Assessment Scale (CAFAS), care coordinators were trained and certified to test for their reliability as raters by the federal evaluation contractor, MACRO International. In addition to specific training on the instruments and procedures for completing them, data collectors were also trained to establish a safe and comfortable setting for collecting information. Children and families were assured of confidentiality, and were also assured that they could stop participating in the evaluation at any time and continue to receive services (see Appendix A).

\section{Instrumentation}

Instruments used for the Local and National evaluation were prescribed by MACRO and approved by the federal Center for Mental Health Services for all sites funded in the 1997 and 1998 grant cycles. MACRO is the federal contractor for the national evaluation and the instruments used to collect standardized information across all participating sites have been approved by the federal Office of Management and Budget and IRB approval of the Center for Mental Health Services. The instruments used in this study were selected for secondary analysis to address the aims of this dissertation focusing on the assessment of strengths.

For the purpose of exploring strengths assessment from the perspective of both the family and care coordinator, a dual administration of the BERS instrument 
was included in the local evaluation protocol. The BERS is completed by the primary care coordinator within the first 30 days of enrollment in the program. The family ratings were collected independently by the evaluation associate, also in the first 30 days of enrollment. The raw data entry and scoring of the BERS was completed by the evaluation team and the dual raters did not have access or knowledge of the scores at the time of completing their rating.

\section{Descriptive Information Questionnaire (DIO)}

The DIQ contains 37 items that describe the child and family and includes demographic information, risk factors, family composition, physical custody of the child, referral source, child's mental health service use history, and child's presenting problem. Data collected with the DIQ were utilized to provide descriptive data and predictor variables. The DIQ contains no subscales, and no tabulation or scoring conventions apply to the DIQ (Center for Mental Health Services, 1999).

The DIQ data provides comparison data for children and families being served in the project site with other projects funded by the Center for Mental Health Services. MACRO has reported baseline DIQ data on 5,262 children (Center for Mental Health Services, 2002).

\section{Child Behavior Checklist (CBCL)}

The CBCL is collected by the family evaluation associate within the first $\mathbf{3 0}$ days of enrollment through an interview process. The CBCL gathers information 
from the parent or caregiver about the child's symptoms and problems and the interviewer is trained to collect all data in a supportive manner, as families can be stressed with the volume of data requested. For this reason the evaluation data were collected at a place and time most convenient to the family member, at their home or at the Partnership office.

The CBCL was designed to provide a standardized measure of behavior problems of children ages 4 through 18 . The CBCL has been widely used in mental health services research, as well as for clinical purposes. The checklist is a caregiver report of social competence and behavior and emotional problems. It consists of 17 social competence items and 113 behavior problem items. The social competence section collects information related to involvement in organizations, sports, peer relations, and school performance. The behavior problem section documents the presence of symptoms. The CBCL provides scale scores on a number of empirically derived factors (Achenbach, 1991). The CBCL assesses children's symptoms on a continuum and provides two broad band (i.e., internalizing and externalizing) syndrome scores and 12 narrow band syndrome scores (e.g., attention problems, depressive mood, conduct problems). A Total Problem score is also generated.

Reliability and validity. Achenbach (1991) has reported information regarding internal consistency, test-retest reliability, construct validity, and criterion-related validity. Good internal consistency was found for the Internalizing, Externalizing, and Total Problems scales (alpha $\geq .82$ ). The CBCL 
demonstrated good test-retest reliability after seven days (Pearson $\underline{\mathbf{r}}$ at or above .87 for all scales). The instrument has been normed on a proportionally representative sample of children across income and racial/ethnic groups. Racial/ethnic differences in total and subscale scores of the CBCL disappeared when controlling for socioeconomic status (SES), suggesting a lack of instrument bias related to racial/ethnic differences.

\section{Child and Adolescent Functional Assessment Scale (CAFAS)}

The approved evaluation protocol for this project specified the CAFAS was to be completed by the primary therapist/care coordinator within the first $\mathbf{3 0}$ days of enrollment based on the data provided by referral sources and the care coordinators enrollment interview with the child and family. The CAFAS is a functional assessment tool anchored by behavioral descriptions completed by a trained rater. The CAFAS is a required assessment tool for all children served in intensive programs in the State of Oregon, including residential and day treatment settings. For this reason and to provide multiple perspectives of individual needs assessment for this study, the CAFAS was completed by the therapist/care coordinator, though an interview protocol exists to gather and rate this data from a parent interview.

The CAFAS is a widely used instrument that assesses the degree to which a child's emotional, behavioral, or substance abuse disorder is disruptive to his or her functioning in each of several psychosocial domains. The CAFAS can be 
completed by a clinician who is working with the child or by a lay interviewer, who uses information obtained through a structured interview.

Reliability and validity. Good inter-rater reliability has been found among a variety of raters including mental health intake workers, providers, lay raters, and graduate students. In a recent study, Hodges and Wong (1996) reported that the most behaviorally oriented scales had the highest reliability, with correlations for the total CAFAS score ranging from .92 to .96 across four different samples. Intra-class correlations for total scores ranged from .84 to .89 . Adequate testretest reliability has also been reported (Cross \& McDonald, 1995).

A variety of studies (e.g., Hodges, Lambert, \& Summerfelt, 1994) demonstrated the construct, concurrent and discriminant validity of the CAFAS when used with child clinical samples. Correlations between the CAFAS and other measures of emotional and behavioral problems (e.g., Child Assessment Schedule, the Child Behavior Checklist) were significant and suggest good construct validity. Analyses conducted on data from the evaluation of CMHS-funded demonstration projects found expected relationships between the CAFAS Total Score and the number and type of services used, amount of services used, and cost of services within a system of care (Hodges, Doucette, \& Liao, 1999). An earlier study found the CAFAS to be a better predictor of service use (e.g., restrictiveness of placement setting, residential versus nonresidential placements, types and costs of services received over time) than other psychological measures (Summerfelt, 1994). In addition, the CAFAS differentiated between clinical and non-clinical 
groups as effectively as the Global Level of Functioning and Global Assessment of Functioning Scale, but did not require a clinician to administer. Logistic regression analyses revealed that youth with higher CAFAS scores were more likely to have difficulties in school, problems with the law, and poor social relationships (Hodges \& Wong, 1996).

\section{Behavioral and Emotional Rating Scale (BERS)}

A primary aim of this study is to assess the adoption of a strengths perspective by the family and primary therapist/care coordinator and to explore the concordance of these ratings of strengths in five domains. As recommended by researchers interested in assessing child behaviors and strengths, multiple perspectives is important to obtain a broader sampling of children's behaviors and strengths across settings (Achenbach, 1993; Epstein, 1999b).

The BERS identifies the emotional and behavioral strengths of children through 52 items (Epstein \& Sharma, 1998). Epstein and Sharma described strengths-based assessment as measurement of those emotional and behavioral skills, competencies, and characteristics that create a sense of personal accomplishment; contribute to satisfying relationships with family members, peers, and adults; enhance one's ability to deal with adversity and stress; and promote one's personal, social, and academic development. The BERS is designed to be completed by caregivers or professionals (i.e., teachers or therapists) to rate the behaviors of children ages 5 to 18 . 
Reliability and validity. The BERS has demonstrated test-retest reliability, inter-rater reliability, and internal consistency (Epstein, Harniss, Pearson, \& Ryser, in press). Test-retest reliability coefficients for the BERS subscales ranged from .85 to .99 with a 10-day interval between the two ratings. Inter-rater reliability was tested using a sample of 96 students with emotional and behavioral disorders who were rated by their special education teachers. Cronbach's alpha coefficients for the scales were .83 or above.

To establish content validity, Epstein and Sharma (1998) conducted an extensive literature search, and asked key professionals in the field to submit, categorize, and rank order items based on their relevance to child strengths. Item discrimination and factor analysis were then used to validate the measure and eliminate superfluous items. Five key factors emerged forming the subscales. The BERS was then normed on two national samples: children who did not have emotional and behavioral disorders $(\underline{n}=2,176)$ and children with such disorders $(\underline{n}=861)$.

Subscales. The BERS contains the following five empirically-derived subscales: (a) Interpersonal Strength refers to a child's ability to control his/her emotions or behaviors in social situations, (b) Family Involvement assesses a child's participation in and relationship with his/her family, (c) Intrapersonal Strength examines a child's view of his/her competence and accomplishments, (d) School Functioning assesses a child's competence in school and classroom tasks, and (e) Affective Strength captures a child's ability to accept affection from others 
and express feelings toward others. A total strengths score can also be calculated and compared to national samples for both a normal population, as well as children with serious emotional disturbances.

As the BERS is a recently released instrument, there is a limited body of research in its use in outcome evaluation. Some studies have used the BERS to evaluate and predict specific disorders in children (Ogilvie, 2000); evaluate consistency of reporting of strengths by teachers and parents (Friedman, Leone, \& Friedman, 1999) and describe functional improvements (Center for Mental Health Services, 1999). The BERS is standardized, norm-referenced from a strengthsbased scale that may be used to develop treatment plans, educational plans, or to assess treatment outcomes. The BERS was used in this study to evaluate the assessment of strengths by both the professional and the family, and to determine the extent of agreement on the child's strengths as measured by BERS across the domains noted above. 


\section{CHAPTER IV}

\section{RESULTS}

For the standardized measures used in this study, scores were computed according to the testing manuals and cleaned, entered, and checked for accuracy in the local and national evaluation database by the evaluation staff of the Partnership project. The evaluation staff at Portland State University exported the data from the MACRO data table to an SPSS (1996) program file and developed syntax to score the BERS total score and subscale scores. The scored values for the Descriptive Information Questionnaire (DIQ), BERS, and CAFAS were also exported to an SPSS file for this study.

To conduct the secondary analysis of the baseline data, the ratings on the Behavioral and Emotional Rating Scale (BERS), Child Behavior Checklist (CBCL) and Child and Adolescent Functional Assessment Scale (CAFAS) were examined for completeness. Cases with incomplete data in the BERS, CAFAS, or CBCL scales were not included in the sample for this analysis. There were initially 116 cases with baseline data available for analysis. Missing data were problematic for the BERS scales as the planned analysis required data from each of the five subscales. For subscales missing one or two items, the mean score for that subscale was substituted as described in the BERS manual (Epstein \& Sharma, 
1998). For subscales with more than two missing items, the subscale score was deemed invalid and that case was eliminated from the analysis. The cases eliminated through this process resulted in a final study sample of $N=85$ children for whom all baseline data were complete and who were enrolled in services from January 1999 through February 2002. There were 19 cases excluded from the final sample because of missing data in the BERS subscales, with 17 of those eliminated because of missing data in the School Functioning subscale of the BERS.

The sample for the secondary analysis was limited to those cases with baseline data with complete descriptive data and standard scores, total scores, and subscale scores for the BERS completed within the baseline assessment period by two raters, a parent and a professional assigned as a care coordinator. The 85 cases with complete baseline data from two raters on four instruments comprised $73 \%$ of the initial sample of children and families for whom baseline data were collected. These data were imported as variables into the Statistical Package for Social Science (SPSS, 1996) specific to this study in a combined data file containing the scores for the CAFAS, CBCL, and DIQ and the file containing the BERS scores from the parent and care coordiriator. The mean scores on the CBCL and CAFAS for all cases with baseline data $(N=116)$ were compared with the study sample to determine that the study sample was comparable to the total served at baseline. The CBCL total problem score for baseline group was $(M=73.61$, $S D=7.96)$ compared to the final study sample $(M=74.17, S D=7.59)$. The 
CAFAS score was $96.67(S D=44.49)$ for the total baseline sample and 95.13 (SD $=46.00$ ) for the study sample. An analysis of these scaled scores and review of descriptive data determined the study sample was representative of the group of children and families served by the Partnership, and was not statistically different from the initial study sample, $t(82)=.668, p=.51$, based on CBCL total score, and $t(76)=-.292, p=.771$, based on CAFAS score.

\section{Child and Family Characteristics}

The descriptive data and baseline scores were also compared with the national evaluation data for the purpose of comparing the Clackamas sample to the larger sample of children and families served across service sites funded by the Center for Mental Health Services. Descriptive statistics were used to characterize the population being served, compare them with a national sample, and to describe antecedent variables. Child characteristics at baseline included age, gender, family history, severity of problems, referral source, and functional level.

Descriptive characteristics of the children and their families are reported in Table 1 and compared to the National sample data provided by MACRO (Center for Mental Health Services, 2002). The Clackamas baseline data $(N=85)$ was compared to the baseline data from a national sample of youth served through projects funded by the Center for Mental Health Services $(N=5,262)$. All projects provided community-based services to a comparable target population children with serious emotional and behavioral disorders in need of intensive 
services beyond usual and customary outpatient treatment. Eligibility for services was limited to children assessed as having a serious emotional disorder and in need of services from two or more mental health, educational or social services organizations to meet multiple needs. Due to diversity of local projects and goals, there was variability among the target populations being served in relationship to income, ethnicity, and personal and family history, though children and families in the Clackamas sample had much in common with youth and families being served in other communities. These descriptive statistics compare the Clackamas sample to aggegrated data from 63 sites which included some projects focused on communities with a high representation of children of color, including several projects serving primarily Indian children. There is an appreciable difference in racial and ethnic backgrounds, with the Clackamas sample comprising $90 \%$ of Euro-American (reported as White) compared to $58 \%$ of the national sample. The difference derives primarily from the underrepresentation of African-American (reported as Black) in the Clackamas sample reported as $1.2 \%$, compared to $22 \%$ of the national sample. Native Americans comprised $3.6 \%$ of the Clackamas sample compared to $12.4 \%$ of the national sample. The Clackamas sample does reflect the racial and ethnic composition of the target community and the program was serving children of color and families in poverty at a higher rate than their occurrence in the general population of Clackamas County. 
Table 1

Child and Family Characteristics

\begin{tabular}{lcc}
\hline & & National Sample \% \\
Child Characteristics & $\begin{array}{c}\text { Clackamas Partnership } \\
(N=85)\end{array}$ & $\begin{array}{c}\text { Coms Grant } \\
(N=5.262)\end{array}$ \\
\hline & & \\
Male & 71.8 & 68.0 \\
Female & 28.2 & 32.0 \\
Age & 12.9 & 12.3 \\
Race & & \\
Native American or Alaskan & 3.6 & 12.4 \\
Asian & 1.2 & 0.6 \\
Black & 1.2 & 22.0 \\
Pacific Islander & 0.0 & 0.6 \\
White & 90.4 & 58.1 \\
Other & 3.6 & 9.5 \\
Of Hispanic Origin & & \\
Yes & 7.1 & 11.3 \\
$\quad$ Mexican & 80.0 & 64.9 \\
$\quad$ Puerto Rican & 0.0 & 16.3 \\
Cuban & 0.0 & 2.5 \\
Dominican & 0.0 & 2.4 \\
Central American & 0.0 & 2.5 \\
South American & 20.0 & 1.8 \\
Other Hispanic & 0.0 & 9.6 \\
No & 92.9 & 88.7 \\
& & \\
\hline
\end{tabular}

Descriptive statistics regarding families in the study population generally reflect the national sample in terms of their living environment, but differ in the history of the biological family as shown in Table 2 . The study sample has a higher representation of single father families, adoptive parents and wards of the state. The histories of the children in the Clackamas sample appreciably exceed 
statistics reported in the national sample in the level of exposure to family

violence, mental illness, psychiatric hospitalization of a parent, law violations, and substance abuse.

Table 2

Family Characteristics and Family Risk Factors

$\begin{array}{ll}\begin{array}{l}\text { Study Sample \% } \\ (N=85)\end{array} & \begin{array}{l}\text { National Sample \% } \\ (N=5.262)\end{array}\end{array}$

Family Characteristics

Two biological Parents

Biological Mother only

20.2

35.7

10.7

Biological Father only

8.2

Foster Parents/State Wardship

14.3

Siblings

0.0

2.4

Aunt and/or Uncle

6.0

Friend(s)

Other

0.0

2.4

25.7

45.0

4.3

3.4

9.8

0.4

2.0

5.6

0.1

3.6

Family Risk Factors

Family Violence

70.9

48.2

Mental Illness

77.2

49.8

Psychiatric Hospitalization

48.4

30.2

Convicted of Crime

58.7

46.1

Substance Abuse

81.0

66.0

Income below $\$ 15,000$

43.0

49.0

As can be seen in Table 3, the service history of children included in the study sample appreciably exceeds the national sample with regard to previous services received, with higher rates of mental health services and higher levels of 
Table 3

Child History and Health Status

Study Sample \% National Sample \%

Child History and Health Status Intake Referral Information

$\begin{array}{lrr}\text { Corrections } & 11.8 & 12.9 \\ \text { Court } & 3.5 & 8.9 \\ \text { Schools } & 15.3 & 18.5 \\ \text { Mental Health } & 40.0 & 25.1 \\ \text { Physical Health } & 0.0 & 1.6 \\ \text { Child Welfare } & 15.3 & 12.7 \\ \text { Substance Abuse Clinic } & 0.0 & 0.2 \\ \text { Caregiver } & 1.2 & 9.1 \\ \text { Self } & 0.0 & 1.5 \\ \text { Other } & 12.9 & 9.7\end{array}$

Previous Services

Outpatient Services

School-based Services

Day Treatment

Residential Treatment

Alcohol/Drug Treatment
85.7

83.3

26.5

44.0

15.5

51.2

51.3

40.5

53.0

24.4

22.6

16.7

Sexually Abusive

\section{Child Health Status}

Medication for Physical Problems Medication for Emotional/Behavioral Eligible for Medicaid
36.5

82.4

40.5
64.1

53.3

13.3

26.8

13.3

25.5

27.3

20.7

35.0

14.9

24.6

7.4

not reported not reported not reported 
care, such as residential and day treatment services prior to referral to the Partnership project. The personal history of children served at the study site has approximately twice the incidence of psychiatric hospitalization, physical abuse and sexual abuse compared with the national sample. Though not reported for the national population, it should be noted that a majority of the Clackamas population have received medication for emotional and behavioral problems.

The severity of behavioral and emotional disorders of the children served in the Clackamas project is comparable to the national population based upon the reported standardized scores of problems and functioning levels and equivalent sccres on the overall strength quotient, as seen in Table 4. The total BERS score for this comparison is based on standardized scores for the normal population (NEBD score), the norms used for the MACRO study reported in the national sample scores below.

Table 4

Scores on Standardized Instruments at Admission

\begin{tabular}{lllll}
\hline & \multicolumn{2}{c}{ Study Sample } & \multicolumn{2}{c}{ National Sample } \\
\cline { 2 - 5 } & & $S D$ & & $S D$ \\
\hline CAFAS & 95.13 & 46 & 106.4 & NR \\
CBCL & 74.17 & 7.6 & 70 & NR \\
$\begin{array}{l}\text { BERS (NEBD scoring) } \\
\text { Parent } \\
\text { Therapist }\end{array}$ & 84.35 & 12.4 & 85.9 & NR \\
& 78.82 & 12.6 & NR & NR \\
\hline NR = not reported in MACRO 4/2002 Data & &
\end{tabular}


Identification of Strengths

Research Question 1: Are there differences between families' and professionals' assessments of strengths and national norms for children with serious emotional disturbances?

Descriptive statistics of mean scores on the five subscales of the BERS were analyzed: Family Involvement (FI), Interpersonal Strength (IS), Intrapersonal Strength (IaS), School Functioning (SF) and Affective Strength (AS). Percentile scores were determined for the means of each subscale by comparison to the norms provided by Epstein and Sharma (1998) for children with emotional and behavioral disorders. Alpha coefficients have been calculated and reported for the study sample and these are comparable to alphas from the normative data from a national sample reported by Epstein and Sharma (see Tahle 5).

When compared to the norms provided by Epstein and Sharma (1998) for children with emotional and behavioral disorders, the parent ratings of children's strengths were generally above the $50^{\text {th }}$ percentile, ranging from the $50^{\text {th }}$ to $75^{\text {th }}$ percentile. Parent ratings were at the $\mathbf{7 5 \%}$ percentile in the Affective Strength (AS) subscale and above the $60^{\text {th }}$ percentile in the subscales of Family Involvement (FI), Intrapersonal Strength (IaS) and School Functioning (SF). The therapists' ratings were consistently lower than the parents' ratings across four of the five subscales, based on percentile values for children with serious emotional disorders. Internal consistency (Alpha) of the individual subscales was computed for parents 
and therapists in the sample and is consistent with the normative data, ranging from .78 to .94 for both parents and therapists, indicating a high level of internal consistency of the subscales.

Table 5

Mean Scores of Parent and Therapist Standard BERS Subscale Scores

\begin{tabular}{|c|c|c|c|c|c|}
\hline \multirow[b]{2}{*}{ Subscale } & \multicolumn{3}{|c|}{ Study Sample } & \multicolumn{2}{|c|}{ National Sample } \\
\hline & $M$ & $S D$ & Alpha & $\begin{array}{l}\text { Scores from } \\
\text { National } \\
\text { Norms }\end{array}$ & Alpha \\
\hline \multicolumn{6}{|l|}{ Parent Respondent } \\
\hline Interpersonal Strength (IS) & 10.31 & 3.12 & .92 & 50 & .92 \\
\hline Family Involvement (FI) & 11.26 & 2.78 & .82 & 63 & .89 \\
\hline Intrapersonal Strength (laS) & 11.32 & 3.00 & .84 & 63 & .85 \\
\hline School Functioning (SF) & 10.06 & 2.98 & .85 & 50 & .85 \\
\hline Affective Strength (AS) & 11.72 & 3.11 & .81 & 75 & .84 \\
\hline Total BERS score & 106.14 & 16.53 & & & \\
\hline \multicolumn{6}{|l|}{ Therapist Respondent - } \\
\hline Interpersonal Strength (IS) & 9.68 & 3.01 & .94 & 50 & .92 \\
\hline Family Involvement (FI) & 10.67 & 2.94 & .83 & 58 & .89 \\
\hline Intrapersonal Strength (IaS) & 9.93 & 2.96 & .88 & 50 & .85 \\
\hline School Functioning (SF) & 9.84 & 2.81 & .78 & 50 & .85 \\
\hline Affective Strength (AS) & 10.05 & 2.79 & .84 & 50 & .84 \\
\hline Total BERS Score & 100.06 & 15.94 & & & \\
\hline
\end{tabular}

Note: Higher Scores represent higher ratings of strengths.

$N=85$, Normative mean $=10 ; S D=3$.

Percentile compared to EBD Sample $N=861$ as reported by Epstein and Sharma (1998).

\section{Agreement on Ratings of Strengths}

Research Question 2: Is there agreement in BERS subscale ratings by parents and professionals regarding strengths of the child across multiple domains? 
Parents' and therapists' ratings of strengths acioss the domains as measured by the BERS were analyzed for strength and direction of the concordance. This analysis follows previous studies (Friedman, Leone, \& Friedman, 1999; Harniss, Epstein, Ryser, \& Pearson, 1999) that suggested expanding the use of the BERS with multiple informants. Strong relationships have been found in previous research in some but not all the strengths domains. The analysis explores the specific question of concordance between therapist and parent concerning the child's strengths. The ratings were obtained during the assessment and data collection period within the first 30 days of enrollment.

Concordance was analyzed using Pearson's product-moment correlation coefficient as can be seen in Table 6 . Cohen's (1988) criteria designate correlations above .5 as indicators of medium correlation. Lack of agreement in rating across domains was expected between parents and therapists. Higher concordance may be partially attributed to the therapists' attention to the parents' descriptions of the child's strengths during the assessment period as therapist raters had limited opportunities for direct observation of the child.

The coefficient values on the diagonal measure the relationships between the parent and care coordinator on the same subscale of the BERS. Three of the five subscales approach or exceed a correlation of .50 indicating above moderate agreement between parents and service providers. A higher level of agreement between parents and therapists was seen in the subscales of Family Involvement 
and School Functioning with a moderate level of correlation in the subscales for Interpersonal Strength, Intrapersonal Strength, and Affective Strength.

Table 6

Concordance Among the Five BERS Subscales for Parent and Therapist

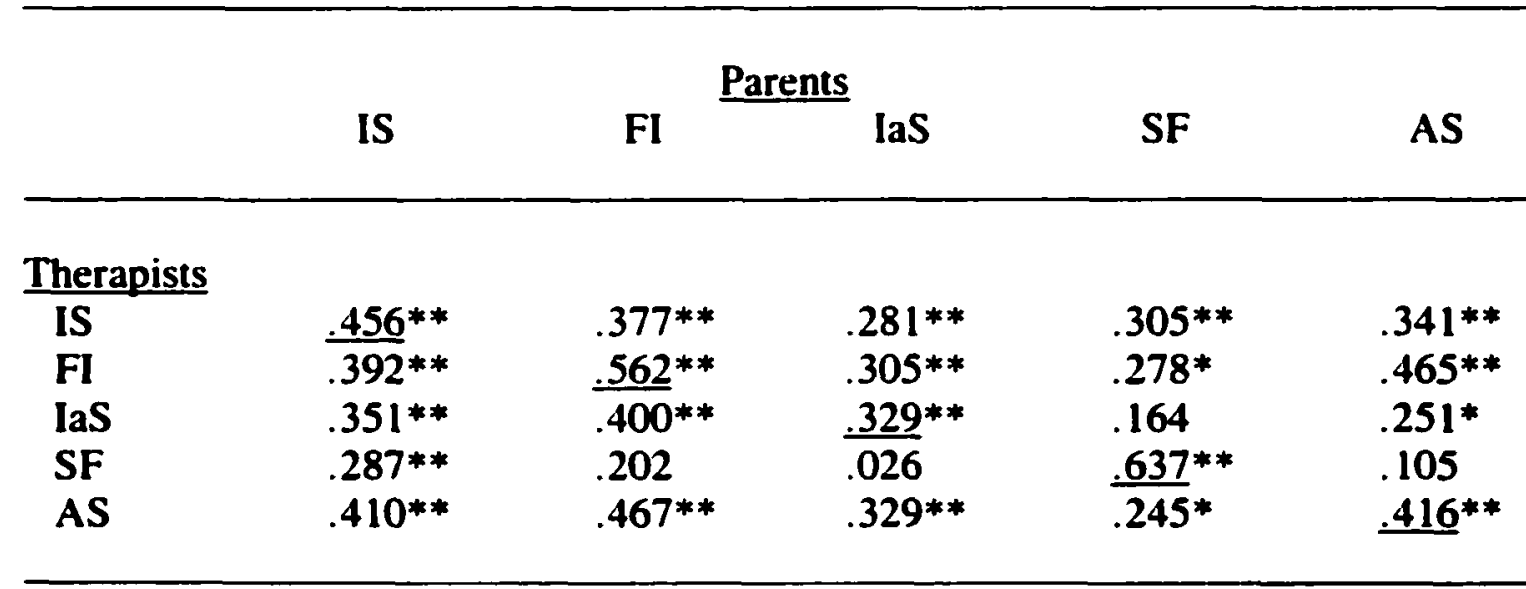

FI = Family Involvement; IS = Interpersonal Strength; IaS = Intrapersonal Strength; $\mathbf{S F}=$ School Functioning; AS = Affective Strength.

${ }^{*} p<.05{ }^{* *} p<.001$.

The concordance between parents' and therapists' ratings on the same subscale of the BERS, as seen in Table 6, do appear to be substantially greater than for other combinations of subscales, supporting the validity of the subscales as reported by Epstein and Sharma (1998). Concordance of the subscale scores on ratings by parents and therapists on the same subscale are as follows:

Interpersonal Strength (IS) .456; Family Involvement (FI) .562; Intrapersonal Strength (IaS) .329; School Functioning (SF) .637; and Affective Strength (AS) .416. These scores are reported on the diagonal of Table 6 . 
Additional correlations are also reported in Table 6; these measure the relationships across respondents and subscales. The correlations for care coordinator ratings on different subscales is reported below the diagonal and correlations for parent ratings on the same subscales above the diagonal. The values in the correlation matrix range from .026 to .637 . Of the 25 correlations in this matrix 18 were statistically significant at the $p<.001$ level. Correlations between subscales for the same group of raters range from .105 to .465 with a mean of .287 for the parents; and from .026 to .467 with a mean of .311 for the therapists.

The lowest correlation between subscales for both therapists and parents was the relationship between ratings on the School Functioning (SF) and Intrapersonal Strength (IaS) subscales. The parents' correlation between the SF and IaS subscales was .164 and the therapists' correlation between these subscales was .026

\section{Differences on Strengths Ratings}

Research Question 3: What are the differences between families' and professionals' ratings of strengths across the domains measured by the BERS?

A repeated measures analysis of variance (ANOVA) was used to examine differences in mean standard strength scores, primarily to examine rater by subscale interactions. A repeated measures ANOVA was conducted using the 
BERS subscale scores to determine Rater, Scale, and Rater X Scale Interactions, as shown in Table 7.

\section{Table 7}

Repeated Measures Analysis of Variance of BERS Subscale Scores

\begin{tabular}{lcccc}
\hline Source & $d f$ & $M S$ & $F$ & $p$ \\
\hline Between Subjects & 1 & 171.67 & 12.36 & .001 \\
\hline Rater (R) & 84 & 13.89 & & \\
Error (R) & 4 & & & \\
Within Subjects & & & & \\
\hline Scale (S) & 336 & 59.84 & 7.49 & .000 \\
Error (S) & 4 & 15.54 & 6.93 & \\
R x S & 336 & 2.24 & & \\
Error (R x S) & & & & \\
\hline
\end{tabular}

There was significant main effect due to Rater $[F(1,84)=12.36, p=$ $.001]$ across all scales. Parent raters had significantly higher ratings of strengths compared to therapists on all scales. Scale main effects were significant $[F(4,336)$ $=7.49, p=.000]$ supporting the discriminant validity of the subscales. The mean scores of Family Involvement (FI) and Affective Strengths (AS) generally 
were the highest of the overall combined ratings and the School Functioning Subscale (SF) the lowest (see Figure 2).

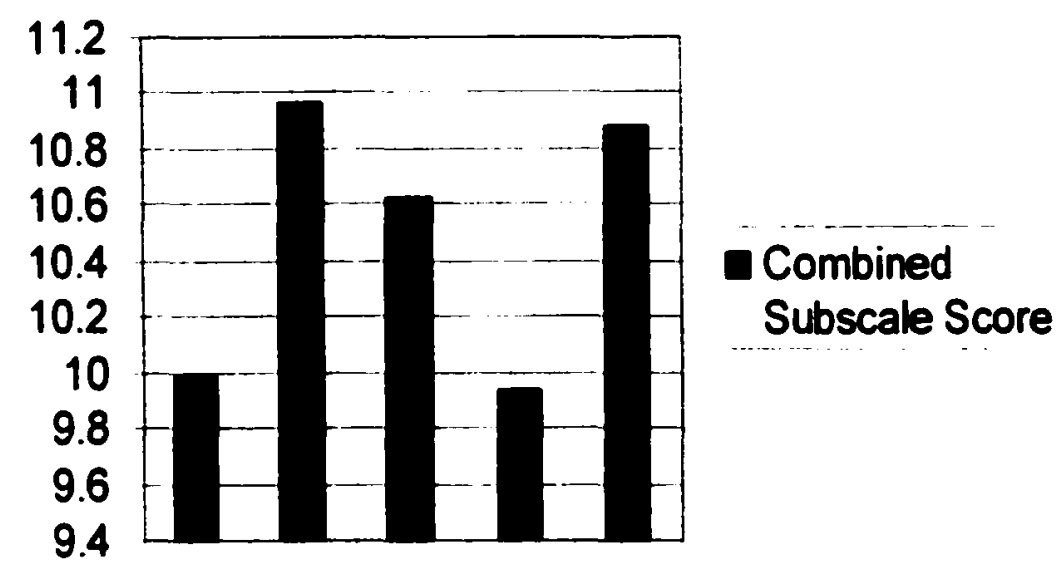

IS FI las SF AS

Figure 2. Scale main effects.

The Rater $\times$ Scale interaction effect was significant $[F(4,336)=6.93, p=$ .000] (see Figure 3). The difference between therapists and parents was greatest on the Intrapersonal Strength (IaS) and Affective Strength (AS) subscales. The smallest difference was on the School Functioning (SF) subscale.

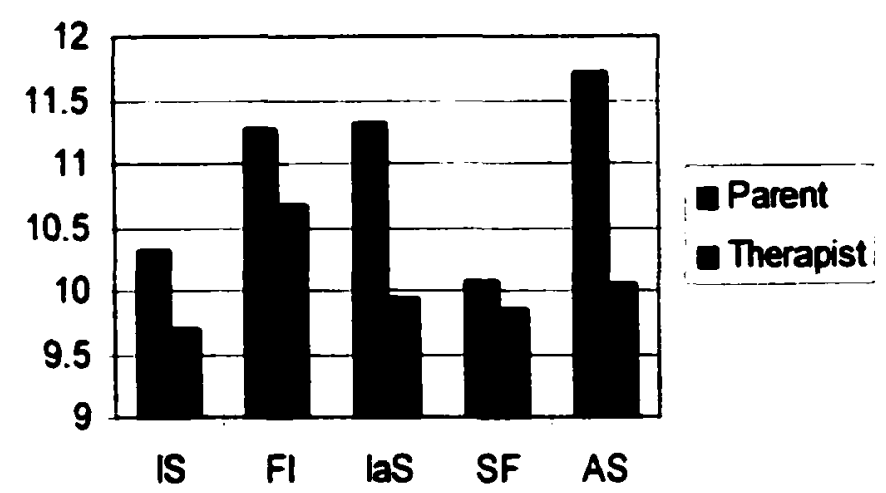

Figure 3. Rater by scale interaction effects. 
Post hoc pairwise comparisons were using the $t$ test for independent means. Parents' and therapists' scores on the same subscales, when compared, indicated a significant difference on the Intrapersonal Strength (IaS) scores [Mean Difference $=1.39, S D=3.46, t(84)=3.70, p=.0001$. There was also a significant difference on the Affective Strength (AS) scores between parents' and therapists' scores [Mean Difference $=1.67, S D=3.20, t(84)=4.80, p=.000]$. There was also a difference on the Family Involvement (FI) scale approaching significance [Mean Difference $=.59, S D=2.68$ ), $t(84)=2.02, p=.046]$. These significant findings of difference on subscales ratings support the value of multiple raters in assessing strengths and the importance of examining the rater by subscale differences (see Table 8 ).

Table 8

BERS Subscale Score Mean Difference Between Parent and Therapist Ratings

\begin{tabular}{|c|c|c|c|c|}
\hline Source & $\begin{array}{c}\text { Mean } \\
\text { Difference }\end{array}$ & $S D$ & $\boldsymbol{t}$ & $p$ \\
\hline Interpersonal (IS) & .62 & 3.20 & 1.79 & .076 \\
\hline Family Involvement (FI) & .59 & 2.68 & 2.025 & .046 \\
\hline Intrapersonal Strength (IaS) & 1.39 & 3.46 & 3.70 & .000 \\
\hline School Functioning (SF) & .22 & 2.47 & .836 & .406 \\
\hline Affective Strength (AS) & 1.67 & 3.20 & 4.806 & .000 \\
\hline
\end{tabular}




\section{Comparing Strengths and Deficits Ratings}

Research Question 4: What is the relationship between behavioral and emotional strengths and functional impairment as reported by the therapist?

The correlation of scores between BERS and CAFAS (therapist ratings) was studied to analyze the relationship between measurement of deficits and strengths as reported by the therapist. The correlation between the total BERS and CAFAS was Pearson's $r=-.609, p<.007$. This significant correlation is in the expected direction based on the inverse relationship of the BERS and CAFAS scales, with higher BERS scores indicating more strengths and higher CAFAS scores indicating more functional impairments. The relationship of strengths and deficit scores is further explored in Question 7.

Research Question 5: What is the relationship between behavioral and emotional strengths and behavior problems as reported by the parent?

The correlation between the BERS score from the parent and CBCL from the parent is $r=-.547, p<.048$ reaching a statistically significant relationship. This is in the expected direction since the BERS total score is higher based a higher assessment of strengths, the inverse relative to the total behavior problem score of the CBCL, also reported by the Parent. These relationships are further explored in Question 7. 
Research Question 6: What is the relationship between behavioral problems as reported by the parent and the functional problems as reported by the therapist?

The association between assessments of behavioral problems (as reported by the family) and functional assessment (as reported by the therapist) was explored to probe the relationship between deficit-based assessments. The internalizing and externalizing subscales of the CBCL and the subscale scores of the CAFAS were also correlated using Pearson's $r$ to determine the relationship between assessment of behavioral problems and functional assessments from the perspectives of the families and the professionals.

The correlation of the total scores of the CBCL and CAFAS $(r=.204)$ was not significant. Subscale score correlations on the CAFAS and CBCL are reported in Table 9. The externalizing and internalizing scales of the CBCL were tested for association with the total CAFAS and the subscales of the CAFAS. No significant correlations were seen between CBCL Internalizing subscale and the subscales of the CAFAS. Correlations between the CBCL Externalizing subscale and the Home/Community $(r=.323, p<.01)$; Behavior Toward Others $(r=.364, p<$ $.01)$ and the School/Work subscales of the CAFAS $(r=.256, p<.05)$ were significant. 


\section{Table 9}

Correlations Between Child Behavioral Checklist (CBCL) Scores and Child and Adolescent Functional Assessment Scale (CAFAS) Scores

\section{CBCL Subscales}

\section{Internalizing Externalizing}

\section{CAFAS Scores}

Total CAFAS Score

CAFAS Subscales

1. Mood/Emotions

2. Self-Harm

3. Thinking

4. Home Role

5. Behavior

6. Substance Use

7. School/Work

8. Community Role
.097

$.249 *$

.216

.169

.048

$-.007$

.013

.084

.079

$.323 * *$

.174

$.364 * *$

.088

.128

.090

$.256^{* *}$

$-.161$

$-.061$

NOTE: CBCL scores reported by the parent and CAFAS scores reported by therapist at baseline. $N=73$ pairs; ${ }^{*} p<.05 ;{ }^{* *} p<.001$

\section{Relationship of Child Characteristics and Assessed Strengths}

Research Question 7: What are the relationships between recognition of strengths and child characteristics?

Multiple regression analysis, as seen in Table 10, was used to explore the relationships between predictor variables (age, gender, and severity as measured by 
CBCL and CAFAS scores) and the dependent variable, assessed strengths (BERS). The total numerical values (raw scores) of the BERS were used for this analysis, as the standardized BERS scores are adjusted for gender differences. Prior to this analysis, scatterplots were examined to determine if the relationship appeared linear or curvilinear indicating a more complex interaction between assessment of strengths and deficits. The scatterplot analysis revealed generally negative but linear relationships between the strengths and deficit scores.

Severity of problems as reported by the parent and functioning as reported by the therapist were used in the separate regression models analyzing the relationships with assessed strengths by that group of raters. In the first regression model, parent problem scores (CBCL externalizing score) were a significant predictor of strengths scores (Coefficient Beta $=-.62, p<.000$ ). In the second model therapist CAFAS scores were predictive of strengths scores (Coefficient Beta $=-.60, p<.000)$. Therapist strengths scores were predicted by gender (Coefficient Beta $=.18, p<.05)$ at a level approaching significance. Using the regression procedure, neither gender nor age was predictive of higher strengths scores by parents.

A third model analyzed CAFAS subscale scores. In this model the home subscale of the CAFAS was predictive of therapist strengths score (Coefficient Beta $=-.47, p<.000$ ) with no other CAFAS subscale or child's characteristics being significant predictors of the strengths score. 
Table 10

Summary of Regression Analysis for Variables Predicting Strengths Scores

Variable

$$
R^{2}
$$

Beta

Prediction of Parents' BERS raw score from Child Characteristics and CBCL Subscales:

Model 1 $.4 * *$

Externalizing CBCL $-.62 * *$ Internalizing $\mathrm{CBCL}$ $-.04$ Child's Gender $-.11$

Child's Age .01

Prediction of Therapists' BERS raw score from Child Characteristics and CAFAS Total Score:

Model 2

CAFAS Total

Child's Gender

Child's Age
$.39 * *$

$$
\begin{aligned}
& -.60^{* *} \\
& .18^{*}
\end{aligned}
$$$$
.13
$$

Prediction of Therapists' BERS raw score from Child Characteristics and CAFAS Subscale Scores:

Model 3 $.55^{* *}$

Home

Community

$-.47^{* *}$

Moods/Emotions

$-.18$

Substance Abuse

$-.13$

School/Work

$-.09$

Child's Gender

$-.08$

Thinking Scale

.13

Child's Age

$-.06$

Self-Harm Behavior

$-.06$

Behavior

$-.15$

$-.24$

${ }^{*} p<.05 ;{ }^{* *} p<.001$ 


\section{CHAPTER V}

\section{DISCUSSION}

The findings support the primary aim of this study, to explore the assessment of strengths by multiple raters. The results verify that family members do identify and recognize strengths of their children at a higher level than therapists using the same assessment instrument. The second aim, exploring family involvement in assessment, is supported by findings of significant levels of correlation between families and professionals on strengths subscales and on specific subscales of instruments assessing behavior problems. Exploration of areas of difference on assessments across specific subscales of strengths and deficits measurements reveals statistically significant differences in patterns of strengths between family members and professionals revealing an important difference by rater in the assessment of children's strengths in the intrapersonal and affective domains.

Support for the conclusions is presented through a review of the research aims and research questions. Limitations of the study affecting the conclusions are discussed. Theoretical implications of the findings, suggestions for further research, and implications for practice are presented. 
A conceptual model was proposed and two practice constructs were investigated: assessments of strengths and participation of the family in assessment. These practice constructs were defined, measured and descriptive and inferential statistics were used to explore some of the constructs in the conceptual practice model and refine its implementation. This study explores these practice constructs through analysis of data collected at enrollment from both the parent and professional. Investigation of a conceptual practice model, as recommended by Hernandez and Hodges (2000), provides a basis for an ongoing analysis of the logic of the proposed model of practice.

The analyses of measurements of strengths and problems from multiple perspectives supports including parent voice in assessment of their children. Using empirically tested instruments as a method for increasing participation of parents during the assessment period was investigated. The results support that parents bring unique information to the assessment process. These findings suggest the utility of using the BERS instrument in combination with deficit-based measures to provide the additional perspectives provided by multiple raters. The findings support the utility of examining both concordance and difference in the analysis of scores on the subscales of the BERS, CAFAS and CBCL. Gathering and reporting subscale scores on these measures can enhance shared communication in assessment and treatment planning and provide a richer source for discourse about the needs of the child. Often measurements used in program evaluation are not routinely integrated in the day to day work of the clinician nor shared with the 
family and child. Sharing assessment data in this manner can facilitate communication about strengths, needs, and improvements and enhance participation of both the youth and their family in recognizing strengths and progress. This study provides a data revealing the relationship between supporting the utility of comparing perspectives to increase family and youth participation in both assessment and planning.

\section{Identification of Strengths}

Differences were seen between families and professionals in assessing strengths both in comparison to the national norms and in relation to each other. Parents consistently reported a higher level of strengths across all domains. The application of this strengths perspective in children was supported by the use of the strengths-assessment instrument, the Behavioral and Emotional Rating Scale (BERS; Epstein \& Sharma, 1998) employed in this study. According to Epstein and Sharma, strengths-based assessment involves

the measurement of those emotional and behavioral skills, competencies, and characteristics that: (a) create a sense of personal accomplishment; (b) contribute to satisfying relationships with family members, peers, and adults; (c) enhance the ability to deal with adversity and stress; and (d) promote personal, social and academic development. (p. 3)

The BERS was developed to measure the strengths that all children possess and with the assumption that children can be motivated by the manner in which significant adults respond to them. This study investigates the use of a strengths 
assessment involving both the family and professional using the BERS scale. When adults emphasize strengths, this may lead to more active engagement in appropriate activities and pro-social behaviors on the part of children or youth. These results support the importance of the multiple perspectives in assessing these strengths, as parent and professionals bring significantly different perspectives.

A strengths perspective shared by parents and professionals serves to instill hope and create a context for the family and community to sustain that hope for positive outcomes (Modrcin, 1999). Adoption of a strengths perspective studied with adults can inform practice for children and families. A strengths perspective was found to improve outcomes for adults with serious mental disorders. Services focusing on strengths rather than pathology, use of flexible resources beyond traditional mental health services and fostering a creative atmosphere between clients and providers through training and supervision were associated with positive outcomes (Modrcin, 1988). Identification of strengths and the full involvement of the youth and their family in developing a plan of care are viewed as critical variables to success of a wraparound plan for children and adolescents (Franz, 2000). The results of this study extend these observations and research findings. Through the consistent use of the strengths measure, the opportunity for deeper communication between families and professionals about observed strengths is increased. Exploration of concordance and differences in assessments between families and professionals supports open discourse and increases opportunities to recognize and build on strengths of the child. 


\section{Concordance of Family and Care Coordinator}

Concordance of Strengths subscale scores was measured and explored by analyzing parent and professional perspectives. The assessment of the care coordinator during the assessment period was informed both by parent report and interaction with the child during the first 30 days of engagement. The level of concordance in these scores can be partially attributed to the care coordinators attending to the parents during the assessment period as the care coordinators have less exposure to the child and therefore fewer opportunities to observe behaviors compared to the parents. A moderate correlation was found between families and professionals on the same BERS subscales indicating a level of agreement on the strengths and assets of the child.

Sharing assessment data enacts an approach recommended by family researchers and advocates in which the family's input is sought and valued at all levels. This practice enacts a paradigm shift from the traditional view of the mental health professional as the expert, with power differentially weighted to the professional and often denied to the family (DeChillo, Koren \& Mezera, 1996; McCammon, Spencer, \& Friesen, 2001). The level of concordance at baseline supports the assertion that families and professionals are interdependent in completing assessments and planning care on behalf of children with SED and listening is critical to developing genuine mutuality; moving from a traditional stance of power and authority to one of mutual agreement, rapport and effectiveness (Collins \& Collins, 1990; Heflinger \& Bickman, 1996). This study 
gives credence to the influence of parent perspective in assessment of both strengths and problems. Utilizing empirical measures and reporting these scores individually to families and through program level research may be a method to include parental perspectives and increase family voice in a systematic manner.

The use of valid and reliable scores from parents provides a tool for assuring parent input in the assessment and provides a baseline measure for measuring progress over time through repeated measures. The use of measures does not replace the need for increasing parental participation through other methods at the program and systems levels, but does provide a useful and verifiable method for assuring parent participation in assessment through consistent use of measures completed by parents and sharing the data reciprocally.

\section{Differences in Assessment of Strengths}

Examination of discrepancies in ratings between parents and care coordinators revealed significant differences in subscales related to Intrapersonal Strengths, Affective Strengths and Family Involvement. While the difference in the Family Involvement score may be accounted for by more observation time by the parents, the difference in assessment of Intrapersonal Strengths and Affective Strengths are significant findings. The findings support the importance of incorporating the family's perspective during the assessment period and not relying on the professional as the expert on the affective domains. This finding was different from an a priori expectation that care coordinators might identify more 
strengths in areas emphasized in professional training, such as in the affective domains represented by the Affective Strengths and Intrapersonal Strengths subscales. The results support assertions by family members that their input should be heard and heeded, and challenges assumptions that professionals have unique insight in the affective domains. The data provide an opportunity for both professionals and parents to explore differences in perceptions to increase the level of discourse about areas of agreement and difference and thereby support increased participation of the family. Completing and sharing assessment data consistently through accessible, efficient, and relevant tools can support both the helping process and the need to verify outcomes.

\section{Relationships to Strengths and Deficits Scores}

Negative correlations between the traditional deficit measures and the Strengths scales supports the utility of the overall total strengths quotient score. Both parents' and therapists' deficit scores correlate negatively with the BERS. In the regression models, the externalizing $\mathrm{CBCL}$ subscale predicted strengths with significance and the internalizing subscale was not predictive of higher strengths. The internalizing subscales of the CAFAS also did not predict higher strengths indicating the CBCL or CAFAS subscales reflecting internalizing behaviors may measure domains of behavior independent of perceived strengths. The strong relationships of the strengths scores and externalizing subscales of the CBCL and CAFAS suggest that it may be more difficult for parents and professionals to 
identify strengths in youth with higher levels of assessed behavior problems, or that these youth exhibit fewer strengths. These relationships of problem scores and identification of strengths need more study to examine the relationships of externalizing behaviors and strengths assessment.

\section{Relationship of Scores of Problems and Strengths}

In comparing parent and therapist scores on the CBCL and CAFAS, a high degree of agreement was seen across the subscales of these instruments indicating that the therapists were attending to the concerns of the parents at intake and had similar assessments of the children independently. This analysis of CBCL and CAFAS scores follows the study by Phillips (1999) which reported a high correlation between the externalizing scale of the CBCL and the CAFAS Home/Community subscales completed by foster parents and caseworkers and support the utility of using the subscales of the CBCL and CAFAS to explore the perspectives of two raters using these instruments, though more study is needed on the relationship of the subscales of these instruments.

Higher deficit scores, notably the Externalizing subscale of the CBCL and the Home Scale of the CAFAS, were predictive of lower Strengths scores. Neither gender nor age predicted a higher Strengths score by families, indicating that gender did not influence the assessment of strengths in a systematic manner for parents. 
In the regression analysis, the externalizing subscale of the CBCL was most predictive of parents' strengths scores. For therapists, the CAFAS Home Role subscale had the most predictive value indicating therapists of children acting out in the home environment systematically rate their strengths lower. Female gender was a predictor of a higher strengths rating by therapists.

\section{Limitations of the Study}

The sample from the Clackamas Partnership was compared to a national study of CMHS-funded demonstration sites around the country providing intensive care coordination to children with serious emotional disorders and high needs. The findings showed the study sample, while comparable in age, gender and referral sources had twice the rate of previous psychiatric hospitalization $(51.2 \%$ to $25.5 \%$ in the National sample) and much higher rates of history of abuse, runaways, and suicide attempts. Ethnic and racial/minorities were underrepresented in Clackamas compared to the national sample. The parents' assessment of problems as measured by the CBCL was higher than the national sample and the functional impairment level as assessed by the therapists was lower than the national sample. Though the samples were comparable on deficit and strengths scores, extension of these results beyond the study sample are not statistically supported and the findings should be interpreted as exploratory in nature.

Construct validation is useful in the interpretation of the findings, even without a causal connection. The antecedents and processes associated with the 
constructs measured through this study were developed through definition of constructs and the conceptual model. A description of the sample was conducted to explore similarities in local and national samples. Caution is exercised in the interpretation of these results beyond the population and treatment range actually sampled, however, this analysis with its articulated and measurable constructs is useful to establish a direction for future research and explores relationships among practice constructs being studied (Cook, 1993). Further analysis of strengths and deficit scores over time would increase our understanding of how perceptions of strengths interact with the relationship of the rater with the child.

Limitations to generalizability of this study is the temporal dimension of these baseline assessments conducted during the first two years of this project. During this period, there was staff training and certification in the CAFAS assessment initially, but rater drift may have occurred due to staff turnover. While the data were generally provided in the first 30 days of engagement in services, the amount and quality of staff contact with families and youth was not included in this research. Variability of the quantity and quality of this participation may affect the BERS scores provided by the care coordinators.

An independent measure of family participation was not included in this study, though a survey of family empowerment and participation was collected for the local evaluation of the project and could be considered for inclusion in future research to assess the quality of participation by the family. 


\section{Suggestions for Future Research}

This dissertation strives to provide empirical support for use of strengthsbased assessment provided by both families and professionals. Researchers have acknowledged difficulty in establishing controlled experiments on wraparound practice methods and have recommended testing of clearly conceptualized impact studies with an articulated logic model and verifiable descriptions of the interventions (Friedman, 1997; Knapp, 1995). Individualized, family-focused, and strengths-based interventions have gained support as service components, but have been insufficiently tested (Lourie, Stroul, \& Friedman, 1998).

Future research could include use of these instruments to assess change over time and further examination of the concordance on these measures to determine if changes in agreement or differences in scores may reflect increased involvement of the family in treatment. Direct measurement of family participation could be introduced to the analysis to determine if a relationship with family report of participation and concordance of the assessments might be found. Analysis of other relationships, such as diagnostic categories, is beyond the scope of this study, but would be useful to explore patterns of strengths recognition between families and professionals related to diagnostic categories or other measures of functioning.

Future research could explore alternate hypotheses regarding the perspectives of the family and professional assessments of strengths with some attempt to control to determine if the BERS objectively measures change over time 
or may be a reflection of changed perceptions of the family or professional.

During the engagement process, each participant influences the perceptions of others. These alternative hypotheses could consider if strengths scores are higher from families because they know them better of if therapists score lower because they are more objective.

Efforts to provide services for children with SED in their own communities, instead of institutional care, requires continued research to determine whether positive outcomes are associated with the proposed practice model. Because the services being provided are comprehensive, individualized, flexible, and strengthsbased, they are inherently more difficult to describe and evaluate (Friedman, 1997).

\section{Implications for Practice}

Implications of this research for social work practitioners are the findings that families have important and unique information on their children - especially in regards to strengths. This is an important finding supporting when considered in the context of the serious behavior problems of these children and the challenges faced by these families. In spite of these problems, families identify strengths in areas not perceived by professionals.

This study provides empirical support for the validity of family perspective and suggests that collecting and sharing data regarding strengths may be a method to enhance engagement between families and professionals. 
For social work administrators, the implications of identifying strengths through an instrument that can be completed by families provides a powerful tool that can be easily introduced and implemented in a variety of settings.

Social work's imperative to influence and reform systems calls for social work practitioners and administrators to lead the way in introducing tools and processes that emphasize strengths over pathology, disease and dysfunction. Social work has a responsibility to support consumer and family participation as a right, not a privilege bestowed upon worthy families. The evidence provided in this study indicates all families have a unique contribution to provide to the assessment of their children.

Critical to the success of services to children and families with the highest needs is the precision of fit between the needs and the intervention provided. It is expected that better outcomes result from a careful matching of the child's and family's strengths and needs with the level of services provided; this is a principle of wraparound practice and of a genuine managed care practice model (Sabin, 1994). The most precise fit between needs and interventions should result in the most efficient and effective care. Consequences of a mismatch between the family's needs and strengths and services provided can mean either over-serving or under-serving the child, resulting in limited positive outcomes, unnecessary costs, more restrictive placement than is optimal, and loss of confidence in the effectiveness of future interventions (Sosna, 1999). 
Inclusion of families in assessment and treatment planning, focusing on strengths and providing flexible and effective services and supports to children in lieu of institutional care are critical principles to implement and sustain improved practices in communities. These findings suggest the utility of including multi informant measurement and communication about the findings into the day to day practice of agencies and professionals providing services to children with the highest needs.

Research reveals an essential point about implementing systems of care; changes in the infrastructure of the system must be paralleled by changes in service delivery practices. If change occurs in only one of these areas, the organization of the system and its practices will not be integrated and instead, a new type of fragmentation will occur between principles and actual practice. Bickman's (1996c) study of Stark County, Ohio points to a well-developed infrastructure, with model interagency collaboration, that was apparently producing no positive clinical outcomes. This lack of positive clinical outcomes seemed to be based on a service delivery model that had not evolved along with the rest of the system-one that has remained locked into a 50-minute outpatient therapy model. Verification of implementation of desired practice constructs through empirical measurement is introduced and supported by these results.

The wraparound approach is consistent with an ecological paradigm of social work emphasizing the importance of material assistance, positive feedback, emotional caring and social companionship as mediators or "buffers" to stress and 
potentiators of coping abilities (Tracy \& Whittaker, 1987). In this paradigm the child is predicted to function best when the service system coordinates most efficiently with the family system (Burns, Schoenwald, et al., 2000). Malysiak (1998) emphasized the family acting as a decision-making participant in this process of ecological strengths enhancement. Key to inclusion of families as essential partners are individualized, intensive, culturally contextualized, and flexible mental health and social services based on the needs, desires, and strengths of children and families. This more precise fit of services and supports contrasts with the usual and customary approach of providing mental health and social services for children with serious emotional disorders through existing service options prescribed by funding streams and categorical eligibility. This study verifies that family participation in assessment provides useful data about domains of the child's functioning and contributes to a strengths perspective.

The purpose of this study has been to advance research through the articulation and measurement of key practice constructs of strengths identification and family participation in assessment associated with positive outcomes but not sufficiently tested. The importance of empirical validation of family participation emphasized in recent literature on promising practices in children's mental health programs includes: (a) the need to define family-provider collaboration in operational terms that can be empirically validated; (b) measurement of how family-provider collaboration can impact proximal and distal outcomes for the individual child as well as the system of care; and (c) assessment of the 
relationship of family-provider collaboration to satisfaction, empowerment, and ability to advocate for the child (Simpson, Koroloff, Friesen, \& Gac, 1999). Shared assessment and identification of strengths are some components of this collaborative practice model that have been explored in this study.

Adopting a strengths perspective in Social Work practice has gained increased attention as a practice principle. The perspective a professional brings to interaction with a client or family has a profound impact. As compared to medical sciences, social work and mental health interventions are highly influenced by the perspective of the professional, traditionally driven by an expectation to uncover pathology (Graybeal, 2001). In the transaction between families and professionals there is a simultaneous and inseparable operation of the person-environment system directly impacting the child. This formulation requires active participation by family members in treatment planning and decision-making (Heflinger \& Bickman, 1996).

The findings fulfill a primary aim of this study - to explore strengths-based assessment from multiple perspectives. Comparing concordance and differences in perceptions of parents and professionals fulfill the aim of exploring the unique contributions of families in the assessment process. Identification of strengths and building on these strengths through participation of the family are principles that can improve practice and support community and home-based care for children with serious emotional disorders. 


\section{REFERENCES}

Achenbach, T. M. (1991). Manual for the Child Behavior Checklist/4-18 and 1991 Profile. Burlington: University of Vermont, Department of Psychiatry.

Achenbach, T. M. (1993). Implications of multiaxial empirically based assessment for behavior therapy with children. Behavior Therapy, 24, 91116.

Allen, R., \& Petr, C. (1995). Family-centered service delivery: Acrossdisciplinary literature review and conceptualization. Kansas, MO: University of Kansas, The Beach Center on Families and Disability.

Attkisson, C. C., Dresser, K., \& Rosenblatt, A. (1993). Service systems for youth with severe emotional disorder: System of care research in California. In L. Bickman \& D. Rog (Eds.), Creating a children's mental health system: Policy, research and evaluation (236-280). Beverly Hills: Sage.

Behar, L. (1985). Changing patterns of state responsibility: A case study of North Carolina. Journal of Clinical Child Psychology, 14, 188-195.

Benard, B. (1993). Resiliency paradigm validates craft knowledge. Western Center News, 6(4), 6-7.

Benard, B. (1996). Resilience research: A foundation for youth development. New Designs for Youth Development, 12(3), 4-10.

Bickman, L. (Ed.). (1987). Using program theory in evaluation. San Francisco: Jossey-Bass.

Bickman, L. (1996a). A continuum of care: More is not always better. American Psychologist, 5l(7), 689-701.

Bickman, L. (1996b). Reinterpreting the Fort Bragg evaluation findings: The message does not change. The Journal of Mental Health Administration, $23(1), 137-145$. 
Bickman, L. (1996c). The Stark County evaluation. Presentation to the Stark County Family Council, Canton, Ohio.

Bickman, L., Guthrie, P. R., Foster, E. M., Lambert, E. W., Summerfelt, W. T., Breda, C., \& Heflinger, C. A. (1995). Evaluating managed mental health services: The For Bragg experiment. New York: Plenum Press.

Bickman, L., Lambert, E. W., Andrade, A. R., \& Penaloza, R. V. (2000). The Fort Bragg continuum of care for children and adolescents: Mental health outcomes over 5 years. Journal of Consulting and Clinical Psychology. 68(4), 710-716.

Bickman, L., Summerfelt, W. T., Firth, J., \& Douglas, S. (1997). The Stark County evaluation project: Baseline results of a randomized clinical experiment. In C. T. Nixan \& D. Northrup (Eds.), Evaluating mental health services (pp. 231-258). Thousand Oaks, CA: Sage Publications.

Bramely, J. (1999). Measuring wraparound in practice. Burlington: University of Vermont.

Brun, C., \& Rapp, R. C. (2001). Strengths-based case management: Individuals' perspectives on strengths and the case manager relationship. Social Work. 46(3), 278-288.

Bruns, E. J., Burchard, J. D., \& Yoe, J. T. (1995). Evaluating the Vermont system of care: Outcomes associated with community-based wraparound services. Journal of Child and Family Studies, 4, 321-339.

Burchard, J. D. (1998). How wraparound services can help overcome three common barriers to successful transition services. The Community Circle of Caring Journal, 2(4), 49-51.

Burchard, J. D., \& Clarke, R. T. (1990). The role of individualized care in a service delivery system for children and adolescents with severely maladjusted behavior. The Journal of Mental Health Administration, $17(1)$, 48-60.

Burchard, J. D., Hinden, B., Carro, M., Schaefer, M., Bruns, E., \& Pandina, N. (1995). Using case-level data to monitor a case-management system. In B. J. Friesen \& J. Poertner (Eds.), From case management to service coordination for children with emotional, behavioral, or mental disorders: Building on family strengths (pp. 169-187). Baltimore: Brookes Publishing Company. 
Burns, B. J. (1991). Mental Health service use by adolescents in the 1970's and 1980's. Journal of American Academy of Child and Adolescent Psychiatry, $30,144-150$.

Burns, B. J. (1994). The challenges of children's mental health services research. Journal of Emotional and Behavioral Disorders, 2, 254-259.

Burns, B. J. (1996). What drives outcomes for emotional and behavioral disorders in children and adolescents? (New Directions for Mental Health Services, 71). San Francisco: Jossey-Bass.

Burns, B. J., Farmer, E. Angold, A., \& Costello, E. J. (1996). A randomized trial of case management for youths with serious emotional disturbance. Journal of Clinical Child Psychology, 25(4), 476-486.

Burns, B. J., \& Goldman, S. K. (Eds.). (1999). Promising practices in wraparound for children with severe emotional disturbance and their families. Systems of care: Promising practices in children's mental health (1998 Series, vol. 4). Rockville, MD: Center for Mental Health Services.

Burns, B. J., Hoagwood, K., \& Maultsby, L. T. (1998). Improving outcomes for children and adolescents with serious emotional and behavioral disorders: Current and future directions. In M. H. Epstein, K. Kutash, \& A. J. Duchnowski (Eds.), Outcomes for children and youth with emotional and behavioral disorders and their families: Programs and evaluation best practices (pp. 686-707). Austin, TX: Pro-Ed.

Burns, B. J., \& Hoagwood, K. K., \& Mrzeck, P. J. (1999). Effective treatment for mental disorders in children and adolescents. Clinical Child and Family Psychology Review, 2(4), 199-254.

Burns, B. J., Schoenwald, S. K., Burchard, J. D., Faw, L., \& Santos, A. B. (2000). Comprehensive community-based interventions for youth with severe emotional disorders: Multisystemic therapy and the wraparound process. Journal of Child and Family Studies, 9(3), 283-314.

Center for Mental Health Services. (1997). Annual report to Congress on the evaluation of the comprehensive community mental health services for children and their families, 1997. Atlanta, GA: MACRO International Inc.

Center for Mental Health Services (1998a). Annual report to Congress on the evaluation of the comprehensive community mental health services for children and their families, 1998. Atlanta, GA: MACRO International Inc. 
Center for Mental Health Services. (1998b). Center for Mental Health Services National evaluation manual. Atlanta, GA: Author.

Center for Mental Health Services. (1998c). Guidance for applicants: Child mental health initiative. Washington DC: Substance Abuse and Mental Health Services Administration. Center for Mental Health Services.

Center for Mental Health Services (1999). Annual report to Congress on the evaluation of the comprehensive community mental health services for children and their families, 1999. Atlanta, GA: MACRO International Inc.

Clark, H. B., Lee, B., Prange, M. E., \& McDonald, B. A. (1996). Children lost without the foster care system: Can wraparound service strategies improve placement outcomes? Journal of Child and Family Studies, 5(1), 39-54.

Clark, H. B., Prange, M. E., Lee, B. Stewart, E. S., McDonald, B. B., \& Boyd, L. A. (1998). An individualized wraparound process for children in foster care with emotional/behavioral disturbances: Follow up findings and implications from a controlled study. In M. H. Epstein, K. Kutash, \& A. Duchnowski (Eds.), Outcomes for children and youth with emotional and behavioral disorders and their families (pp. 513-542). Austin, TX: Pro-Ed.

Collins, B., \& Collins, T. (1990). Parent-professional relationships in the treatment of seriously emotionally disturbed children and adolescents. Social Work, 35(6), 522-527.

Cook, T. D. (1993). A quasi-sampling theory of the generalization of causal relationships. In L. B. Sechrest, \& A. G. Scott (Eds.), Understanding causes and generalizing about them (New Directions for Program Evaluation No. 57) (pp. 39-81). San Francisco: Jossey Bass.

Courneyer, D. E., \& Johnson, H. C. (1991). Measuring parents' perceptions of mental health professionals. Research on Social Work Practice, I(4), 399415.

Cowger, C. D. (1994). Assessing client strengths: Clinical assessment for client empowerment. Social Work, 39(3), 262-263.

Cross, T., Barzon, B., Dennis, K., \& Issacs, M. (1989). Towards a culturally competent system of care. Washington, DC: Georgetown University, National Technical Assistance Center. 
Cross, T., \& McDonald, E. (1995). Evaluating the outcome of children's mental health services: $A$ guide for the use of available child and family outcome measures. Boston: Judge Baker Children's Center.

Cross, T., \& Saxe, L. (1997). Many hands make mental health systems of care a reality: Lessons from the Mental Health Services for Youth Program. In C. A. Nixon \& D. A. Northrup (Eds.), Evaluating mental health services: How programs for children "work" in the real world (pp. 45-72). Thousand Oaks, CA: Sage Publications.

Dalton, R., Pellerin, K., Carbone, V., Therict, A., Thibodeaux, D., Stewart, L., \& Wolfe, M. (2000). Treatment outcome among child psychiatric outpatients in a community mental health center. Community Mental Health Journal, 36(2), 195-203.

DeChillo, N., Koren, P. E., \& Mezera, M. (1996). Families and professionals in partnership. In B. A. Stroul (Ed.), Children's mental health: Creating systems of care in a changing society (pp. 389-407). Baltimore: Paul H. Brookes.

DeChillo, N., Koren, P. E., \& Schultze, K. H. (1994). From paternalism to partnership: Family and professional collaboration in children's mental health. American Journal of Orhopsychiatry, 64(4), 564-576.

Dennis, C. (1992). The history of wraparound and the role of families. Paper presented at the First Annual Wraparound Conference, Pittsburgh, PA.

Dinnebeil, L. A., \& Rule, S. (1994). Variables that influence collaboration between parents and service coordinators. Journal of Early Intervention, $18(4), 349-361$.

Dollard, N., Evans, M. E., Lubrecht, J., \& Schaeffer, D. (1994). The use of flexible service dollars in rural community-based programs for children with serious emotional disturbance and their families. Journal of Emotional and Behavioral Disorders, 2(2), 117-125.

Duchnowski, A. J., \& Friedman R. M. (1990). Children's mental health: Challenges for the nineties. Journal of Mental Health Administration, 17, 3-12.

Dunst, C., Trivette, C., \& Deal, A. (1994). Supporting and Strengthening Families. Cambridge, MA: Brookline Books. 
Elliott, D. J., Koroloff, N. M., Koren, P. E., \& Friesen, B. J. (1998). Improving access to children's mental health services: The family associate approach. In M. H. Epstein, K. Kutash, \& A. Duchnowski (Eds.), Outcomes for children and youth with emotional and behavior disorders and their families: Programs and evaluation best procedures (581-609). Austin, TX: Pro-Ed.

Epstein, M. H. (1999a). The development and validation of a scale to assess the emotional and behavioral strength of children and adolescents. Remedial and Special Education, 20(3), 258-262.

Epstein. M. H. (1999b). Using strength based assessment in programs for children with emotional and behavioral disorders. Beyond Behavior, 9, 2527.

Epstein, M. H. (2002, September 9). Strengths-based assessment. Presentation at program evaluation and performance improvement conference, Portland, Oregon.

Epstein, M. H., Harniss, M. K., Pearson, N., \& Ryser, G. (In press). The Behavioral and Emotional Rating Scale: Test-retest and inter-rater reliability. Journal of Child and Family Studies.

Epstein, M. H., \& Sharma, J. (1998). Behavioral and Emotional Rating Scale: A strength-based approach to assessment. Austin, TX: Pro-Ed.

Farmer, B. (1996). Selected experiences and findings in managing care from the comprehensive community mental health children and their families grantees. Washington, DC: National Resource Network for Child and Family Mental Health at the Washington Business Group.

Foster, M. E., Kelsch, C. C., Kamradt, B., Sosna, T., \& Yang, Z. (2001). Expenditures and sustainability in systems of care. Journal of Emotional and Behavioral Disorders, 9(1), 53-62.

Franz, J. (1999). The secret of the card shop caper. Presentation at Wisconsin Council on Children and Families, Madison, WI.

Franz, J. (2000). Principles of wraparound practice. Presentation to the Clackamas Partnership, Oregon City, OR. 
Franz, J., \& Miles, P. (1994. May). Looking to the wraparound process as an antidote for the collapse of our assembly-line human service industries. The Calliope Joumal, 5-8.

Friedman, C., \& Poertner, J. (1995). Creating and maintaining support structure for case managers. In B. J. Friesen \& J. Poertner (Eds.), From case management to service coordination for children with emotional, behavioral, or mental disorders: Building on family strengths (pp. 257-274). Baltimore: Paul H. Brookes Publishing Company.

Friedman, K. A., Friedman, P., \& Leone, P. (2002). Teacher and counselor perceptions of children's strengths at elementary, middle, and high school levels. Paper presented at the 14th Annual Research Proceedings (pp. 175180). Tampa: University of South Florida, Research and Training Center for Children's Mental Health.

Friedman, K. A., Leone, P. E., \& Friedman, P. (1999). Strengths-based assessment of children with SED: Consistency of reporting by teachers and parents. Journal of Child and Family Studies, 8, 169-180.

Friedman, R. M. (1997). Services and service delivery systems for children with serious emotional disorders: Issues in assessing effectiveness. In $\mathrm{C}$. $\mathrm{T}$. Nixon \& D. A. Northrup (Eds.), Evaluating mental health services: How do programs for children "work in the real world?" (pp. 16-44). Thousand Oaks, CA: Sage Publications.

Friedman, R. M., \& Burns, B. J. (1996). The evaluation of the Fort Bragg demonstration project: An alternative interpretation of the findings. The Journal of Mental Health Administration, 23, 128-136.

Friedman, R. M., Katz-Leavy, J. W., Manderscheid, R. W., \& Sondheimer, D. L. (1998). Prevalence of serious emotional disturbance in children and adolescents: An update. In R. W. Manderscheid \& M. A. Sonnenschein (Eds.), Mental health, United States, 1998 (pp. 110-112). Washington, DC: U.S. Government Printing Office.

Friedman, R. M., \& Street, S. (1985). Admission and discharge criteria for children's mental health services: A review of the issues. Journal of Clinical Child Psychology, 14, 229-235. 
Friesen, B. J. (1989). Parents as advocates for children and adolescents with serious emotional handicaps: Issues and directions. In R. M. Friedman, A. J. Duchnowski, \& E. L. Henderson (Eds.), Advocacy on behalf of children with serious emotional problems (pp. 28-44). Springfield, IL: Charles C. Thomas.

Friesen B., \& Koroloff, N. (1990). Challenges for child and adolescent mental health. Health Affairs, $11,125-136$.

Garmezy, N. (1994). Reflections and commentary on risk, resilience, and development. In R. J. Haggerty, L. R. Shjerrod, N. Garmezy, \& M. Rutter (Eds.), Stress, risk, and resilience in children and adolescents: Processes, mechanisms, and interventions (pp. 1-18). Cambridge, England: Cambridge University Press.

Graybeal, C. (2001). Strengths-based social work assessment. Families in society, 82(3), 233-242.

Greenbaum, P. E., Dedrick, R. F., Kutash, K., Brown, E. C., Larieri, S. P., \& Pugh, A. M. (1998). National Adolescent and Child Treatment Study (NACTS): Outcomes for children with serious emotional and behavioral disturbance. In M. H. Epstein, K. Kutash, \& A. Duchnowski (Eds.), Outcomes for children and youth with behavioral and emotional disorders and their families (pp. 21-54). Austin, TX: Pro-Ed.

Hanley, J. H., \& Wright, H. H. (1995). Child mental health professionals: The missing link in child mental health reform. Journal of Child and Family Studies, 4(4), 383-388.

Harniss, M. K., Epstein, M. H., Ryser, G., \& Pearson, N. (In press). The Behavioral and Emotional Rating Scale: Criterion-related validity. Journal of Psychoeducational Assessment.

Heflinger, C. A., \& Bickman, L. (1996). Family empowerment: A conceptual model for promoting parent-professional Partnership. In C. A. Heflinger \& C. T. Nixon (Eds.), Families and the mental health system for children and adolescents: Policy, services and research (96-116). Thousand Oaks, CA: Sage Publications. 
Heflinger, C. A., Northrup, D. A., Sonnichsen, S. E., \& Brannan, A. M. (1998). Including a family focus in research on community-based services for children with serious emotional disturbance: Experiences from the Fort Bragg evaluation project. In M. E. Epstein, K. Kutash, \& A. Duchnowski (Eds.), Outcomes for children and youth with emotional and behavioral disorders and their families: Programs and evaluation best practices (pp. 261-293). Austin, TX: Pro-Ed.

Henggeler, S. W., \& Borduin, C. M. (1995). Multisystemic treatment of serious juvenile offenders and their families. In I. M. Schwartz \& P. AuClaire (Eds.), Home-based services for troubled children (pp. 113-130). Lincoln: University of Nebraska Press.

Hernandez, M., \& Hodges, S. (1996). The ecology of outcomes. Tampa: University of South Florida, Florida Mental Health Institute, Department of Child and Family Studies.

Hernandez, M., \& Hodges, S. (2000, June 9-13). Turning ideas into action using theory-based frameworks. Paper presented at Training Institutes 2000, New Orleans, LA.

Hodges, K., Doucette, A., \& Liao, Q. (1999). The relationship between the Child and Adolescent Functional Assessment Scale (CAFAS) and indicators of functioning. Journal of Child and Family studies, 8(1), 109-122.

Hodges, K., Lambert, W., \& Summerfelt, W. T. (1994). Validity of a measure to assess impairment: The Child and Adolescent Functional Assessment Scale (CAFAS). Paper presented at the 7th Annual Research Conference, A System of Care for Children's Mental Health: Expanding the Research Base, Tampa, Florida.

Hodges, S., Nesman, T., \& Hernandez, M. (1999). Promising practices: Building collaboration in systems care. Systems of Care: Promising Practices in Children's Mental Health, 1998 Series, Volume VI. Washington, DC: Center for Effective Collaboration and Practice, American Institutes for Research.

Hodges, K., \& Wong, M. W. (1996). Psychometric characteristics of a multidimensional measure to assess impairment: The Child and Adolescent Functional Assessment Scale. Journal of Child and Family Studies, 5(4), 445-467. 
Issacs, M., \& Benjamn, M. (1993). Towards a culturally competent system of care. Washington, DC: Georgetown University, National Technical Assistance Center.

Jensen, J. A., McNamara, J. R., \& Gustafson, K. E. (1991). Parents' and clinicians' attitudes toward the risks and benefits of child psychotherapy: A study of informed-consent content. Professional Psychology, Research and Practice, 22, 161-170.

Jensen, P. (1999). Mental health issues in children. Unpublished presentation at the $12^{\text {th }}$ Annual Research Conference, A System of Care for Children's Mental Health: Expanding the Research Base, Tampa, Florida.

Johnson, H., Cournoyer, D., \& Bond, B. (1995). Professional ethics and parents as consumers: How well are we doing? Families in Sociery: The Joumal of Contemporary Human Services, 76(7), 408-420.

Johnson, H. C., Cournoyer, D. E., \& Fisher, G. (1994). Measuring Worker cognitions about parents of children with mental and emotional disabilities. Journal of Emotional and Behavioral Disorders, 2(2), 99-108.

Jordan, D. D., \& Hernandez, M. (1990). The Ventura Planning Model: A proposal for mental health reform. Journal of Mental Health Administration, 17, 25-47.

Kamradt, B. (1996). Blending funding streams to support system of care reform for children with severe emotional problems and their families. Washington, DC: National Resource Network for Child and Family Mental Health at the Washington Business Group.

Knapp, M. S. (1995). How shall we study comprehensive collaborative services for children and families? Educational Researcher, 24(4) 5-16.

Knitzer, J. (1982). Unclaimed children: The failure of public responsibility to children and adolescents in need of mental health services. Washington, DC: The Children's Defense Fund.

Koren, P., DeChillo, N., \& Friesen, B. J. (1992). Measuring empowerment in families whose children have emotional disabilities: A brief questionnaire. Rehabilitation Psychology, 37(4), 305-321. 
Koren, P. E., Paulson, R., Kinney, R., Yatchmonoff, D., Gordon, L., \&

DeChillo, N. (1997). Service coordination in children's mental health: An empirical study from the caregivers perspective. Journal of Emotional and Behavioral Disorders, 5, 62-172.

Koroloff, N. M., Elliott, D. J., Koren, P. E., \& Friesen, B. J. (1996). Linking low-income families to children's mental health services: An outcome study. Journal of Emotional and Behavioral Disorders, 4(1), 2-11.

Koroloff, N. M., Friesen, B. J., Reilly, L., \& Rinkin, J. (1996). The role of family members in systems of care. In B. Stroul (Ed.), Children's mental health: Creating systems of care in a changing society (pp. 409-426). Baltimore: Paul H. Brookes.

Kutash, K., Duchnowski, A. J., \& Sondheimer, D. L. (1994). Building the research base for children's mental health services. Joumal of Emotional and Behavioral Disorders, 2, 194-197.

Kutash, K., \& Rivera, V. (1996). What works in children's mental health services? Uncovering answers to critical questions. Baltimore: Brookes Publishing.

Liao, Q, Holden, W., \& Epstein, M. H. (2002). Confirmatory factor analysis of the BERS. Paper presented at the 15th Annual Research Conference, A System of Care for Children's Mental Health: Expanding the Research Base, Tampa, Florida.

Liao, Q., Manteuffel, B., Paulic, C., \& Sondheimer, D. (2001). Describing the population of adolescents served in systems of care. Journal of Emotional and Behavioral Disorders, 9(1), 13-29.

Lourie, I., Stroul, B., \& Friedman, R. (1998). Community-based systems of care: From advocacy to outcomes. In M. D. Epstein, K. Kutash \& A. Duchnowski (Eds.), Outcomes for children and youth with behavioral and emotional disorders and their families (pp. 3-20). Austin, TX: Pro-Ed.

Malekoff, A. (2000). Bureaucratic barriers to service delivery, administrator advocacy, and Mother Goose. Families in Society, 81(3), 304-314.

Malysiak, R. (1996). Deciphering the tower of Babel: Preliminary steps towards a theory base for wraparound fidelity. Journal of Child and Family Studies, 7, 11-25. 
Malysiak, R. (1997). Exploring the theory and paradigm base for wraparound. Journal of Child and Family Studies, 6(4), 399-408.

Malysiak, R. (1998). Deciphering the tower of Babel: Examining the theory base for wraparound fidelity. Journal of Child and Family Studies, 7(1), 11-25.

McCammon, S. L., Spencer, S., \& Friesen, B. J. (2001). Promoting family involvement through multiple roles. Journal of Family Social Work, 5(3), 1-24.

McCormack, M., \& Taylor, M. (1998). Clackamas partnership grant application. (Available from The Center for Mental Health Services, SAMHSA, Washington, DC)

McGinty, K. M., McCammon, S. L., \& Koeppen, V. P. (2001). The complexities of implementing a wraparound approach to service provision: A view from the field. Journal of Family Social Work, 5(3), 95-110.

Mechanic, D., Rochefort, D. A. (1992, Spring). A policy of inclusion for the mentally ill. Health Affairs, 128-150.

Mechanic, D., \& Rochefort, D. (1992). A policy of inclusion for the mentally ill. Health Affairs, II(1), 128-150.

Modrcin, M. (1985). The comparative effectiveness of two models of case management services to the chronically mentally ill. Unpublished dissertation, The University of Kansas, School of Social Welfare, Lawrence.

Modrcin, M. (1988). The evaluation of case management services with the chronically mentally ill. Evaluation and Program Planning, 1/(4), 307-14.

Modrcin, M. (1999). Strengths based practice. Presentation to the Clackamas Partnership, Oregon City, Oregon.

Nelson, C. M., \& Pearson, C. A. (1991). Integrating services for children with emotional and behavioral disorders. Reston, VA: Council for Exceptional Children.

Nordness, P. D., \& Epstein, M. H. (2000). Convergent validity of the Behavioral and Emotional Rating Scale. Unpublished study. FROM WHERE? 
Ogilvie, A. M. (2000). The assessment of children with attachment disorder: The Randolph Attachment Disorder Questionnaire, Behavioral and Emotional Rating Scale, and Biopsychosocial Attachment Types Framework. Unpublished dissertation proposal, Portland State University, Portland, Oregon.

Patton, M. Q. (1994). Developmental evaluation. Evaluation Practice, 15, 311 319.

Patton, M. Q. (1997). Utilization-focused evaluation: The new century text (3rd ed.). Thousand Oaks, CA: Sage.

Petr, C. G., \& Allen, R. I. (1997). Family-centered professional behavior: Frequency and importance to parents. Journal of Emotional and Behavioral Disorders, 5(4), 196-204.

Petr, C. G., \& Spano, R. N. (1990). Evolution of social services for children with emotional disorders. Social Work, 35(3), 228-234.

Phillips, R. D. (1999). Correlations between CBCL and CAFAS among foster children. In C. L. Benton, C. Newman, K. Kutash \& R. Friedman (Eds.), $12^{\text {th }}$ annual research conference proceedings (pp. 173-176). Tampa: University of South Florida, Research and Training Center for Children's Mental health.

Pires, S. A. (1996). Lessons learned from the Fort Bragg demonstration: An overview. Washington, DC: Human Services Collaborative.

Pires, S. A., Stroul, B. A., \& Armstrong, M. I. (2000). Health care reform tracking project: 1999 Impact analysis. Tampa: University of South Florida, Research and Training Center for Children's Mental Health, Department of Child and Family Studies, Louis de la Parte Florida Mental Health Institute.

Rapp, C. A., \& Wintersteen, R. (1989). The strengths model of case management: Results from 12 demonstrations. Psychosocial Rehabilitation Journal, 13(1), 23-32.

Rivera, V. R., \& Kutash, K. (1994). Components of a system of care: What does the research say? Tampa: University of South Florida, Florida Mental Health Institute, Research and Training Center for Children's Mental Health. 
Robinson, R. A., \& Whitbeck, J. (1992). Facilitating tailored care for seriously emotionally disturbed children in their communities: Fifteen case studies. Paper presented at the $5^{\text {th }}$ Annual Conference, A System of Care for Children's Mental Health: Expanding the Research Base, Tampa, Florida.

Rosenblatt, A. (1993). In home, in school, and out of trouble. Journal of Child and Family Studies, 2(4), 275-282.

Rosenblatt, A. (1996). Bows and ribbons, tape and twine: Wrapping the wraparound process for children with multi-system needs. Journal of Child and Family Studies, 5(1), 101-117.

Rosenblatt, A. (1998). Assessing the child and family outcomes of systems of care for youth with serious emotional disturbance. In M. H. Epstein, K. Kutash, \& A. Duchnowski (Eds.), Outcomes for children and youth with emotional and behavior disorders and their families: Programs and evaluation best procedures (329-362). Austin, TX: Pro-Ed.

Rutter, M. (1979). Protective factors in children's responses to stress and disadvantage. In M. W. Kent \& J. E. Rolf (Eds.), Primary prevention of psychopathology: Social competence in children (pp. 49-74). Hanover. NH: University Press of New England.

Rutter, M., \& Sandberg, S. (1992). Psychosocial stressors: Concepts, causes and effects. European Child and Adolescent Psychiatry, 1, 3-13.

Ryan, W. (1976). Blaming the victim. New York: Random House.

Sabin, J. E. (1994). The impact of managed care on psychiatric practice. Directions in Psychiatry, 14(9), 1-7.

Saleeby, D. (1992). The strengths perspective in social work practice. White Plains, NY: Longman.

Saleeby, D. (1996). The strengths perspective in social work practice: Extensions and cautions. Social Work, 4l(3), 296-305.

Senge, P. (1994). The fifth discipline fieldbook. New York: Doubleday Publishers. 
Shaffer, D., Fisher, P., Dulcan, M. K., Davies, M., Piacentini, J., Schwab-Stone, M. E., Lahey, B. B., Bourdon, K., Jensen, P. S., Bird, H. R., Canino, G., \& Regier, D. A. (1996). The NIMH Diagnostic Interview Schedule for Children Version 2.3 (DISC-2.3): Description, acceptability, prevalence rates, and performance in the MECA Study. Methods for the Epidemiology of Child and Adolescent mental Disorders Study. Journal of the American Academy of Child and Adolescent Psychiatry, 35. 865-877.

Simpson, J. S., Koroloff, N., Friesen, B. F., \& Gac, J. (1999). Promising practices in family-provider collaboration. Systems of Care: Promising Practices in Children's Mental Health, 1998 Series (vol. 2). Washington, DC: Center for Effective Collaboration and Practice, American Institute of Research.

Singh, N. N., Curtis, W. J. Wechsler, H. A., Ellis, C., \& Cohen, R. (1997). Family friendliness of community-based services for children and adolescents with emotional and behavioral disorders and their families: An observational study. Journal of Emotional and Behavioral Disorders, 5(2), 82-92.

Singh, N. N., Landrum, T. J., Donatelli, L. S., Hampton, C., \& Ellis, C. R. (1994). Characteristics of children and adolescents with serious emotional disturbance in systems of care. Part I: Partial hospitalization and inpatient psychiatric services. Journal of Emotional and Behavioral Disorders, 2, 13-20.

Singh, N. N., Wechsler, H. A., \& Curtis, J. W. (2000). Family friendliness of inpatient services for children and adolescents with EBD and their families: Observational study of the treatment team process. Journal of Emotional and Behavioral Disorders, 8(1), 19-26.

Sosna, J. (1999, July). Precision of fit delivery system. Paper presented at the National Resource Network Meeting, Halfmoon Bay, CA.

SPSS. (1996). Statistical Program for the Social Sciences 11.0 [computer program]. Chicago: SPSS.

Stroul, B. A. (1993). Systems of care for children and adolescents with severe emotional disturbances: What Are the results? Washington, DC: CASSP Technical Assistance Center. 
Stroul, B. A. (Ed.). (1996). systems of care for children and adolescents with severe emotional disturbances: From theory to reality. Baltimore: Paul H. Brookes.

Stroul, B. A., \& Friedman, R. M. (1986, June). A system of care for children and youth with severe emotional disturbances. Washington, DC: Georgetown University Child Development Center, CASSP Technical Assistance Center, Center for Child Health and Mental Health Policy.

Stroul, B. A., \& Friedman, R. M. (1996). The system of care concept and philosophy. In B. A. Stroul (Ed.), Creating systems of care in a changing society (pp. 3-22). Baltimore, MD: Paul H. Brookes.

Stroul, B. A., Pires, S. A., \& Armstrong, M. A. (1998). Health care reform tracking project: Tracking state managed care reforms as they affect children and adolescents with behavioral disorders and their families - 1997 impact analysis. Tampa: University of Florida, Florida Mental Health Institute, Louis de la Parte Research and Training Center for Children's Mental Health.

Summerfelt, W. T. (1994). Examination of the validity of the Child and Adolescent Functional Assessment Scale (adolescents). Doctoral dissertation, Vanderbilt University, Nashville, TN.

Tannen, N. (1991). Therapeutic case management: Guidelines for implementing an individualized care plan for children with severe emotional disturbance. Waterbury, VT: Department of Mental Health and Mental Retardation.

Taylor, M. (2002). Year 5 reapplication to the Center for Mental Health Services. (Available from The Center for Mental Health Services, Washington, DC)

Tracy, E. M., \& Whittaker, J. K. (1987). The evidence base for social support interventions in child and family practice: Emerging issues for research and practice. Children and Youth Services Review, 9(4), 249-270.

Turnbull, A. P., Friesen, B. J., Ramirez, C. R. (1998). Participatory action on research as a model for conducting family research. Journal $A S H, 23(3)$, 178-188.

Tyson, K. B. (1992). A new approach to relevant scientific research for practitioners: The heuristic paradigm. Social Work, 37(6), 541-556. 
U.S. Department of Health and Human Services. (1999). Mental Health: A report of the Surgeon General. Rockville, MD: U.S. Department of Health and Human Services, Substance Abuse and Mental Health Services Administration, Center for Mental Health Services, National Institutes of Health, National Institute of Mental Health.

VanDenBerg, J. (1990). The Alaska youth initiative: An experiment in individualized treatment and education. In A. Alagarin, (list others) (Eds.) et al., $2^{\text {nd }}$ Annual conference proceedings: Children's mental health services and policy: Building a research base (pp. 59-72). Tampa: University of South Florida: Florida Mental Health Institute.

VanDenBerg, J. (1991). Alaska youth initiative. Juneau: Alaska Department of Health and Social Services.

VanDenBerg, J. E. (1992, Summer). Individualized services for children. New Directions for Mental Health Services, 54, 97-100.

VanDenBerg, J. E., \& Grealish, E. M. (1996). Individual services and supports through the wraparound process: Philosophy and procedures. Journal of Child and Family Studies, 5(1), 7-21.

Weick, A., Rapp, C., Sullivan, W. P., \& Kisthardt, W. (1989). A strengths perspective for social work practice. Social Work, 34(4), 350-354.

Weissman, M. M., Warner, V., Wickramaratne, P., Moreau, D., \& Olfson, M. (1997). Offspring of depressed parents, 10 years later. Archives of General Psychiatry, 54, 932-940.

Weller, E. B., Cook. S. C., Hendren, R. L., \& Woolston, J. L. (1995). On the use of mental health services by minors: Report to the American Psychiatric Association Task Force to study the use of psychiatric hospitalization of minors: A review of statistical data on the use of mental health services by minors. Washington, DC: American Psychiatric Association.

Wells, K. (1991). Placement of emotionally disturbed children in residential treatment: A review of placement criteria. American Journal of Orthopsychiatry, 61, 339-347.

Whitbeck, J. (1996). The Individual Needs Survey. Olympia: Washington State Department of Social and Health Services. 
Whitbeck, J., Kimball, G., Olson, D., Lonner, T., \& McKenna, M. (1993). A report from the field - Individualized and tailored care: What makes it work? Olympia: Washington State Department of Social and Health Services.

Wolin, S., \& Wolin, S. (1993). The resilient self. New York: Villiard Books.

Yatchmenoff, D. K., Koren, P. E., Friesen, B. J., Gordon, L. I., \& Kinneg, R. F. (1999). Enrichment and stress in families caring for a child with a serious emotional disorder. Joumal of Children and Family Studies, 7(2), 129-145. 
APPENDIX A

HUMAN SUBJECTS REVIEW AND APPROVAL 


\title{
PORTLAND STATE UNIVERSITY
}

\section{Memorandum}

\author{
To: Chair, Human Subjects Research Review Committee, Portiand State Liniversiry \\ cc: Michael Taylor, Clackamas County Parnership, Nancy Korolofr, RRI \\ From: Barbara J. Friesen \\ Date: $11,26,2001$ \\ Re: Continuation repurt fur research involving human subjects: Clackasmas Cuunty Partnership \\ National Outcome Evaluation
}

\begin{abstract}
Altached are 10 copies of the Continuation Report and accompanying consent forms for the Clackamas County Partnership National Outcome Evaiuation.

If you have any questions, or need more information, please contact me at $5-1166$ (PSU). I am sabbatical leave this year. but the best place to leave a message is on my PSU voice mail.
\end{abstract}

Thanks for your help. 


\section{Human Subjects Research Review Committee Continuation Report for Research Involving Human Subjects Portland State University}

The Institusional Review Bourd (HSRRC) is required by Title 2l. Code of Federal Regulations (Pan 56. 109) and Title 45. Code of Federal Regulations (Part 46.109) to conduct connmung review of ongoing projects not less than once per year. Your assistance in meeting these federal requirements is appreciated Please complete all required sections and submit required attuchments-thank you.

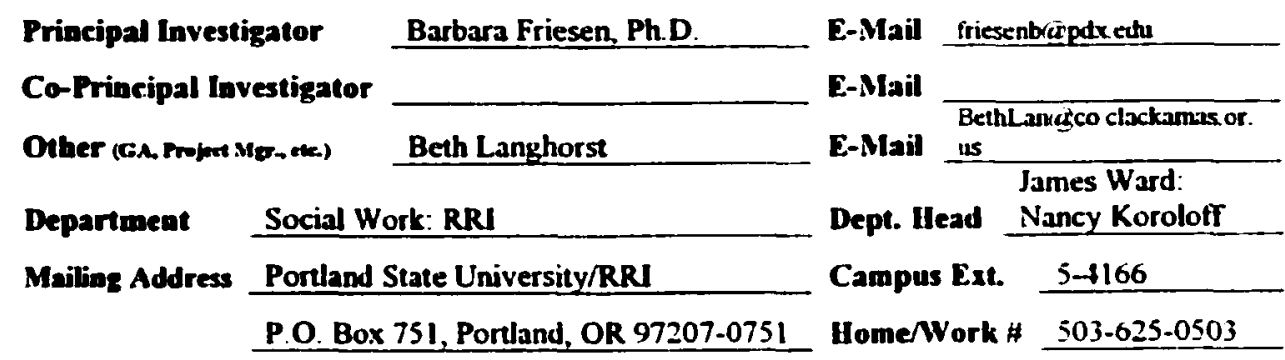

Project Title Clackamas County Partnership National Outcome Evaluation

I certify that this report is accurate and that the research activities invoiving human subjects were conducted as stated in the approved protocol. I will abide by the Federal and University policies related to research involving human subjects.

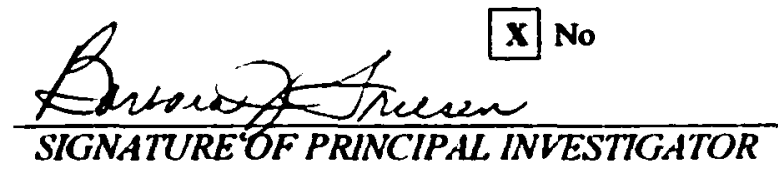

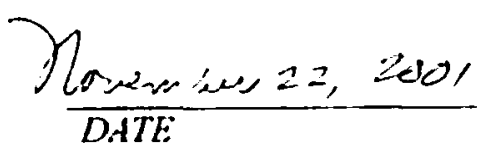

\section{STEP 1:}

Project Funded?

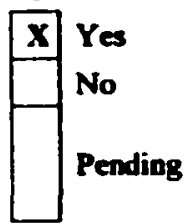

FederalFederal Pass-Through?

\begin{tabular}{|l|l}
$\mathrm{x}$ & Yes \\
No
\end{tabular}

Funding Agency Name.

Clackamas County Partuership (coutunct with PSU); grant funds from the Center for Mental Health Services, Comprebensive Commonity Mental Health Senvices for Children and their Families Program, Substance Abuse and Mentel Health Services Administration

Yes,

Yes, 2: Are all activities involving human subjects, data collection and analysis complete?

$\square$ Yes Data analysis was completed as of [Click to enter date]. Do not proceed to Step 3. Submit only this page to the HSRRC.

$x$ No Proceed to Step 3 
STEP 3: In the space provided, please type a one-page summary of the project, or attach the summary as a separate document. The summary should both describe the project as it was originally conceived and provide a detailed account of its current status.

This study is an outcome evaluation of the Clackamas County Partnership project to create comprebensive, famuly driven. culturally competent community-based services for children with serious emotional disturbances. Agencies included in the Clackamas Partnership, a CMIt IS grantec as of September 1998, are juvenile justice, child welfare, ectucation, mental beath, residential treatmemt cemers and private providers. Clackamas County Mental Health serves as the lead agency for the initiative and has emtered into a contract with the Regional Research lnstitute to conduct an evaluation of the Partnership. MACRO International, a consulting company located in Atlanta, Georgia, holds the federal contract for implementation of the mational evaluation of all CMHS sites. This evaluation consists of instrumemts (see attached list) that allow for the collection of standardized information across all participating sites, as required by congressional mandate and is authorized via federal law, Section 565 of the Public Health Service Act. The design and instrumentation for MLACRO's evaluation has received federal Office of Management and Budget approval, CMIS IRB approval and MACRO IRB approval. MACRO's major responsibilities include the coordination and oversight for the implementation of the national evaluation.

Data are collected locally by clinical and evaluation staff hired by Clackamas County. Training and oversight for data collection are the responsibility of the Partnership Evaluation Team, lead by Barbara Friesen. Ph.D., Principal Investigator for the evaluation (PSU), Beth Langhorst, Ph .D., site-based evaluator, and Michael Taylor. M.S.W. Site Director (Clackamas Co. Mental Healtb). Data are electronically transmitted quarterly to MACRO for analysis. Results will subsequently be reported back to the Partnership and also will be aggregated with data from the other grants so that it can be reported to the Centers for Mental Heath Services and to Congress. All data are housed at the project site.

Data elements for the local evaluation require collection of information from parncipating agencies Managed Information Systems (MOS) and the inclusion of an additional instrumcm-Funily Participation Survey -imto the rotation of standardized instruments being used for the national evaluation. The additional MS data reflects data already collected by other agencies and will not alter families' experiences with these agencies. The Family Participation Survey is collected from the emtire consenting population, following the same periodicity schedule as the rest of the national cvaluation instrumentation. Local analysis of the mational evaluation data and data collected specifically for the local evaluation will be analyzed by the principal investigator and ocher contracted support from PSU, as well as the site-based evaluator. Results will be reported to all local stakebolders (policy-makers, staff, fumilies, and community agencies).

All participating children and families provide information at enrollment in progran services. The first cohort-those who enter the study between 10/1/99 and 9/30/00 - will be re-imerviewed as six momeh intervals to 36 momths. Those children and families who comprise cobort two-entry into the study between 10/1/00 and 9/30/01 will be re-interviewed at 6-month intervals and will be followed to 30 moxths. Those children and families who comprise cohort $3-$ entry into services between $10 / 1 / 01$ and 9/30/02 - will be re-interviewed every 6 months and will be followed to 18 months. Follow-up date will be collected regardless of the service status of the child.

We curremty have 120 children and youth enrolled in the study and have completed fifty-four 6-month. twenty-six 12-mooth and eleven 18-month interviews. We will enroll new participants ithrough September of 2002 . We have had ten fanilies chose to stop participating in the study, primarily when they moved or finished program services. None have withdrawn their consent for us to use the information already collected. We have made one change in the consent process, separating the agreenemt for certain measures to be put in the child's clinieal record from the consent to be in the outcome study 


\section{STEP 4:}

1. Please attach a copy of the current Consent Form/Script/Letter to this report even if it is identical to a previously submitted one or already on file with the HSRRC. Reports submitted without this attachment will be considered incomplete and returned to the investigator.

2. Are you still using Consent Forms/Scripts/Letters with subjects?

\begin{tabular}{l|l}
$\mathbf{X}$ & Yes \\
No
\end{tabular}

3. Do you wish to submit any changes to the Consent Form/Script/Letter for approval during this Continuing Review?

$\mathrm{X}$ Please attach the new version to this report with changes highlighted in bold No

STEP 5: If more space is required for explanations, please attach a separite document.

1. Please check one:

$\mathbf{X}$ Data collection will contimue

Data collection is complete and the data is being analyzed

Qfit: Ple? wre write in space provided below:

2. How many subjects were originally planned for inclusion in this study? 270

3. How many subjects have been enrolled so tar?

4. How many subjects do you still plan to recruit?

5. Have any subjects withdrawn from participating in the research project after giving informed consent? (If yes, indicate the number of subjects who have withdrawn and the reasons.)

X 10 Please write in space provided below:

None asked to withdraw information already provided.

Moved to ancther area of the state or out of state (5)

Did not wish to cominue with outcome study after finishing with program (4)

Never engaged in program services (1) 
6. Have you withdrawn any subjects from the research project after they gave informed consent? (If yes, indicate the number of subjects whom you have withdrawn and the reasons.)

$\square$ GE : Prease write in space provided below:

$\mathbf{x}$ No

7. Have there been any complaints about the research? (If yes, please explain.)

$x$ If Please write in space provided beluw:

A few participants have complained about the length of the interview, but none have refused to complete it. This is a national evaluation; we have little control over the length of the interview, but have engaged in a number of accommodations, including splitting the interview into 2 sessions, to address participants' (and our) concerns about this issue

No

\section{STEP 6:}

Questions A-D relate to minor changes to the application, E-K relate to major changes. If more space is required for explanations, please attach a separate document.

A. Are there any changes in researcher/project director/advisor names, addresses, telephone numbers, or ending date?

$\mathbf{X}$ : Please write in space provided below:

Local site evahuator changed from Erin Mueller, Ph.D. to Beth Langhorst, Ph D. (503) $722-6913$

No

B. Are there any changes that leave the research population at the same or lower risk than risk(s) already approved?

E: Please write in space provided below:

$\mathbf{x}$ No 
C. Have additional subjects of the same type of population indicated in the original application been recruited/added?

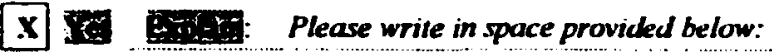

Only as planned; third cohort will continue to be recnuited through September 2002.

No

D. Are there any other minor changes you wish to include in this report?

Did Please write in space provided below:

$\mathbf{x}$ No

E. Are there any changes that leave the research population at a higher risk than risk(s) already approved?

TI Please write in space provided below:

$x$ No

F. Are you adding a subject population difierent from those already approved?

$\square$ :1: Please write in space provided below:

$\mathbf{x}$ No

G. Are you adding questions to a questionnaire or instrument? If yes, please attach a list of added questions or highlight the additions on the instrument.

$\square$ : Please write in space provided below:

$\mathbf{X}$ No 
H. Are you adding any elements that may breach the subjects' confidentiality?

Ia Ex: Please write in space provided below:

$\mathbf{x}$ No

I. Are you adding any deceptive elements to the research or changing the debriefing procedures for previously approved deception?

TE EXIF: Please write in space provided below:

$\mathbf{x}$ No

J Are you changing the way subjects are compensated for participation in research (such as increasing the amount, changing from a lottery to cash, etc.)?

$\square$ Xa Plecase write in space provided below:

$\mathbf{x}$ No

K. Are there any other major changes you wish to include in this report?

45: Please write in space provided below:

$\mathbf{X}$ No

Please return this Contianing Review Report and any attachnents to:

Mailing Addres:

HSRRC

Office of Research and Sponsored Projects (ORSP)

Portland State University

PO Box 751

Portland, OR 97207-0751

For questions or concerms, call (503) 725-8182, or send e-mail to hrme@lists.pdx.edu.
Delivery addres:

111 Cramer Hall

1721 SW Broadway

Portland, OR 97201

Campus Mail Code: ORSP

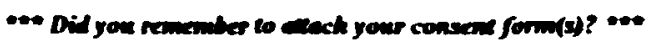

Page 6 


\section{CLACKAMAS COUNTY PARTNERSHIP REGISTRATION AND DESCRIPTIVE INFORMATION Informed Consent}

\section{Purpose}

The Center for Mental Health Services in the United States Department of Health and Human Services is sponsoring a national evaluation of programs that are funded to improve community-based services for children and familtes and a local program evaluation to improve Clackamas County services to children and families. The national evaluation is authorized by Section 585 of the Public Health Service Act. An agency may nol conduct or sponsor, and a person is not required to respond to a collection of information unless it displays a currently valid OMB control number. The OMB control number for this project is $0930-0192$ lexp. date 09/30/2001D. Any questions conceming this project can be answered by calting Beth Longhorst at (503) 722-6913 or Barbara Friesen at (503) 725-4166.

Deseription of Participation

As part of the evaluation, we would like your permission to use the registration and descriptive information you've just provided us as a part of the general evaluation. The outcome evaluation will be discussed with you at another time.

\section{Conidemiatiy}

Special precautions will be laken to protect your family and your child's privacy. The information included in the national evaluation wit have no identitying information, including names and addresses.

By law we must report the physical or sexual abuse of any child or if the danger of imminent physical ham is suspected. In addition, staff may inform parents or guardians if their child is in serious physical danger.

\section{Rights Regarding Decision to Participate}

I understand that if I agree to participate. I have the nght to change my mind and request that evaluation records be destroyed. I also understand that at any time during my participation in the project, it is my right to review the infornation that I have provided. I understand that any choice to not participate in the evaluation will not affect the services my child and family receive or will receive in the fulure.

\section{Voluntary Consen}

By signing this consent torm, I certify that I have read the preceding, or that in has been read to me, and that I understand its coment. My questions (if any) have been answered. A copy of this consent form will be given to me.

My signature below means that I freeby agree to participate in the project.

Caregivet/Guardian (type or print name in full)

Signature of Caregiver/Guardian Date

Name of Chidd (type or print name in fum)

Signature of Institutional Stafl (ft appropriate) Date

Prim Name, Agency and Job Tite 


\section{CLACKAMAS COUNTY PARTNERSHIP OUTCOME EVALUATION informed Consent-Caregiver Version}

\section{Purpose}

The Center for Mental Health Services in the United States Department of Health and Human Services is sponsoring a national evaluation of programs that are funded to improve communitybased services for children and families and a local program evaluation to improve Clackamas County services to children and families. You and your child are invited to participate in this project because your child has received such services. In this project we are interested in finding out about your child's behavior and functioning, the kinds of services you and your child have received, and how you feel about these services. The results of this project will be used to help improve the quality of the services for children and families. The national evaluation is authorized by Section 565 of the Public Health Service Act. Any questions concerning this project can be answered by calling Beth Langhorst at (503) 722-6913 or Barbara Friesen at (503) 725-4166.

\section{Description of Participation}

We will interview you and your child, if your child is 11 or older. These interviews will occur 4 to 7 times depending on when you enter the study. Participation includes an initial interview and follow-up interviews every six months for the duration of the evaluation. We will ask you to continue to participate in the evaluation even if you and your child are no longer receiving services. The interviews will be conducted in your home or at a place that is convenient and comfortable for you. Your interview should take approximately 2 hours to complete. Your child's interview will vary in duration depending on his/her age, but will probably last 1 hour. You will be asked questions about your child's behavior at home, in school and in the community. We also will ask you questions about your family and your experiences with the services your child has received, including mental health and substance use services. Your child will be asked questions similar to the ones you are asked.

As part of the project, we would like your permission to make use of your child's school records, including attendance, disciplinary action, transfer records; juvenile court records; records from the Department of Services to Children and Families; and mental health service records related to your child's care. We will oblain a separate release of information for each school or agency that has provided education or services for your child.

\section{Risks and Benefits}

There will be no direct benefit to you or your child from this project. The risk may be the discomfort some people feel when discussing personal matters.

\section{Compensation}

If you agree to participate in this project you will receive a $\$ 20$ gift certificate to a local merchant for each completed sel of data in compensation for your time and any costs associated with participating in the project. Your child will receive a $\$ 10$ gift certificate each time s/he completes a set of data.

\section{Confidentiality}

Special precautions will be taken to protect your family and your child's privacy. No agency that you and your child are involved with, including schools, will have access to the information you provide about your perceptions and satisfaction with service. The CAFAS, which is completed as a part of the intensive services intake process, will be made available to the evaluation. Evabuation instruments that contain elinical information which could be halphut to your childs

\section{(Caregiver's initials)}

Regional Research Institute for Human Services. Portland State University, 503-725-4166 Clackamas Parthership. Clackamas County Mental Health, 503-655-8264 Updated 11/15101 
mental health treatment can be placed in the mental health record with your consem and the assent of your youth. This information includes the following measures, CBCL, YSR, BERS (completed by Care Coordinator), BERS (completed by caregiver). All forms stored as evaluation information will be coded so that they cannol be associated with individual names. In reports, the information that is collected will never mention individual names.

By law we must report the physical or sexual abuse of any child or if the danger of imminent physical harm is suspected. In addition, staff may inform parents or guardians if their child is in serious physical danger.

\section{Rights Regarding Decision to Participate}

I understand that if I agree to participate, I have the right to change my mind and stop participating or withdraw from the project at any time. If I request it, records pertaining to my child and family will be destroyed. I also understand that at any time during my participation in the project, it is my right to review the measures that I have completed. I understand that any choice to not participate in the evaluation will not affect the services my child and family receive or will receive in the future.

\section{Voluntary Consent}

By signing this consent form, I certify that I have read the preceding, or that it has been read to me, and that I understand its content. My questions (if any) have been answered. A copy of this consent form will be given to me. My signature below means that I freely agree to participate in the project.

Caregiver/Guardian (type or print name in full)

Signature of

Caregiver/Guardian Date

Name of Child (type or print name in tull)

Signature of Institutional Staff (if appropriate)

Print Name, Agency and Job Title Date

\section{Projact Team's Certification}

I certify that I have explained to the above individual the nature of the project as well as the potential benefits and risks associated with participating in the project I also have answered any questions that have been raised and withessed the above signature.

Signature of Witness Date

If you have concerns or problems, please contact The Human Subjects Research Review Committee Orice of Research and Sponsored Projects

111 Cramer Hal

Portland State University

(503) 725-8182 


\section{CLACKAMAS COUNTY PARTNERSHIP OUTCOME EVALUATION \\ Informed Assent/Consent-11-17 years old}

We want to know what you think!

AND we'll give you $\$ 10.00$ for your thoughts!

What: You talk with us about what you think and do when you are at home, in school, and in your neighborhood. We would also like your permission to look at your school records, juvenile court records, and records related to the services you have or are currently receiving. We will get your specific permission for each school or agency we ask for information.

Why: Because you have received or are currently receiving services we need your help to evaluate how effective the Clackamas Partnership is. (Service: you have an IEP, a counselor, a foster parent, probation officer, social worker, or some such person who is working for an agency.) AND, we would like you to help us even if you aren't receiving services anymore.

Where: Where would you like it to be? (at home, at an office, at school?)

When: $\quad$ Every six months for about an hour each time until September 2003 (It could be +-7 times depending on when you entered the study.)

Who sees this stuff?

The CAFAS, which is completed as part of the intensive services intake process, will be made available to the evaluation. Evaluation information that could be helpful to your mental health treatment (Youth Self Report. Child Behavior Checklist, Behavioral and Emotional Rating Seale) can be placed in your mental beahth record if you and your caregiver consent. All other information that you give us will be coded so no one will know your name and it will be kept in a locked cabinet and a secure computer file. No one will be able to find out who you are. If we use any information in a report, the report will not identify any individuals. Other than that, we don't tell ANYONE anything!!!! No one will know you did this (except you, your participating family and us) unless YOU tell them. At any time during your participation in the project you have the right to review the measures that you have completed.

Soune bad Some questions could be uncomfortable for you to answer. We will ask you news: if you have had any contacts with the police, if you use any drugs and/or alcohol, whether you get into trouble in school, how well you get along with family and friends, and what you think about any of the services you have had.

Some good Participation is definitely up to you. If you don't want to answer a questionnews: DON'T! If you decide this is too much for you, you can stop at any time. You can tell us that you don't want to continue an individual interview or with the whole study. You also can ask us to throw away the information that we've gathered.

Initials

Regional Research Institute for Human Services, Portland State University, 503-725-4166. Page 1 of 2 Clackamas Partnership. Clackamas County Mental Health, 503-655-8264

Updated 11/15/01 
Some even When we ve finished each completed set of data, we'll give you a $\$ 10.00$ gift better news: ccrtificate to a local merchant!

What's the (Otherwise known as "the legal stuff".) By law we must report any eatch? information that makes us think that someone might hurt you or has hurt you, any information that makes us think that you might hurt someone, and any information that makes us think you might hurt yourself.

Questions? Call Beth Langhorst (503-722-6913) or Barbara Friesen (503- 725-1166). Either will be happy to talk to you.

\section{Participant's Consent}

I have read this form or it has been read to me. I understand what it says. My questions have been answered and I am not being forced to sign this form. A copy of this form will be given to me.

Please Print Full Name of

Participant

Signature of Participant

Date

I have read and understand the preceding information and agree to the participant's interview

Signature of Caregiver/Guardian

Date

Signature of Institutional Stafi (if appropriate)

Date

\section{Project Team's Certification}

I certify that I have explained the nature and purpose of this project, as well as the potential benefits and risks associated with participating in this project. I also have answered any questions that have been raised. I have witnessed the above signatures.

Sigmanre of Witness

Date

If you have concerns or problems, please contact:

The Human Subjects Research Review Committee

Office of Research and Sponsored Projects

111 Cramer Hall

Portand State University

(503) $725-8182$

Regional Research Institute for Human Services, Portand State Universiny. 503-725-4166. Page 2 of 2 Clackamas Parthership. Clackamas County Mental Health, 503-655-8264 Updated 11/15ro1 


\title{
CLACKAMAS COUNTY PARTNERSHIP OUTCOME STUDY \\ Informed Consent-Young Adult Version \\ (For youth 18 years or older who reach age 18 during follow-up data collection)
}

\begin{abstract}
Purpose
The Center for Mental Health Services in the United States Department of Health and Human Services is sponsoring a national evaluation of programs that are funded to improve community-based services for children and families and a local program evaluation to improve Clackamas County services to children and families. You were invited to participate in this project because your have received such services. At that time your family agreed to participate in the project. Now that you have tumed 18 and are a legal adult, we need to ask you if you would like to continue to be in the project. In this project we are interested in finding out about how you feel; what you do at home, in school and in the neighborhood; the kinds of services you have received, and how you feel about these services. The results of this project will be used to help improve the quality of the services for children and families. The national evaluation is authorized by Section 565 of the Public Health Service Act. Any questions concerning this project can be answered by calling your local site evaluator Beth Langhorst (503) 722-6913 or Barbara Friesen at (503) 725-4166.
\end{abstract}

\section{Description of Participation}

We will interview you 4 to 7 times depending on when you enter the study. This study ends in September 2003. Participation includes an initial interview and follow-up interviews every six months for the duration of the evaluation. We will ask you to continue to participate in the evaluation even if you are no longer receiving services. The interviews will be conducted in your home or at a place that is convenient and comfortable for you. Your interview should take approximately 1 hour to complete.

You will be asked questions about your behavior at home, in school and in the community. We also will ask you questions about your family and your experiences with the services you have received, including mental health and substance use services.

As part of the project, we would like your permission to make use of your school records, inchuding attendance, disciplinary action. transfer records; juvenile count records; records from the Department of Services to Children and Families; and mental health service records related to your child's care. Your agreement to participate in this project and your signature on this form provide your permission for the release of any of these records.

\section{Risks and Banefits}

There will be no direct benefit to you from this project. The risk may be the discornfort some people feet when discussing personal matters.

\section{Compensation}

If you agree to participate in this project you will receive a $\$ 10$ gift certificate to a local merchant for each completed set of data in compensation for your time and any costs associated with participating in the project.

$$
\text { (initials) }
$$

Regional Research Institute for Human Senvices, Portand State University, 503-725-4166. Page 1 of 2 Clackamas Partnership. Clackamas County Mental Heath, 503-655-8264

Updeted 11/15/01 


\section{Confidentiality}

Special precautions will be taken to protect your privacy. Evaluation information that could be useful to your treatment (Child Behavior Checklist, Youth Self Report, Behavioral and Emotional Rating Scale [completed by caregiver]) can be placed in your mental health record. The CAFAS, which is completed as a part of the intensive services intake process, will be made available to the evaluation. Aside from that, no agency that you are involved with. including schools, will have access to the information you provide. All forms in the project will be coded so that they cannot be associated with individual names. In reports, the information that is collected will never mention individual names.

By law we are required to report the physical or sexual abuse of any child or if the danger of imminent physical harm is suspected.

\section{Rights Regarding Decision to Participate}

I understand that if I agree to participate, I have the right to change my mind and stop participating at any time. If I request it, records pertaining to my family and myself will be destroyed. At any time during my participation in the project I have the right to review measures that I have completed. I also understand that any choice to not participate in the evaluation will not effect the services I receive or will receive in the future.

\section{Voluntary Consent}

By signing this consent form, I certify that I have read the preceding, or that it has been read to me, and that I understand its content. My questions (if any) have been answered. A copy of this consent form will be given to me. My signature below means that I freely agree to participate in the project.

Youth's Name (please type or print)

Youth's signature

Date

\section{Project Team's Certification}

I certify that I have explained to the above indivicual the nature of the project as well as the potential benefits and risks associated with participating in the project I also have answered any questions that have been raised and witnessed the above signature.

Signature of Withess Date

If you have concems or problems, please contact

The Human Subjects Research Review Committee

Ofice of Research and Sponsored Projects

111 Cramer Hall

Portland State University

(503) 725-8182

Regional Research Institute for Human Services, Portand State University, 503-725-4166. Page 2 of 2 Clackamas Partnership. Clackamas County Mental Health, 503-655-8264

Updated 7/6/01 


\section{CLACKAMAS COUNTY PARTNERSHIP \\ OUTCOME EVALUATION}

Informed Consent for Putting Measures in Clinical Record

To be attached to Informed Consent for National Outcome Evaluation

I consent to have the following measures I have completed as part of the Partnership outcome study included in my child's clinical record at Clackamas County Mental Health Center.

\begin{tabular}{|l|l|l|l|}
\hline Measure: & $\begin{array}{l}\text { Date } \\
\text { Administered: }\end{array}$ & Initials: & Date: \\
\hline $\begin{array}{l}\text { Achenbach Child Behavior } \\
\text { Checklist }\end{array}$ & & Caregiver: & \\
\hline Achenbach Youth Self Report & & Caregiver: & \\
\hline (with Youth consent/ assent) & & Youth: & \\
\hline $\begin{array}{l}\text { Behavioral and Emotional } \\
\text { Rating Scale (BERS) }\end{array}$ & & Caregiver: & \\
\hline
\end{tabular}

Voluntary Consent

By signing this consent form, I certify that I have read the preceding, or that it has been read to me, and that I understand its content. My questions (if any) have been answered. A copy of this consent form will be given to me. My signature below means that I freely agree to have the clinical measures I have initialed above included as part of my child's clinical record at Clackamas County Mental Health Center.

Caregiver/Guardian (type or print name in full)

Signature of

Caregiver/Guardian Date

Name of Child (type or print name in full)

Signature of Child (if appropriate)

Signature of Institutional Staff (if appropriate)

Print Name, Agency and Job Title Date

Project Team's Centification

I certify that I have explained to the above individual the nature of the project as well as the potential benefits and risks associated with participating in the project 1 also have answered any questions that have been raised and withessed the above signature.

Signature of Witness Date 


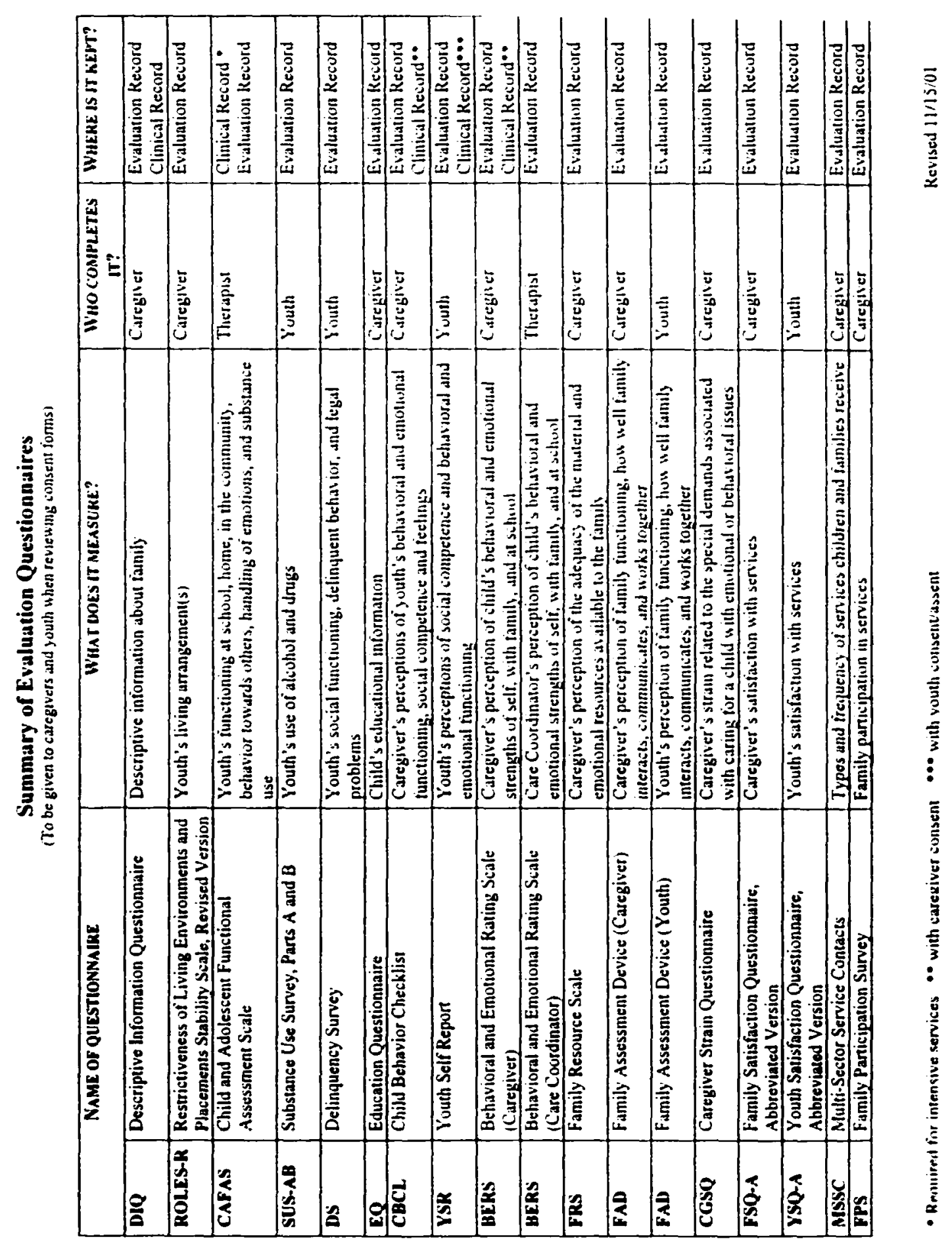


APPENDIX B

ASSESSMENT INSTRUMENTS 


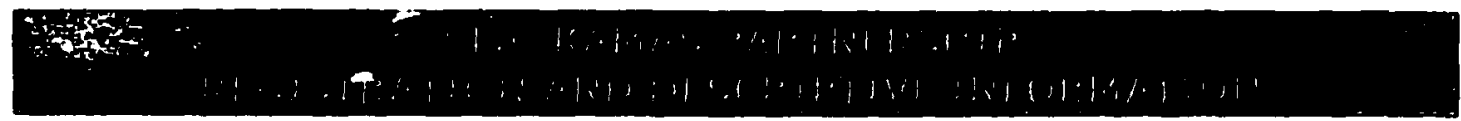

DATE: $\varlimsup_{\text {Mlowtb }}^{\prime} \overbrace{\text { Day }}^{\prime} / \overline{\text { Year }}$ CARE COORDINATOR:

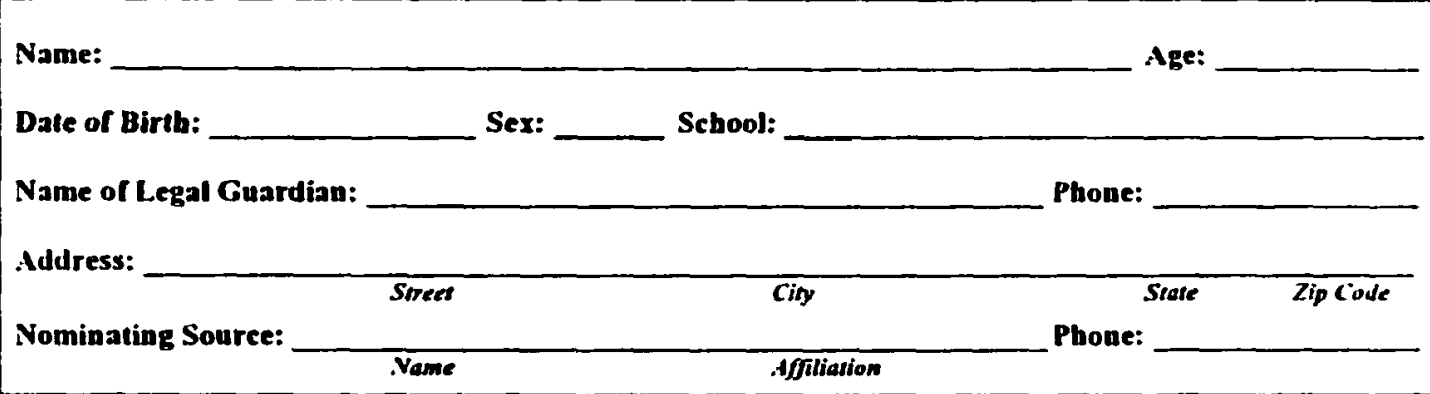

Person administering the interview (DIQINT)

Name: Phone:

$1=$ Service Provider

Agency: $2=$ Data Collector

Method of administering the interview (DIQNIETH)

$1=$ In person

$2=$ Telephone
Language of interview (DIQLANG)
1 = English
2 = Spanish
$3=$ Other

I am going to ask you some questions about (child's name)'s background and family and about services which (child's name) has received. Please answer these questions as best you can, and try to be as complete as possible in your answers.

1. When is (child's name)'s birth date?

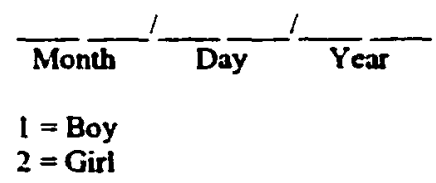

$\begin{array}{ll}\text { 2. Is (child's name) a boy or girl ? } & 1=\text { Boy } \\ 2=\text { Girl }\end{array}$

3. Is (child's name) of Hispanic or Latino culturaVethnic background? $\quad 1=$ No

$$
2=\text { Yes }
$$

3a. [IF YES] Which group best describes his/her Hispanic or Latino cultural/ethnic backgromad? Is he/she ......

$1=$ Mexican, Mexican-American, or Chicano

2 = Puerto Rican

$3=$ Cuban

$5=$ Central American

$4=$ Dominican

$6=$ South American

$7=$ Other Hispanic origin (Please specify) 
4. Which racialethnic group(s) best describes (child's name)? Is he/she ......

[NOTE TO INTERVIEWER: Circle all that apply.]

1 = American Indian or Alsska Native $\quad t=$ Native Hawaiian or Other Pacific Islander

$2=$ Asian

3 = Black or African American $\quad 6=$ Other (Please specify)

5. What is the zip code of the address where (chald's name) currently lives?

6. What agency referred (child's nume) to the Partuership?

INOTE TO INTERVEWER: To aid the respondent, you may prompt with site-specific agency names for each type of agency. Use C.tRD l. if necessany.]

$1=$ Corrections

$2=$ Court

$3=$ School

$4=$ MH agency/Clinic/Provider

$5=$ Physical health care agency/Clinic/Provider

$6=$ Child Welfare/Child protective services

$7=$ Substance abuse clinic/provider

$8=$ Caregiver

$9=$ Self (youth referted himself or herself)

$10=$ Other (Please specify):

7. What were the problems leading to (child's name) being referred for services?

INOTE TO INTERVIEWER: Write down the problems exactly as the respondent says them. then ctrcle the codes below which best describe the problems.)

\begin{tabular}{lll}
\hline 1 = Eating disorders & $12=$ Theft & $23=$ Hyperactive-impulsive \\
2 = Sleep disorders & $13=$ Runaway & $24=$ Attention difficulties \\
3 = Somatic complaints & $14=$ Sexual assault & $25=$ Over-dependence on adults \\
t= Sad & $15=$ Threat to life of others & $26=$ Bladder difficulties \\
$5=$ Anxious & $16=$ Extreme verbal abuse & $27=$ Alcohol/substance abuse \\
$6=$ Self-injury & $17=$ Fire setting & $28=$ Sexual acting out \\
$7=$ Suicide attempt & $18=$ Cruelty to animals & $29=$ Truancy \\
8 = Suicide ideation & $19=$ Inappropriate bowel movements & $30=$ Police contact \\
$9=$ Social contact avoidance & $20=$ Non-compliance & $31=$ Academic problems \\
10= Physical aggression & $21=$ Strange behavior & $32=$ Poor self-esteem \\
$11=$ Property damage & $22=$ Poor peer interaction & $33=$ Other problems (Please \\
& & specify)
\end{tabular}

8. Before today, has (child's name) received any mental health services for the problems that led to the referral?

$1=$ No

$2=$ Yes

INOTE TO INTERVIEWER: If necessary, clarify for the respondent that this can include any services received for the problems, including senvices delivered through the Partnership OR services delivered in other ways, such as through other agencies.]

8a. [IF YES] When did these services begin?

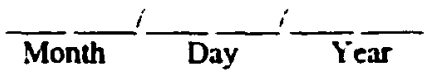


I would like to ask you some questions about services related to (child's name)'s emotional and behavioral problems that (child's name) may have received in the past 12 months.

Did (child's name) receive.

9. Ontpatient services? These services often include evaluation or assessment; individual. group, or family therapy; and/or case management. Case management is sometimes also called $\quad 1=$ No service coordination or care coordination.

10. School-based services? These services often include educational assessment or testing; a selfcontained special education classroom; a resource room; a one to one classroom aide: and/or an Individualized Education Plan (IEP).

11. Day treatment? Day treatment is intensive, non-residential services which last for at least 5 hours a day. These services often include special education, vocational counseling. and/or therapy. These services may be provided in a variety of sertings including schools. mental health centers, hospitals or other community locations.

12. Residential treatment or inpatient psychiatric hospitatization services? These services are often provided in an inpatient hospital setting for observation and treatment or in other out-ofhome treatment facilities or centers. These places npically seric 10 or more children. have 24-hour staff supervision, and can offer a full array of treatment interventions.

13. Alcohol or Substance Abuse Therapy? These are outpatient anw or inpaticnt'residential services specifically for the assessment and treatment of alcohol, drug, and other substance abuse-related problems.

Now I would like to ask some questions about (child's name)'s history.

14. Has (child's nome) ever had a previous psychiatric hospitaliantion?

15. Has (child's name) ever been physically abused?

$$
\begin{array}{ll}
1=\text { No } & 2=\text { Ies } \\
1=\text { No } & 2=\text { les } \\
1=\text { No } & 2=\text { Yes }
\end{array}
$$

16. Has (child's name) ever been serually abused?

17. Has (child's name) ever run away without hisiher caregiver knowing where he/she was? INOTE TO INTERVTEWER: This could be the current caregiver or a past caregiver.]

18. Has (child's name) ever attempted suicide?

$$
1=\text { No } \quad 2=\text { Yes }
$$

$$
\begin{array}{ll}
1=\text { No } & 2=\text { Yes } \\
1=\text { No } & 2=\text { Yes }
\end{array}
$$

19. Does (child's name) have a history of substance abuse including alcohol and drugs?

20. Uas (child's name) ever been sexually abusive to others:

$$
1=\mathrm{No} \quad 2 \approx \text { Yes }
$$


Now I would like to ask some questions concerning (child's name)'s family history.

INOTE TO INTERVIEWER: Biological family should be considered to include biological parents. biological siblings, as well as other extended biological family members such as grandparcnts. uncles. or uunts "reluted" by blood" and not by marriage.]

21. Is there a history of domestic violence/spousal abuse in (child's name)'s biological family but (child's name) was not the direct target of the $\quad 1=$ No $\quad 2=$ Yes violence?

22. Is there a history of mental illness in (child's name)'s biological family? $1=$ No $2=$ Yes

22a. [IF YES] Has one of (child's nume)'s biological parents ever had a psychlatric hospitalization?

$$
1=\text { No } \quad 2=\text { Yes }
$$

23. Has one of (child's nume)'s biological parents ever been convicted of a crime?

$$
1=\text { No } \quad 2=\text { Yes }
$$

24. Is there a history of substance abuse in (child's name)'s biological family?

$$
\begin{array}{ll}
1=\mathrm{No} & 2=\mathrm{Yes} \\
1=\mathrm{No} & 2=\mathrm{Yes}
\end{array}
$$

\begin{tabular}{|c|c|c|}
\hline $\begin{array}{l}1=\text { Biological parent } \\
2=\text { Adoptive/Stepparent } \\
3=\text { Foster parent } \\
4=\text { "Live-in" partnet of parent }\end{array}$ & $\begin{array}{l}5=\text { Sibling (biological. step, etc.) } \\
6=\text { Aunt or uncle } \\
7=\text { Grandparent } \\
8=\text { Cousin }\end{array}$ & $\begin{array}{l}9=\text { Other family relative } \\
10=\text { Friend (adult friend) } \\
11=\text { Other (Please specify): }\end{array}$ \\
\hline 6a. What is your gender, a & $I=$ Male & $2=$ Fernale \\
\hline $\begin{array}{l}\text { Who has legal castody of (child } \\
=\text { Two biological parents OR } \\
1 \text { biological and } 1 \text { stepparent } \\
=\text { Biological mother only } \\
=\text { Biological father only }\end{array}$ & $\begin{array}{l}\text { ame)? } \\
5=\text { Foster parent(s) } \\
6=\text { Sibling(s) } \\
7=\text { Aunt and/or uncle } \\
8=\text { Grandparent(s) }\end{array}$ & $\begin{array}{l}9=\text { Friend (adult friend) } \\
10=\text { Ward of the State } \\
11=\text { Other (Please specifi): }\end{array}$ \\
\hline
\end{tabular}

25. 666 [NOTE TO INTERVIEWER: Question \#25 is skipped at buseline as it is not upplicable.]

Now I'd like to ask you a few general questions about (child's name)'s family.

26. What is your relationship to (child's name)?

Adopical falher only

$8=$ Grandparent(s)

28. Has (child's name) lived in your household for the past 6 mouths, for the entire period?

$$
1=\text { No } \quad 2=\text { Yes [GO TO QUESTION \#29] }
$$

28a. [IF NO] For how many months in the past 6 months did (child's name) live with you?

28b. [IF ZERO MONTHS] For how many days in the past 6 months did you have daily interaction with (child's name)? 
29. What is the anunal household income of (child's nome)'s family?

[NOTE TO INTERVIEWER: Prompt respondent to consider all sources of pre-tax (gross) income. including wages, child support, alimony, and public assistance. The family household income should include the pre-tax incomes of all individuals who live with the child and contribute financially to the child's care. The child's fomily should be considered to be the fumily with whom the child has lived for the majority of the past 6 months. For example. if the child has lived with a foster family for most of the' pust 6 months, we are interested in knowing the foster family's income. (Ise C.ARD 2, if necessury)

$\begin{array}{ll}1=\text { Less than } \$ 5,000 & 6=\$ 25,000-\$ 34,999 \\ 2=\$ 5,000-\$ 9,999 & 7=\$ 35,000-\$ 49,999 \\ 3=\$ 10,000-\$ 14,999 & 8=\$ 50,000-\$ 7,, 999 \\ t=\$ 15,000-\$ 19,999 & 9=\$ 75,000-\$ 99,999 \\ 5=\$ 20,000-\$ 2 \$, 999 & 10=\$ 100,000 \text { and over }\end{array}$

30. What is the highest grade in school that you completed? [Circle appropriate category]

$0-11=$ Kindergarten -11 th grade $\quad 15$ = Bachelor's degree

12 = High school diploma or GED $16=$ Master's degree

13 = Associate degree $\quad 17$ = Professional school degree

$14=$ Some college, no degree $\quad 18=$ Doctoral degree

30a. What is your age?

31. Is (child's name) a Medicajd recipient?

$$
1=\text { No } \quad 2=\text { Yes }
$$

32. Do you or your famiby have to pay for at least part of (child's name)'s behavioral/emotional services?

33. Including (child's name), what is the total number of people in the housebold where (child's name) is currently living?

34. Including (child's name), what is the total number of children in the household where (child's name) is currently living?

35. What in the total number of adults (over 19 years old) in the household where (child's name) is currently living? Include (child's name) in this tolal if (child's name) is over 19.

36. Does (child's name) have recurring or chronic physical heallt problems such as allergies, asthma, migraine leadaches, elc.? $\quad 1=$ No [GO TO QUESTION \#37] $\quad 2=$ Yes

362. Please describe the recurring health problems that be/she bas.

36b. Has (child's name) taken medication related to his/her recurring physical health problems in the last 6 months?

$1=$ No [GO TO QUESTION \#37]

$2=$ Yes 
36e. What are the names of the medications?

In addition to physical health problems, sometimes a doctor or psychiatrist prescribes medication for children to help reduce their emotional or behavioral symptoms. For example, Ritalin is prescribed for Attention Deficit Disorder.

37. Has (child's nume) taken any medication related to his/her emotional or behavioral symptoms in the last 6 months?

37a. What are the names of the medications?

Thank you for answering these questions! [END OF INTERVIEW]

PRELIMINARY DSM-IV DIAGNOSIS: Complete using historical information, if necessary. Circle the primary diagnosis.

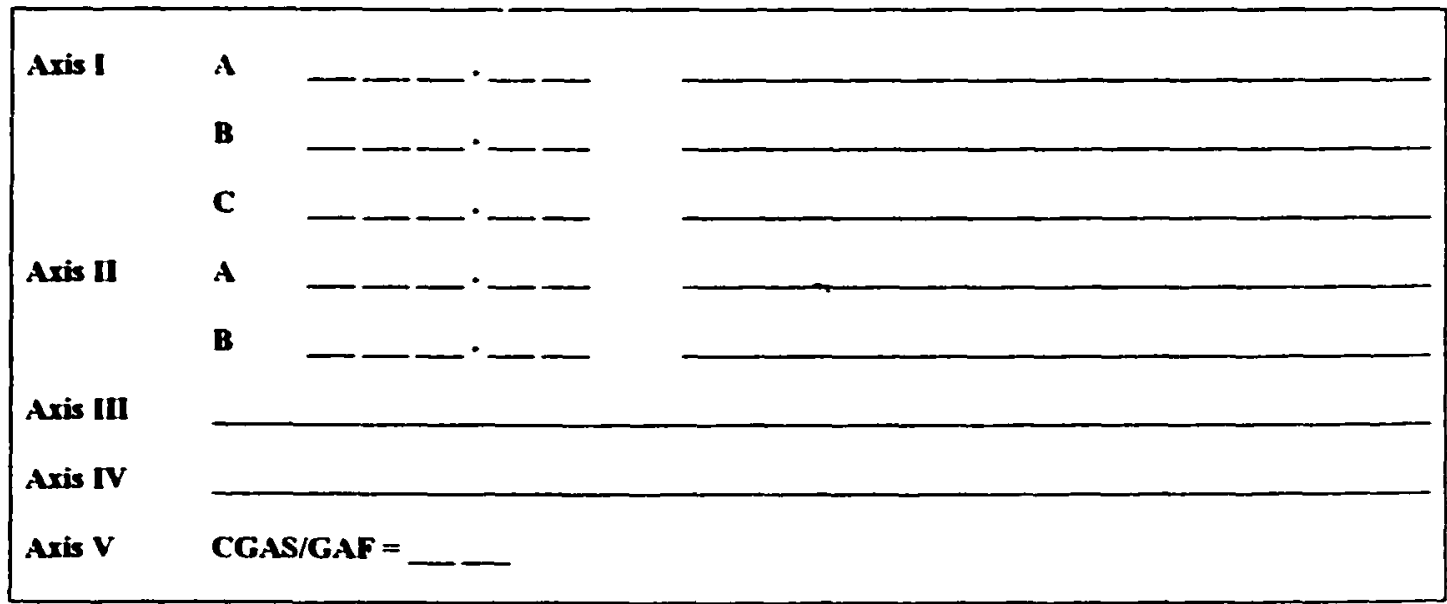




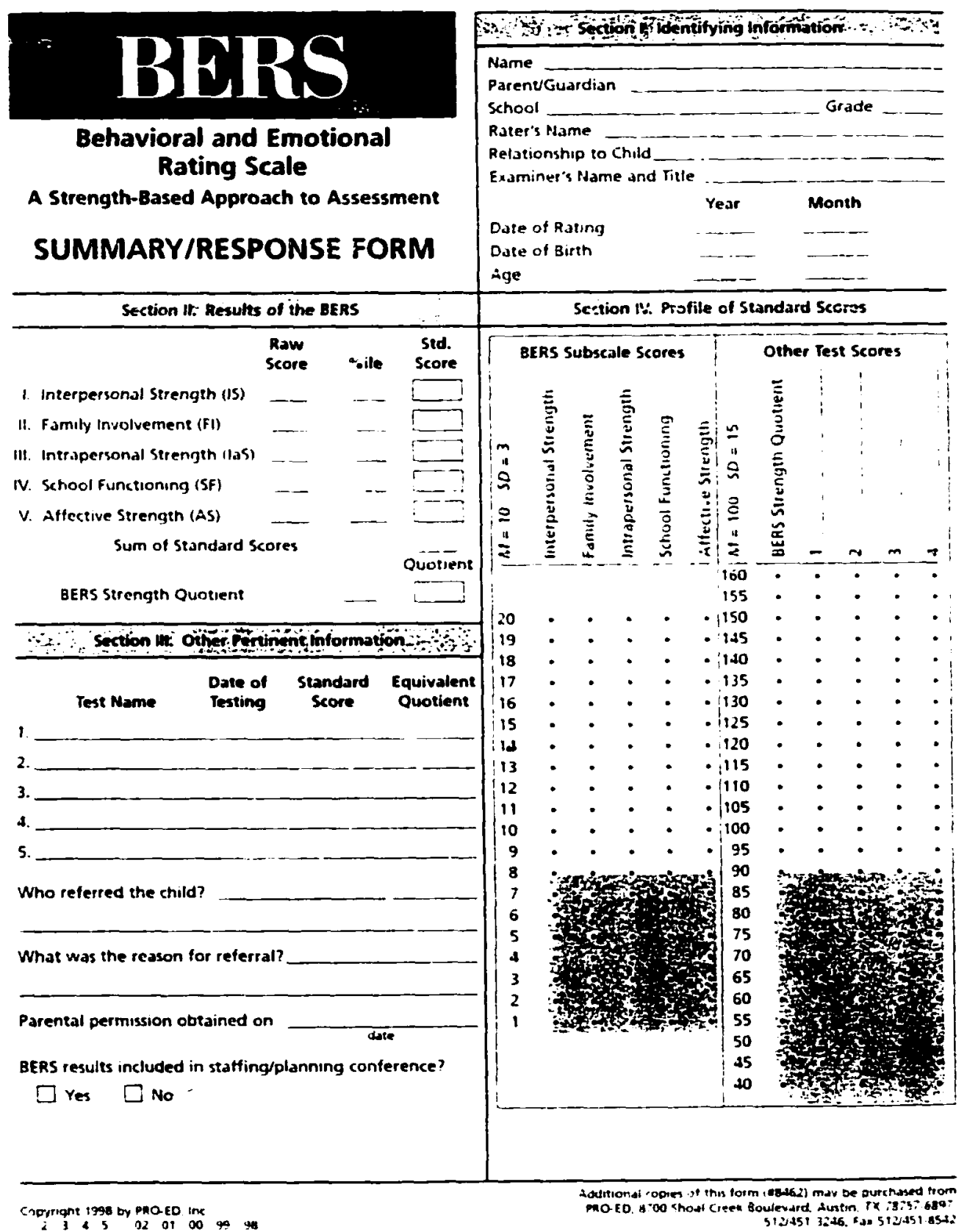




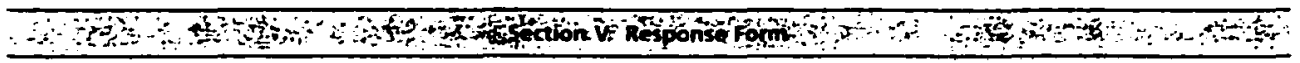

Directions: The Behavioral and Emotional Ruting Scale (BERS) contains a series of statements that are lused to rate a child's behaviors and emotions in a positive way. Read each statement and circle the number that corresponds to the rating that best describes the child's status over the past 3 months. If the statement is bery much like the child. circle the 3 . If the statement is iike the child. circle the 2: if the statement is not much like the child. circle the 1 ; if the statement is not at all ike the child. sircle the 0 . Rute each statement to the best of your knowledge of the child.

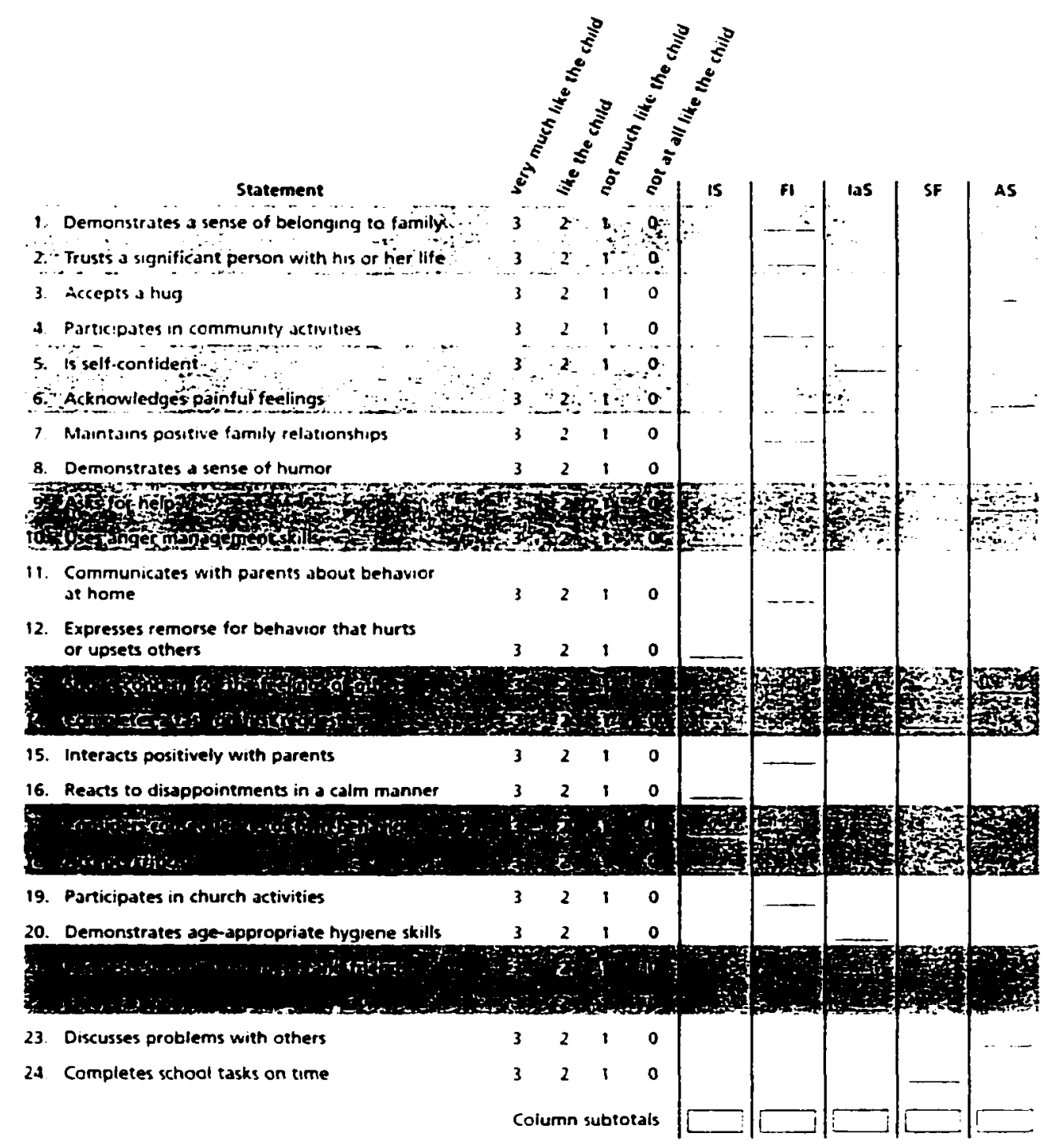




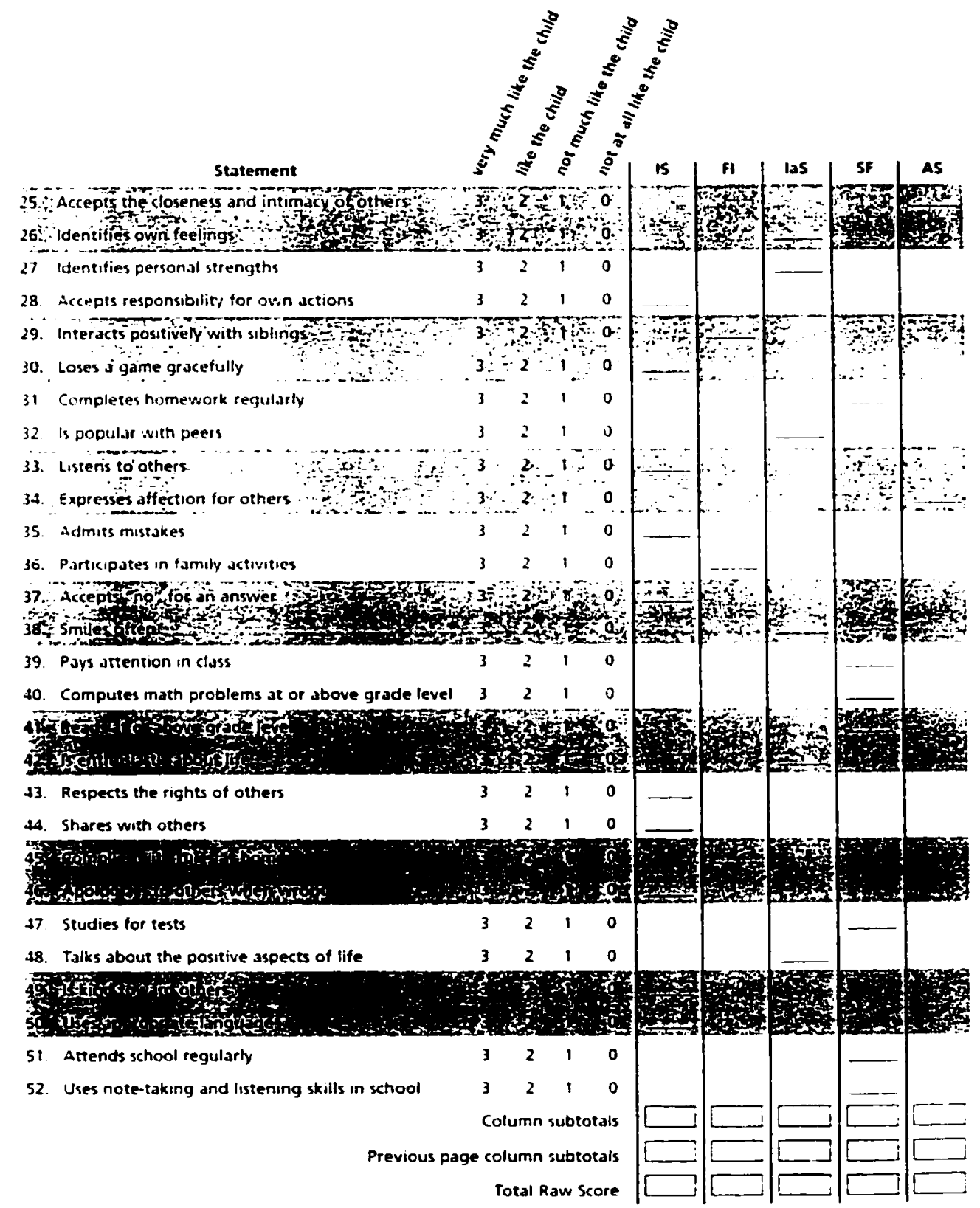




$\because 5$ S-

1. What are the child's favorite hobbies or actrities? What does the child like to do?

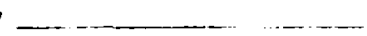

What is the child's iavorite :pori(s)?

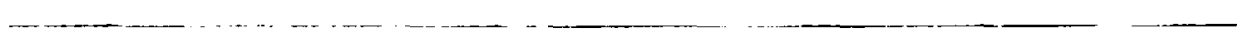

3. In what school subject(s) dees the chilu do best:

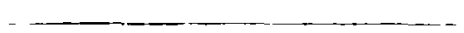

4. Who is this child's best friendis)?

5. Who is thrs child's favorite teucher(s)"

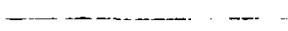
$-\cdots$

6. What job(s) or responsibtlities h.ss this child helat in the community if in the home' -

7 At s time of need. to whnm te g. Darent. te.thther. friend, relative) would this child turn for support?

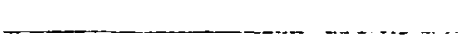

…

8. Describe the best things ubout this child.

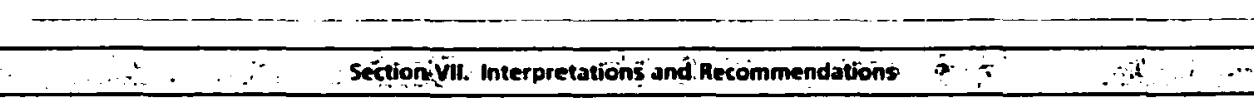
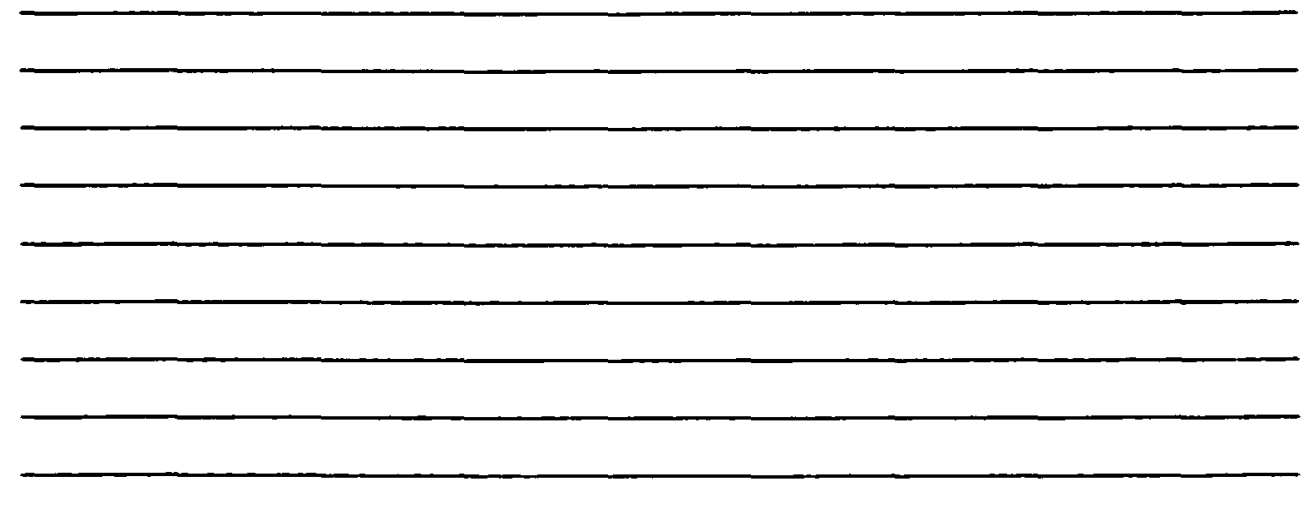


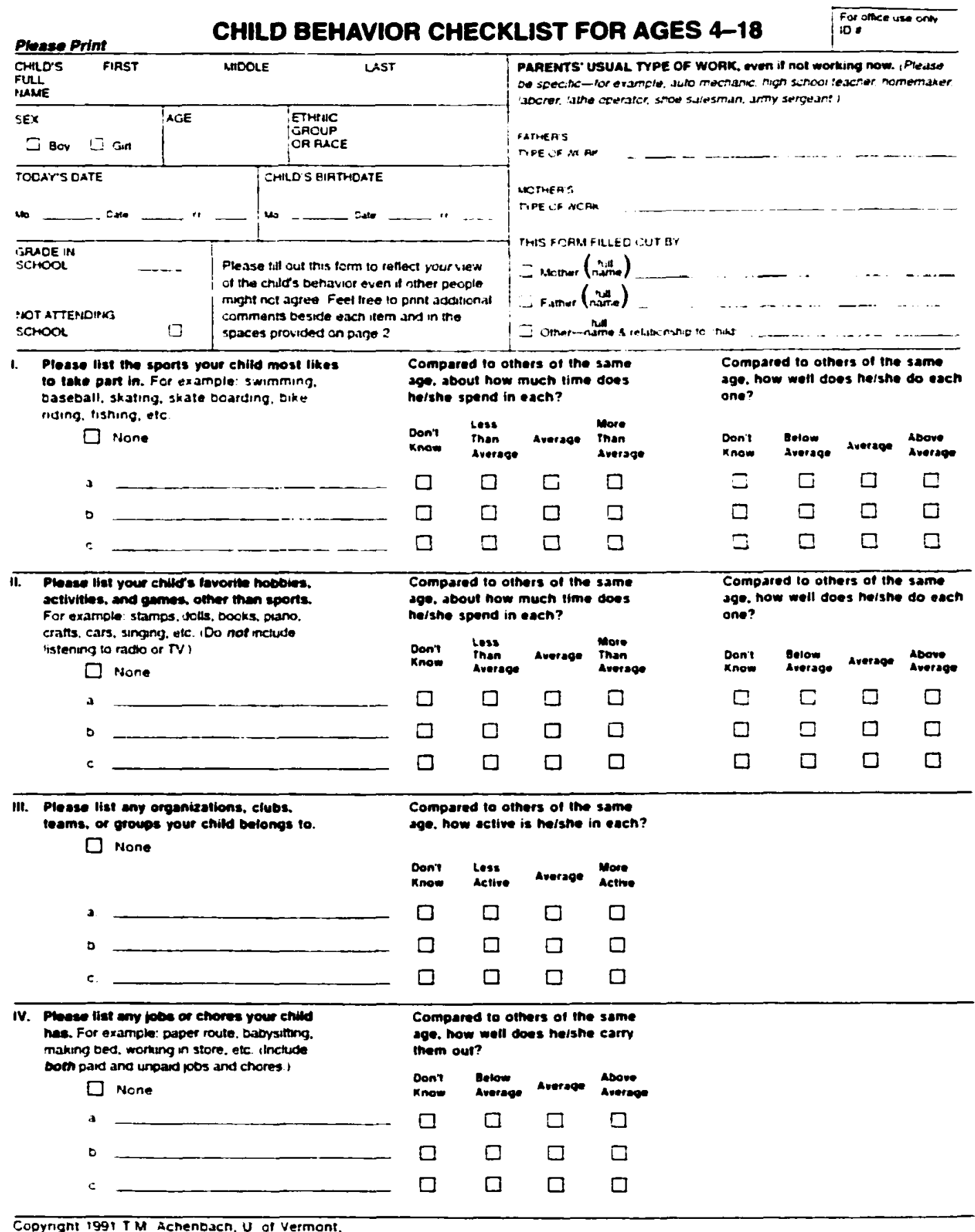

is Prosdect St. Burtington, VT 05t0

+95 Exatom 
Please Print

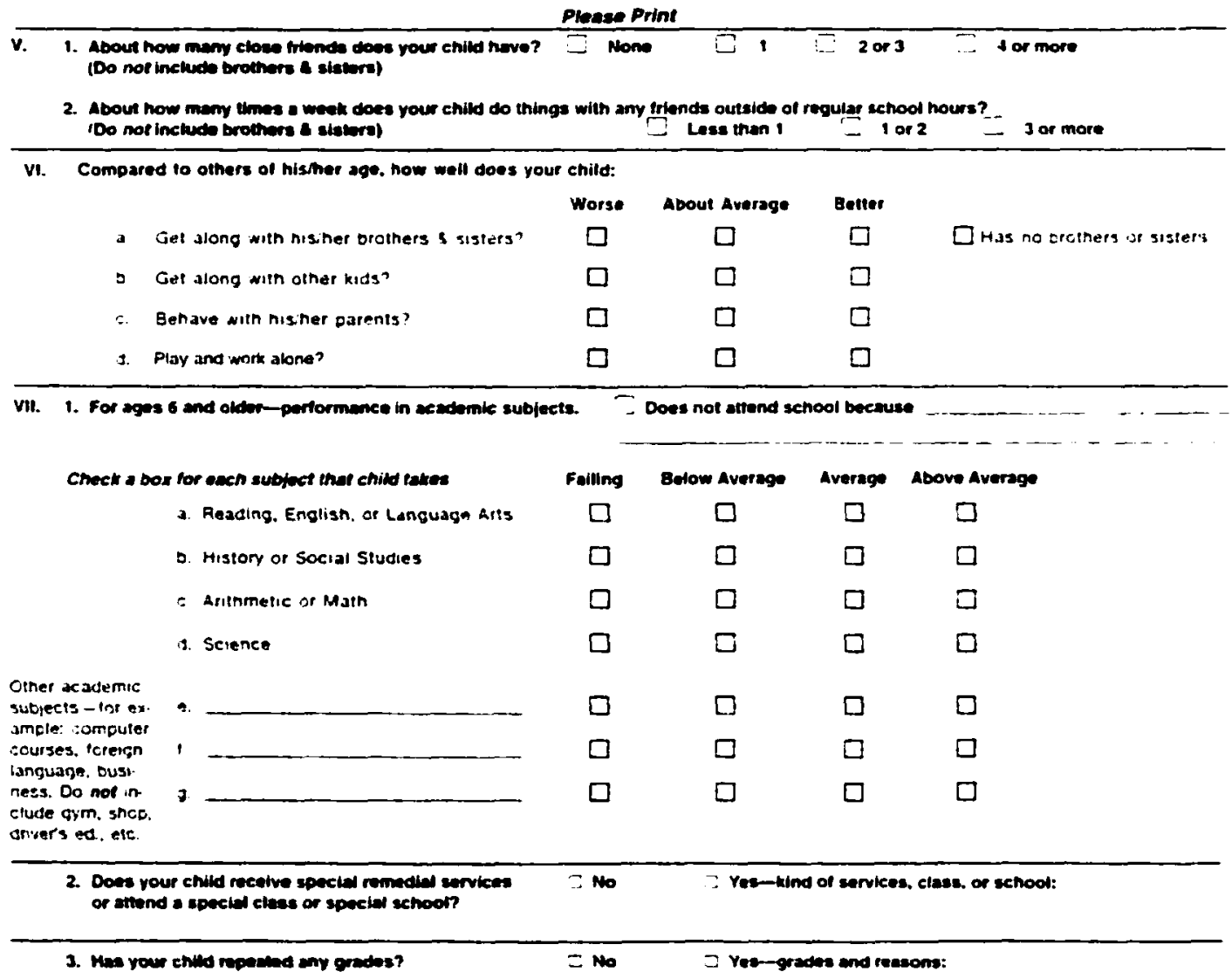

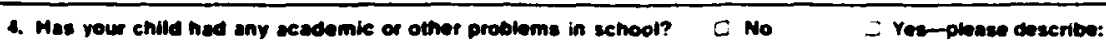

Whon ofie these problems start?

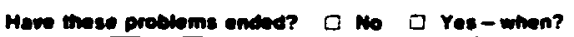

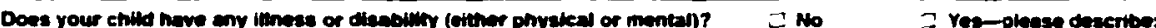

What concerne you most ebout your chis?

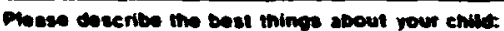




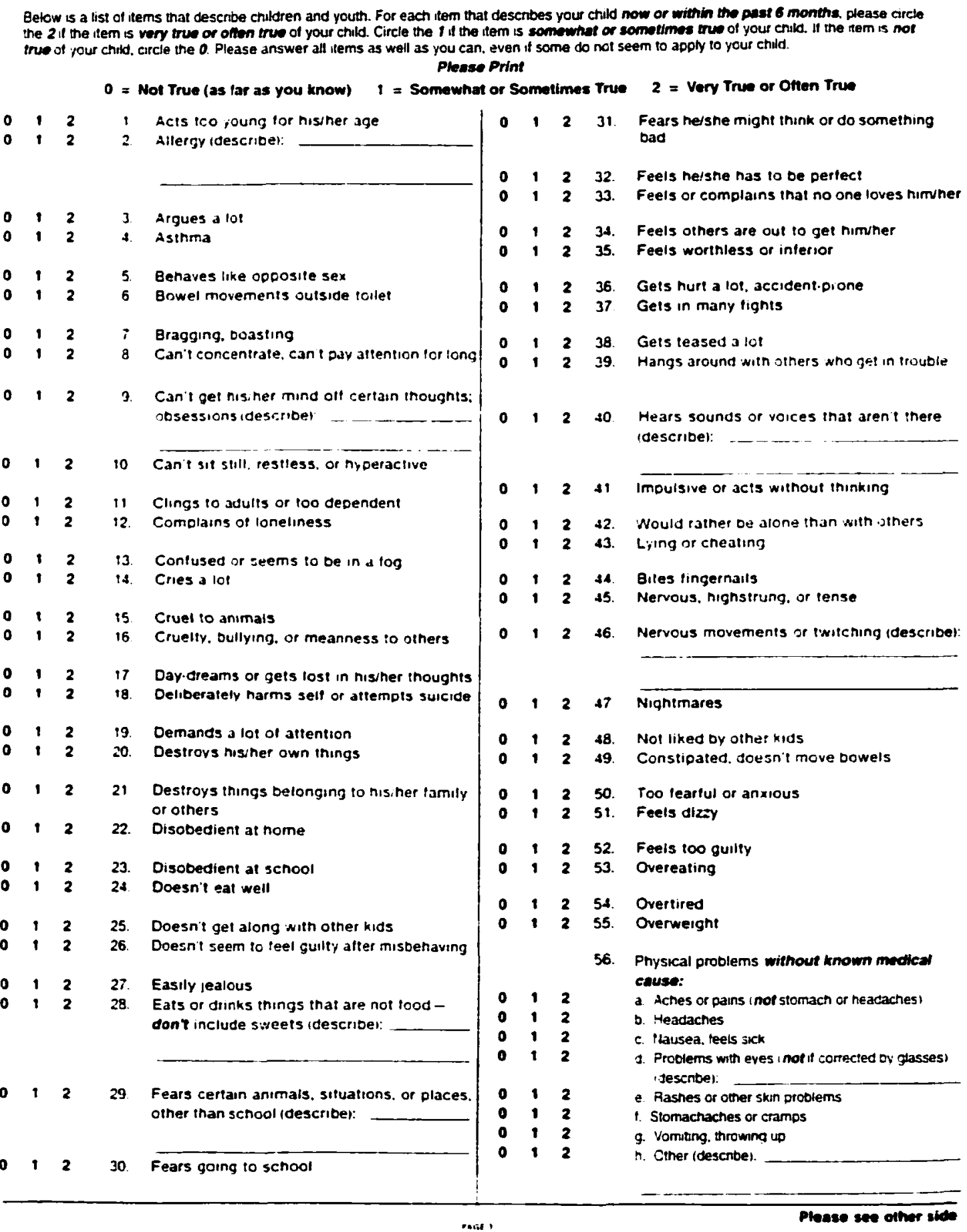


- Not True (as tar as you know) 1 = Somewhat or Sometimes True 2 = Very True or Onen True

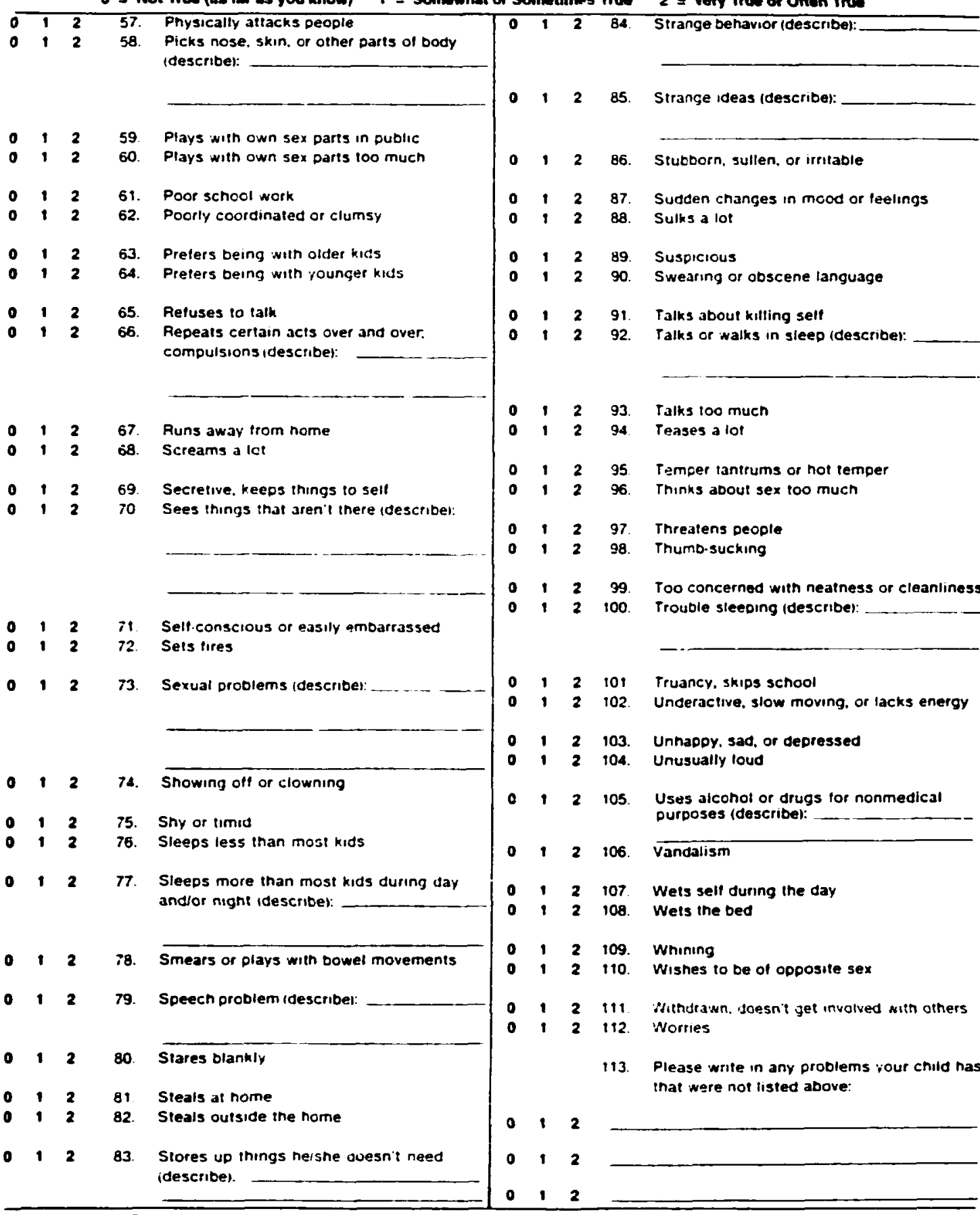

Please be sure you have answered all items. 
CHILD AND ADOLESCENT FUNCTIONAL ASSESSMENT SCALE

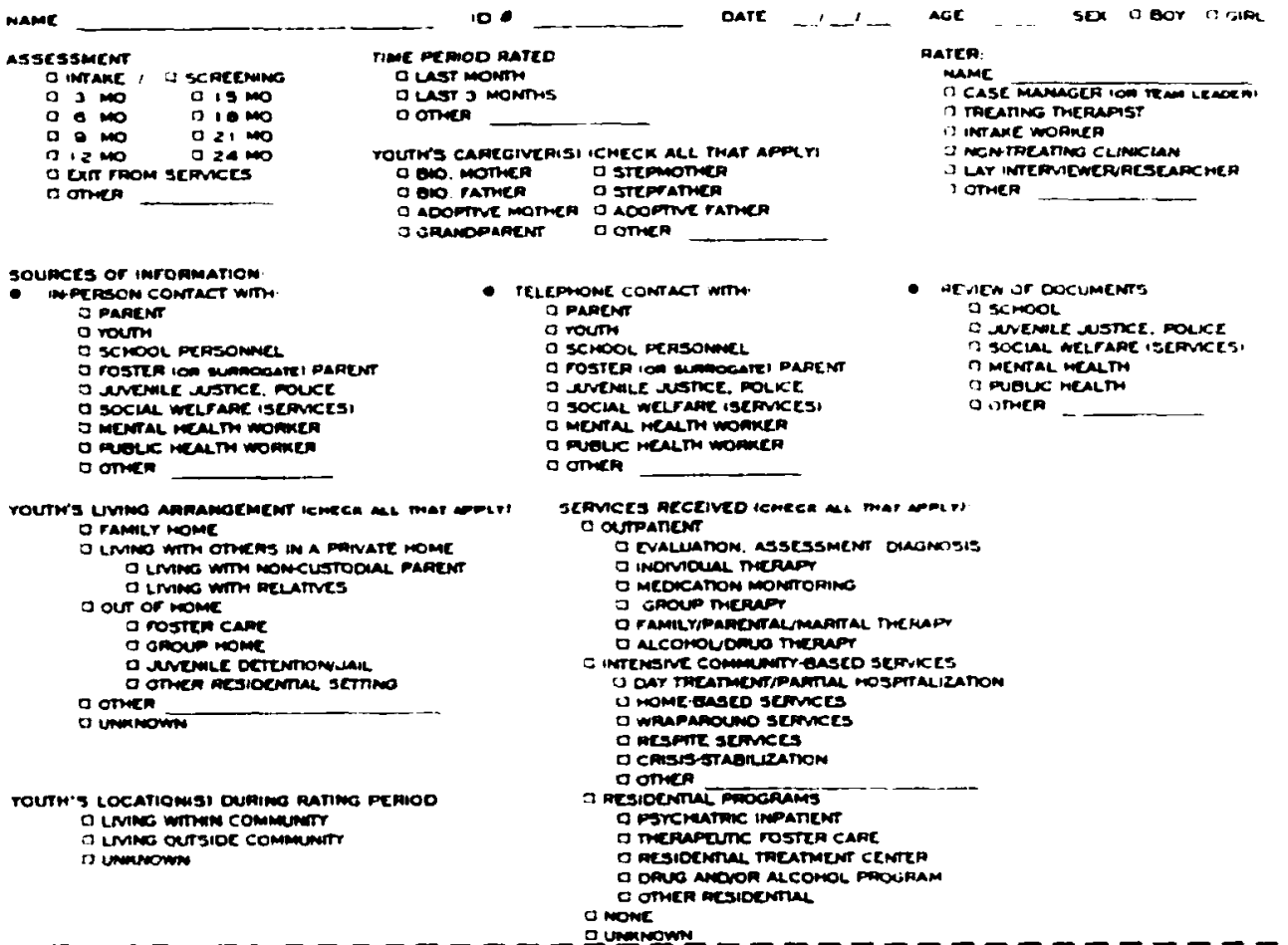

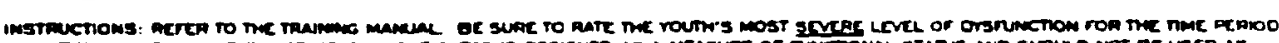

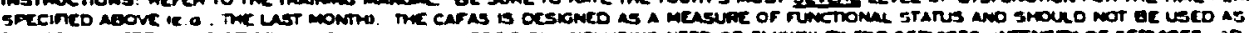

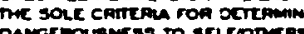

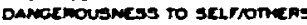

\section{SAEAS SCOAING SUMMARX}

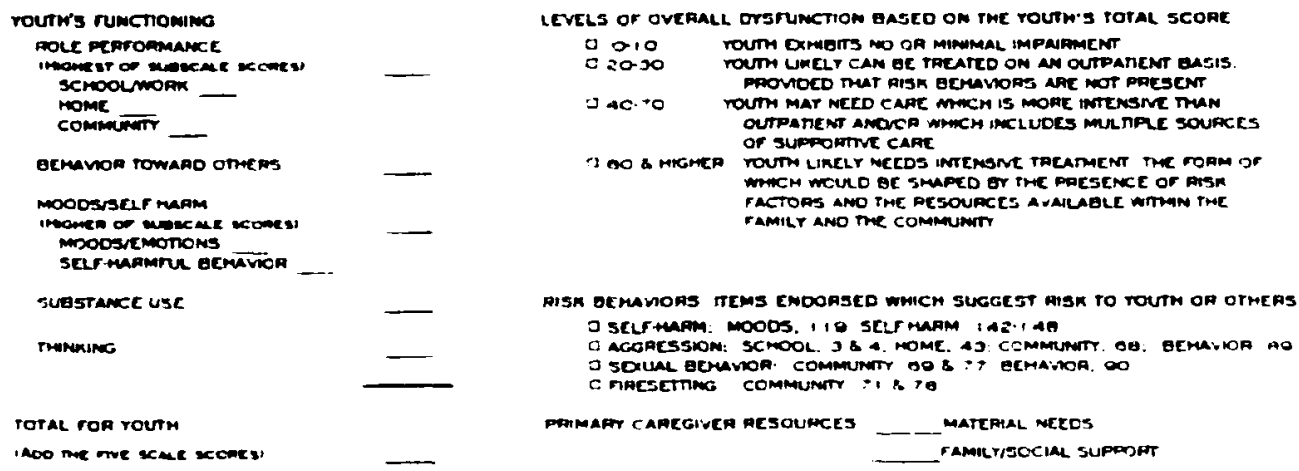



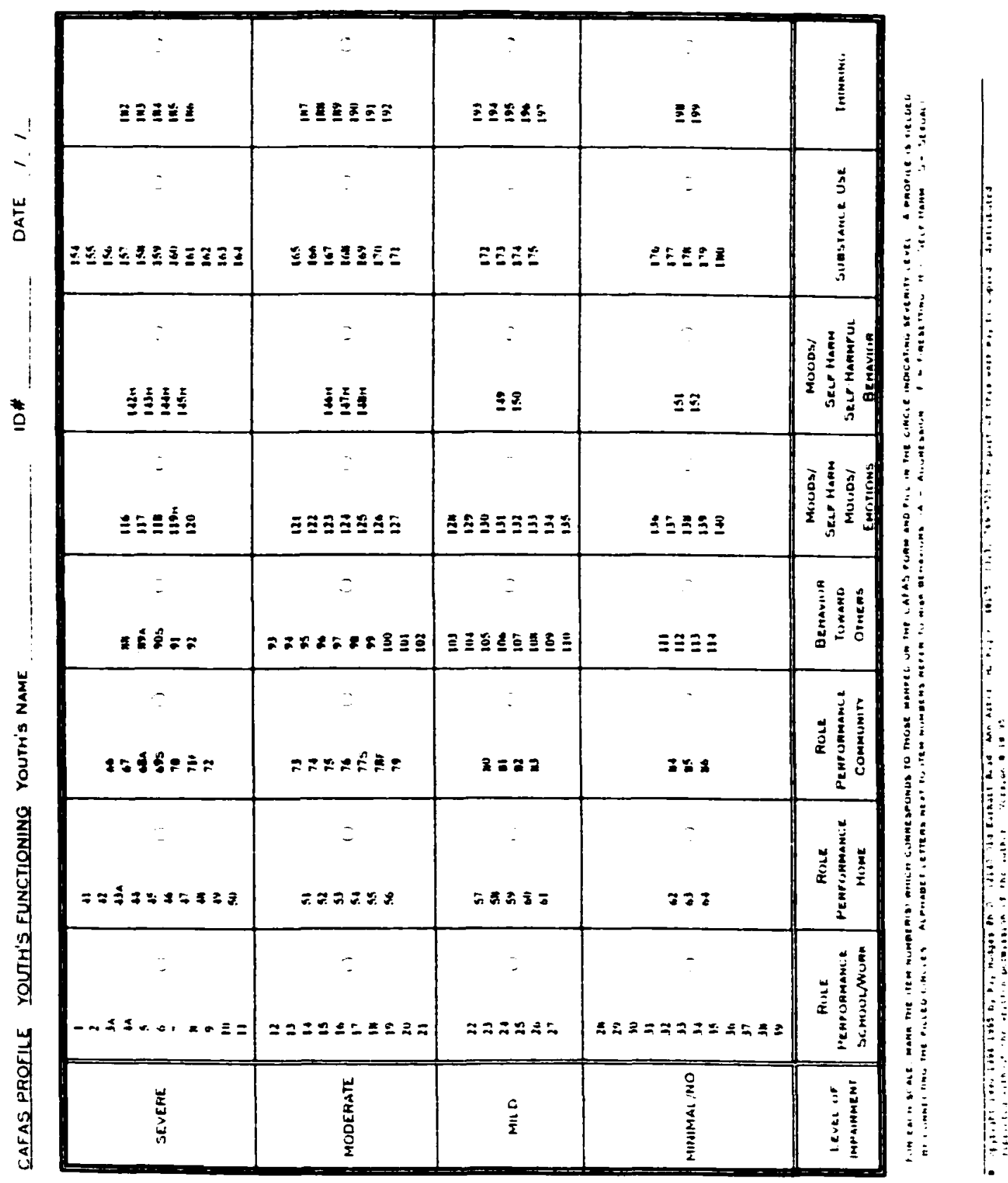
YOUTH'S NAME

$10 \#$

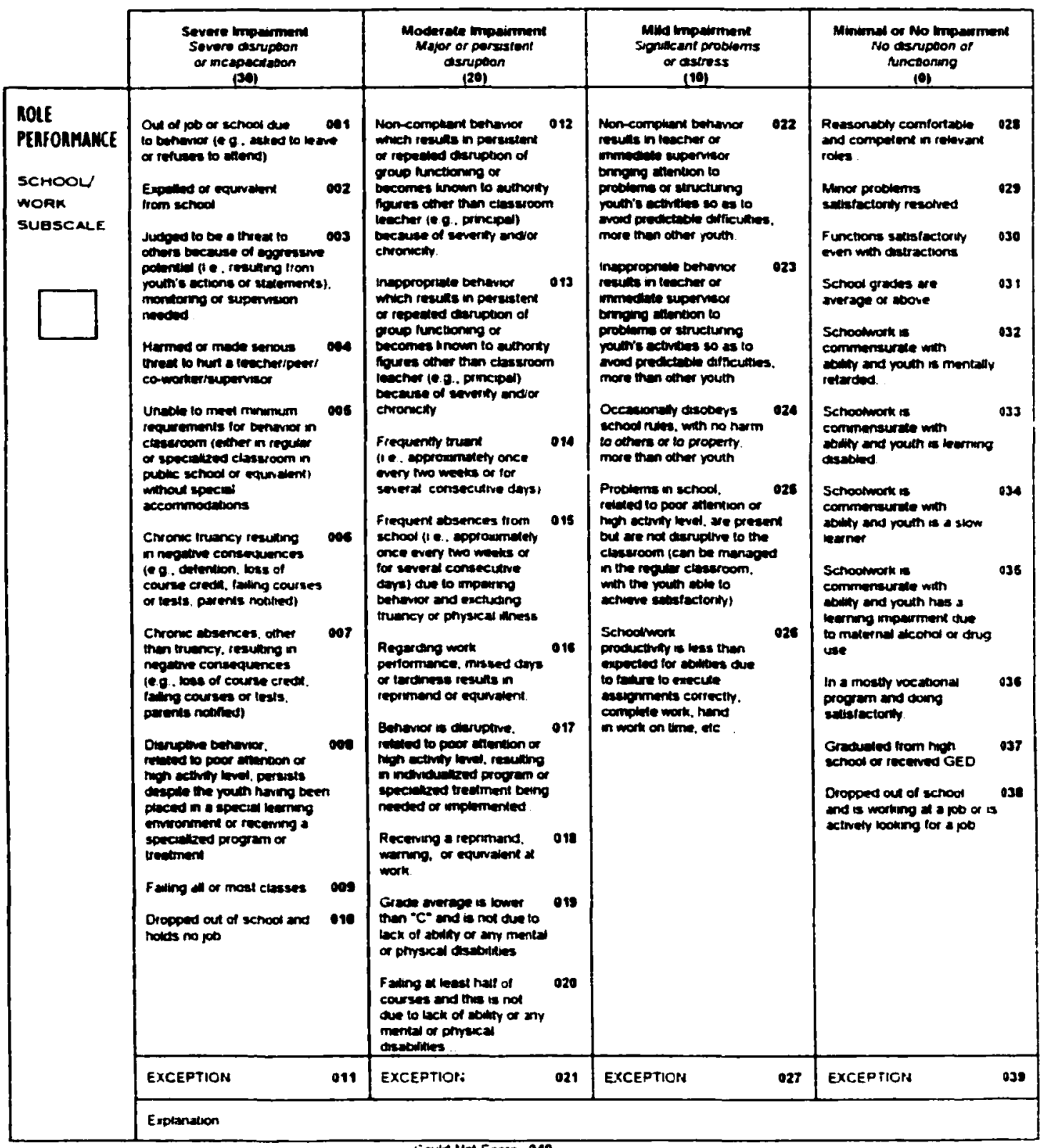

Could Hot Score 040

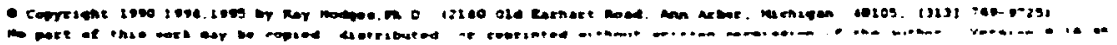


YOUTM'S NANE

ID\#

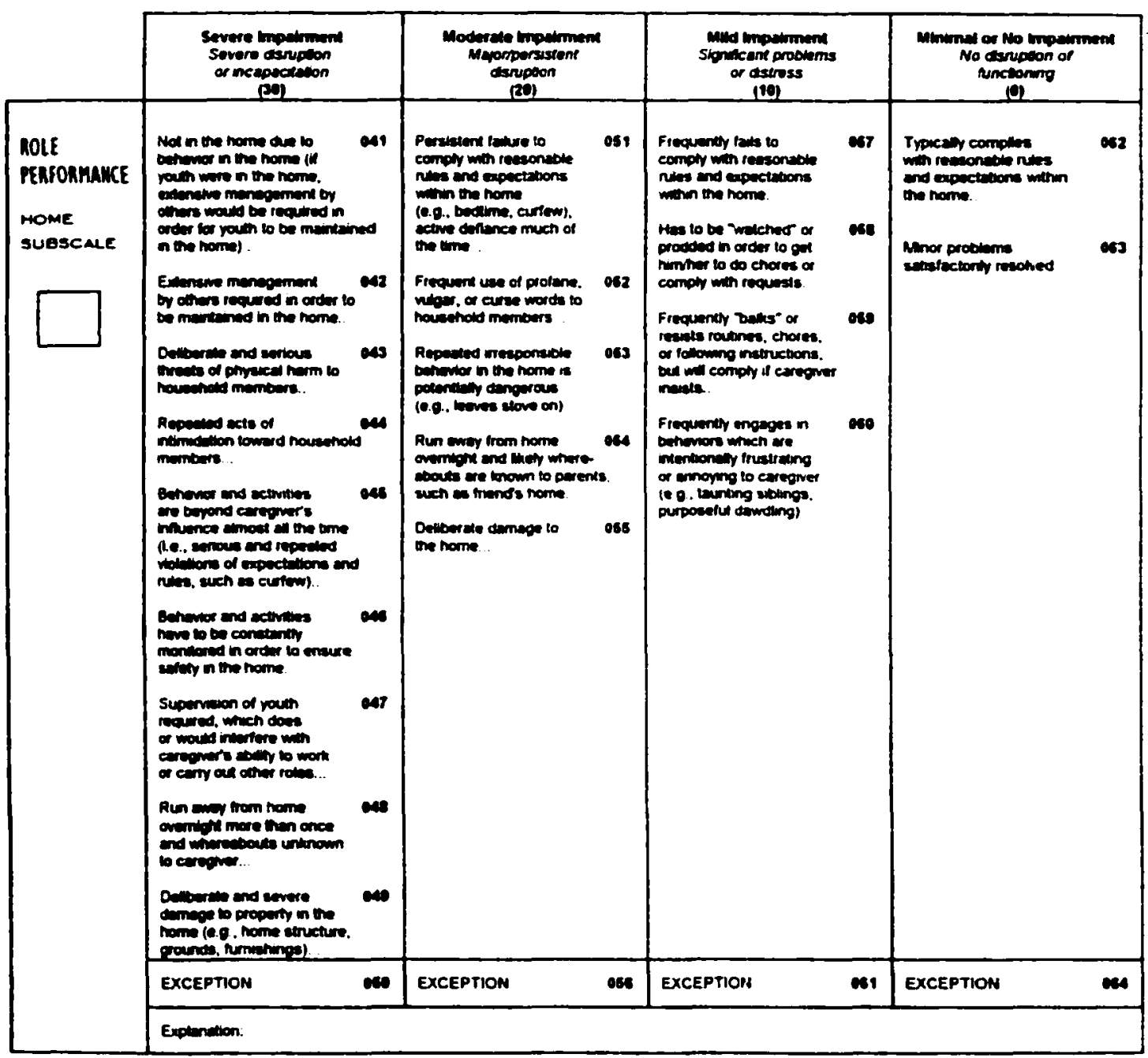

Cound Not Score. ess 
ID\#

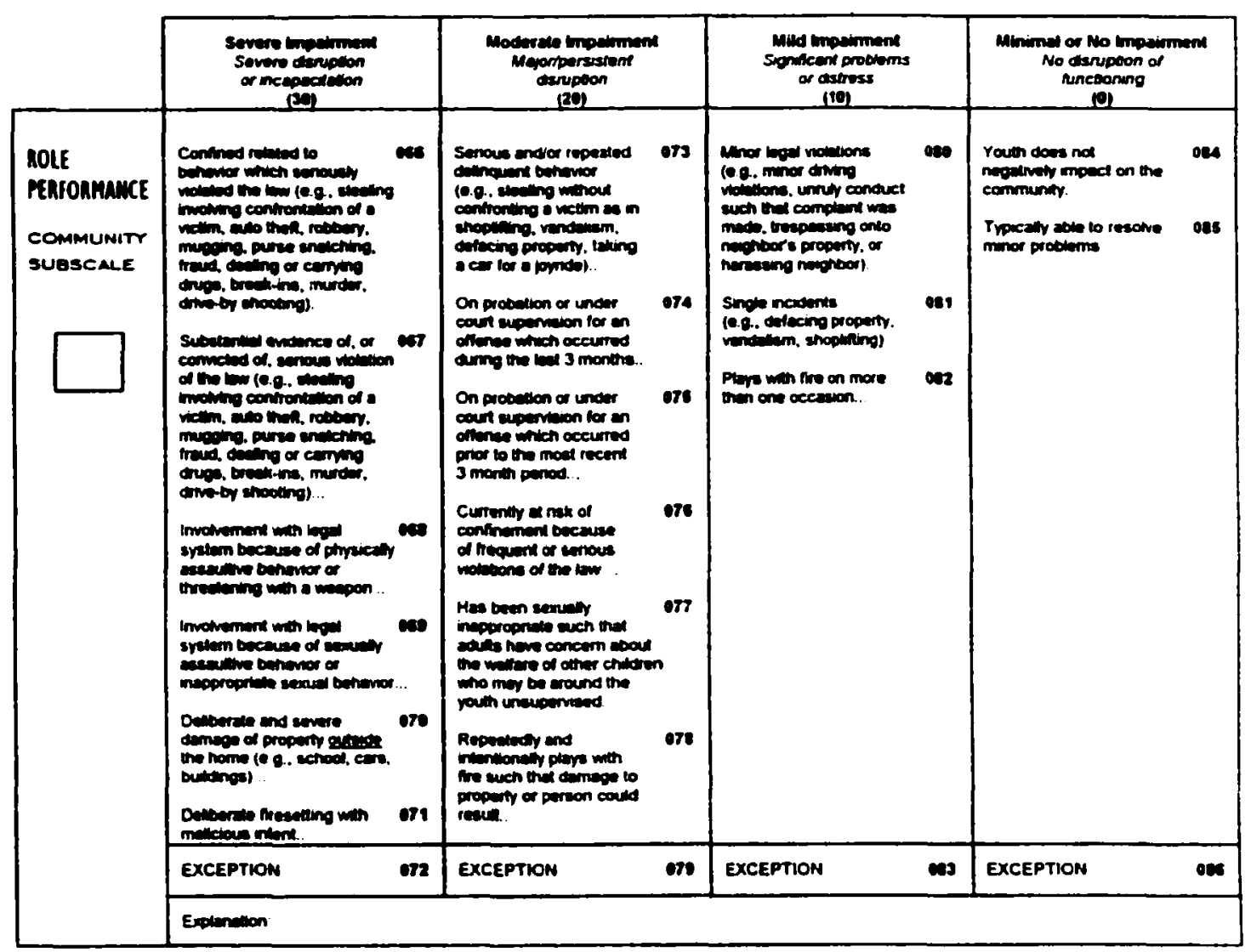

Cous Nol Seare: ont

ROLE PERFORMANCE SCORE = Highest of SCHOOLWORK, HOME. COMMUNITY sUbscores 
ID*

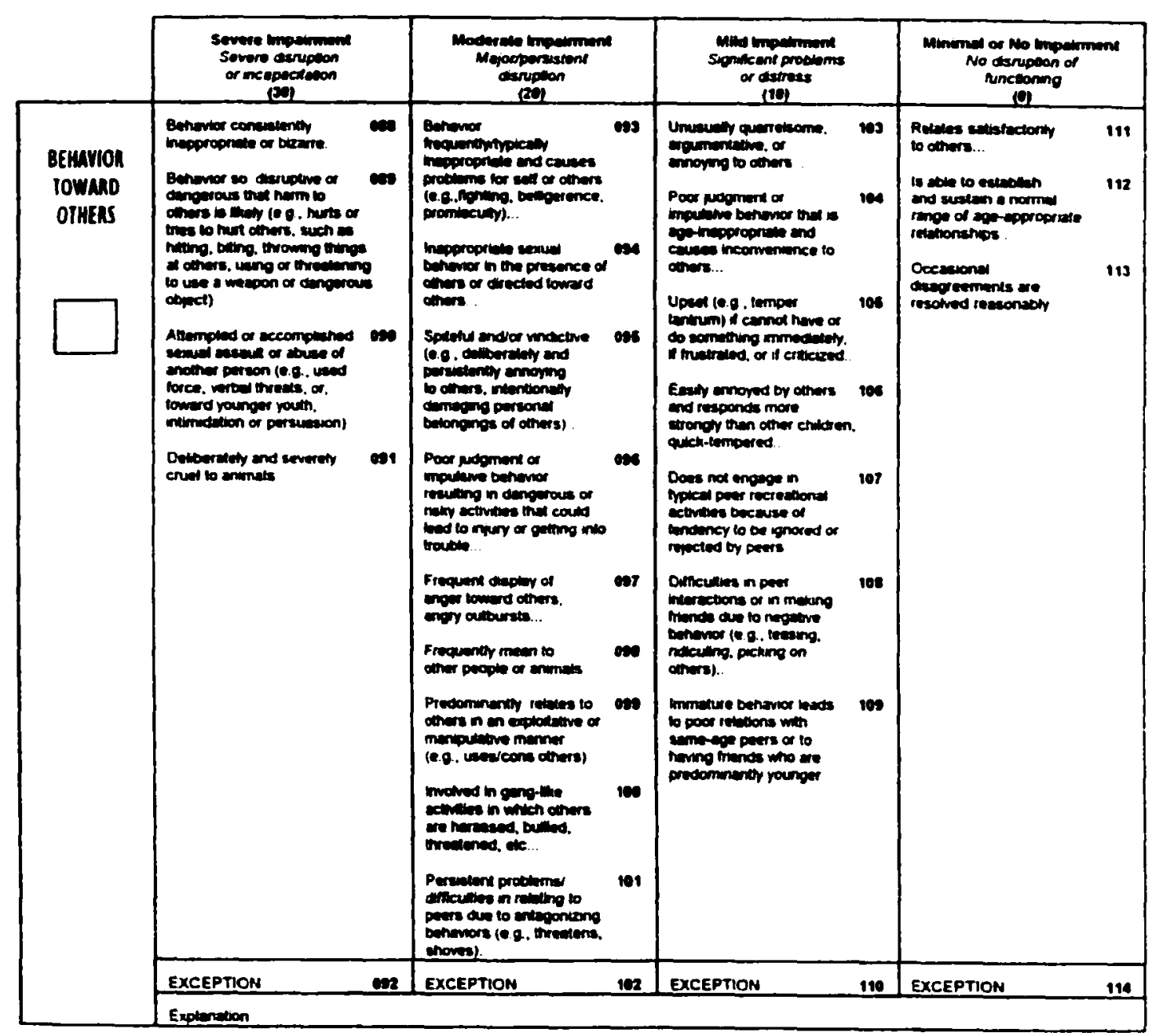

Coud Nox Score 115 
YOUTH'S NAME $10 \#$

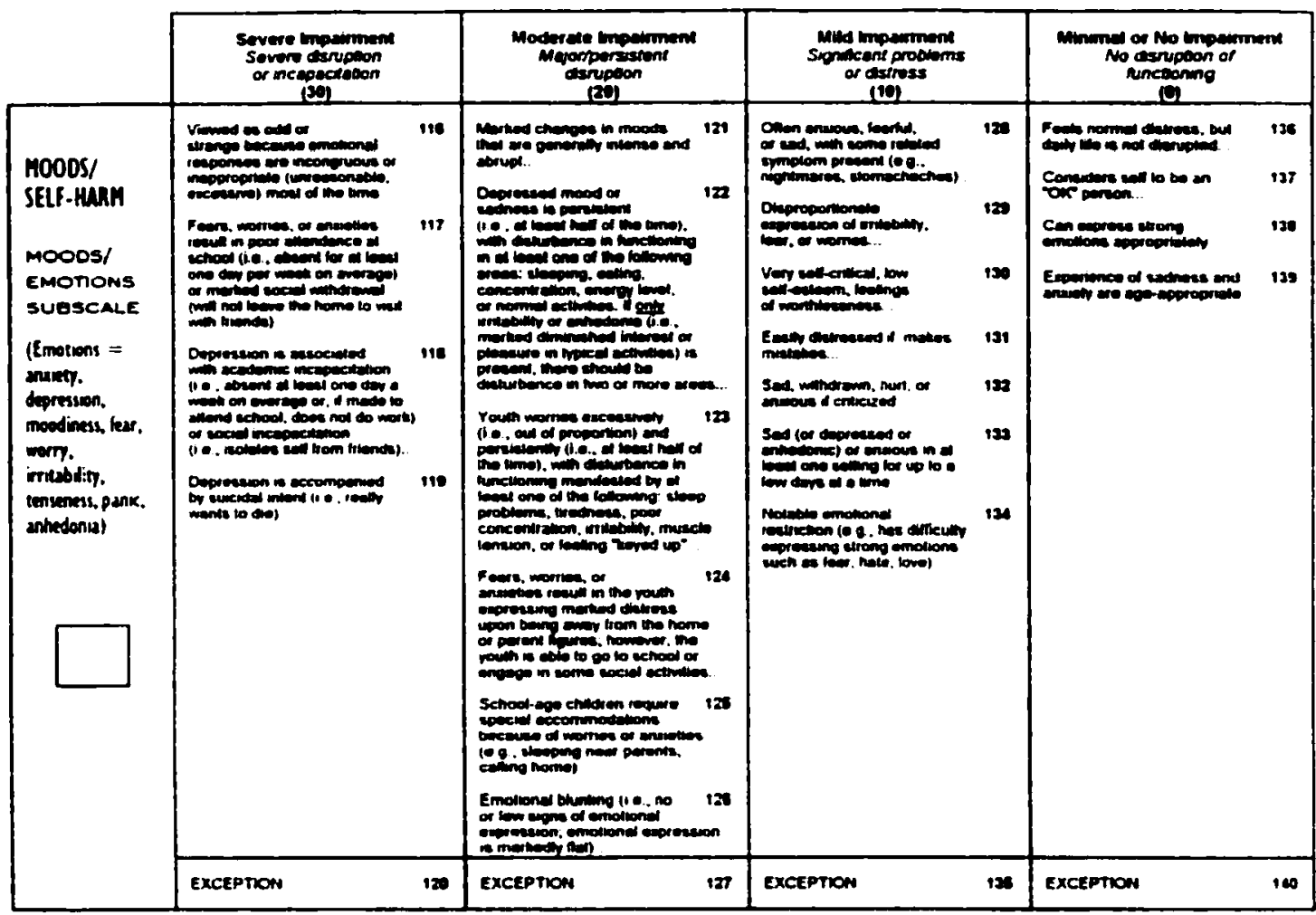

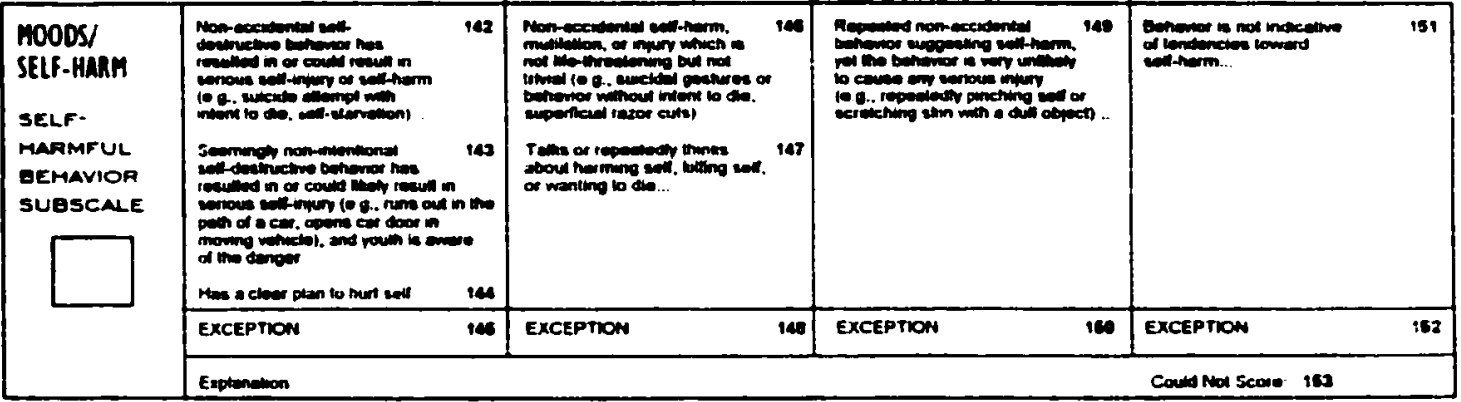

MOODS I SELF HARM SCORE = Higher of MOODS/EMOTIONS and SELF-MARMFUL BEHAVIOR subscores 
YOUTH'S NAME ID\#

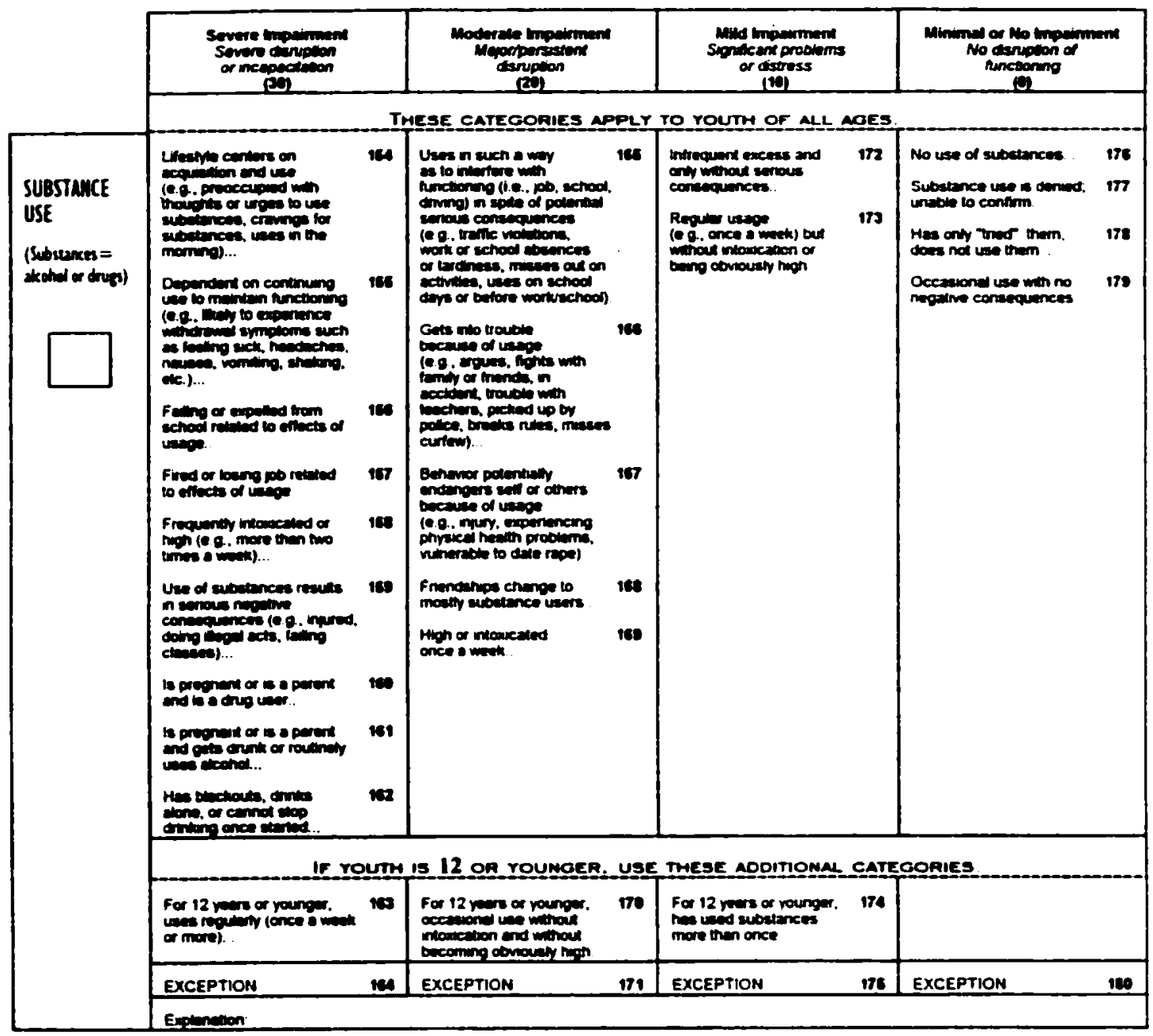

Coutd not Score 181 
YOUTH'S NAME 10*

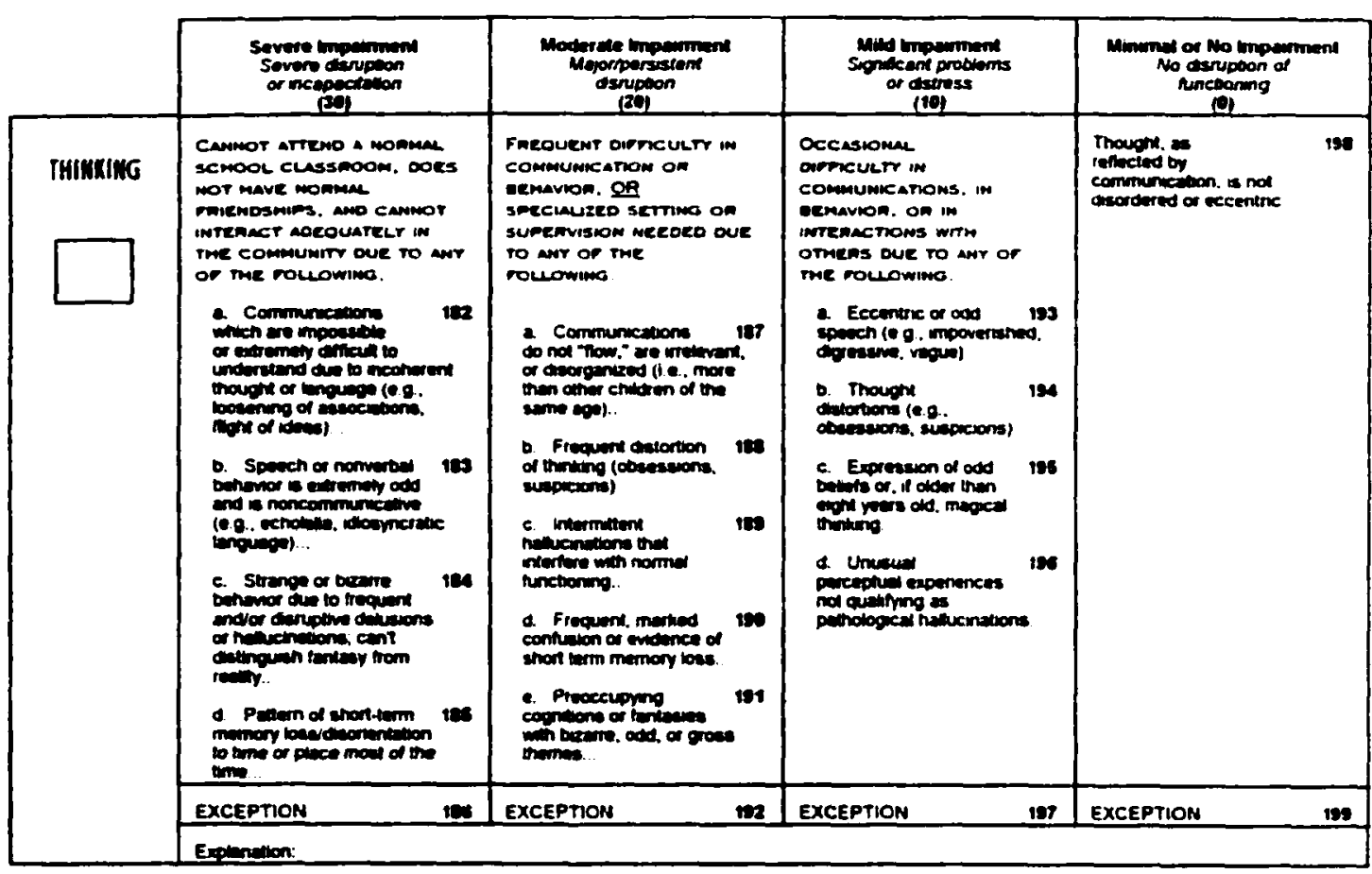

Coudd Nol Scove: 2us

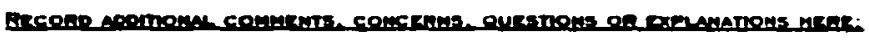


YOUTH'S NAME

ID\#

CAREGIVER BEING RATED: EBIMART FAMILY

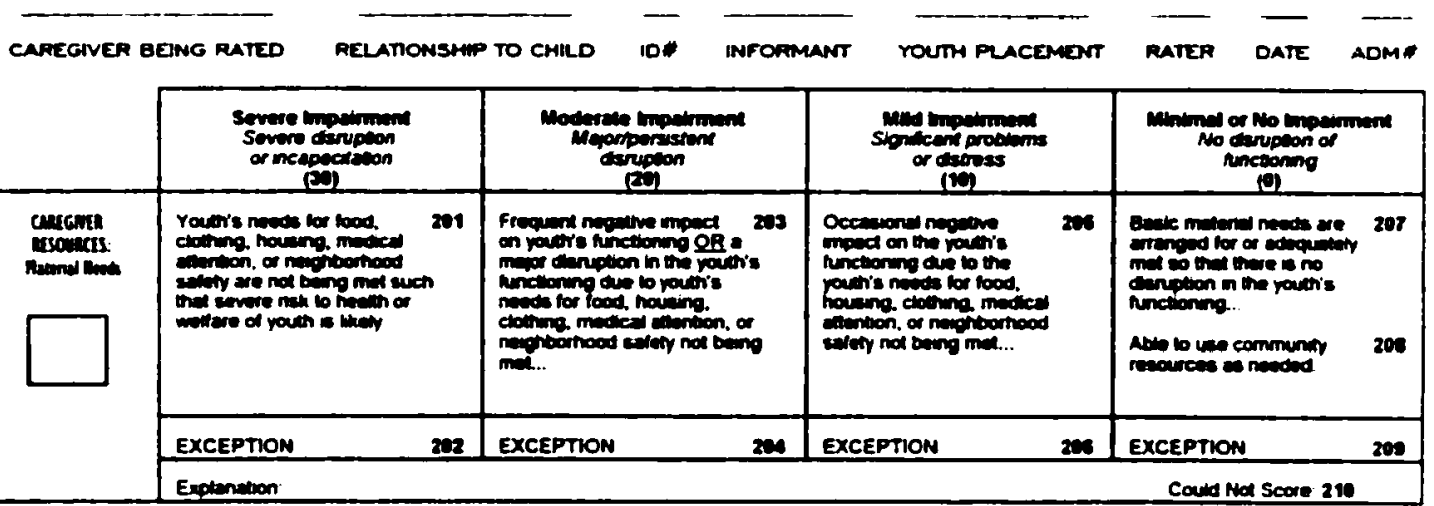

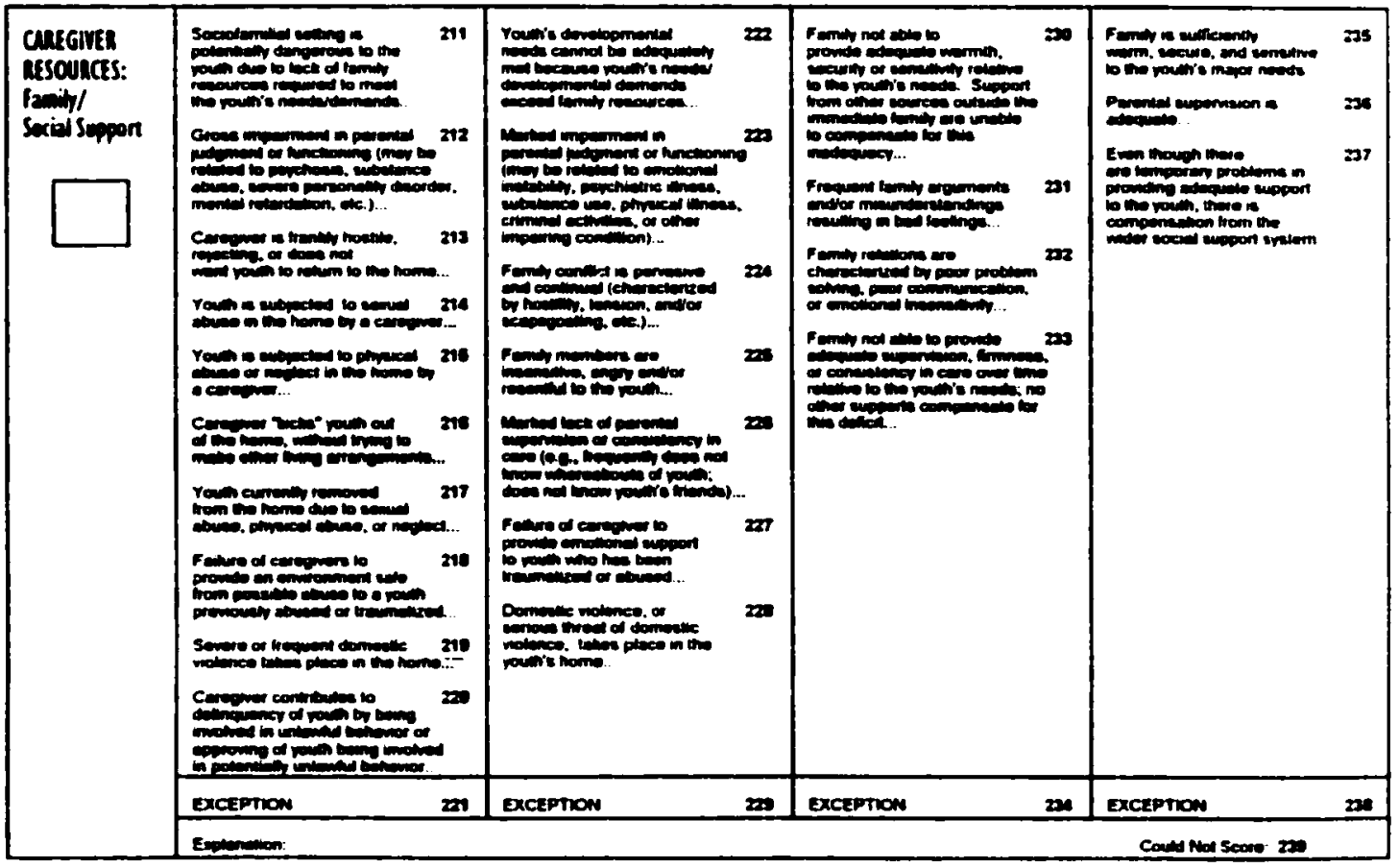

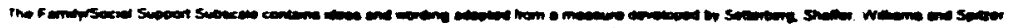


YOUTH'S NAME

ID\#

CAREGIVER BEING RATED: NOM-GUSTODIAL FAMILY QR PARENT NOT LIVING IN CHILD'S HOME

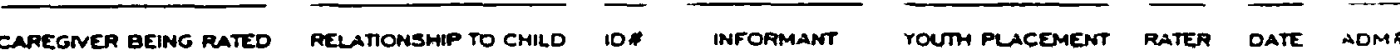

\begin{tabular}{|c|c|c|c|c|}
\hline & 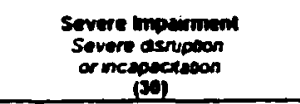 & $\begin{array}{l}\text { Moderate hompument } \\
\text { Mapipersistent } \\
\text { asrupoon } \\
\text { (20) }\end{array}$ & 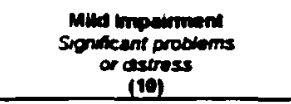 & 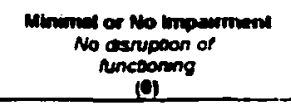 \\
\hline \multirow[t]{3}{*}{ 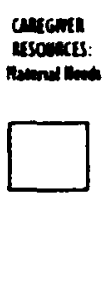 } & 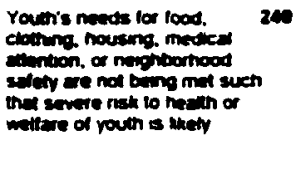 & 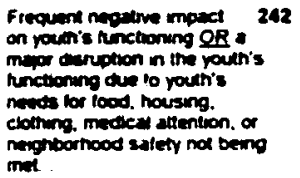 & 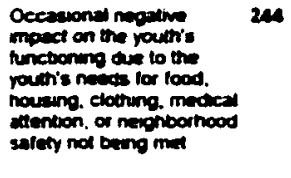 & 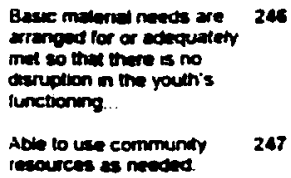 \\
\hline & EXCEPTION & EXCEPTION & EXCEPTION & EXCEPTION \\
\hline & Exponinon. & & & Could Net Score 240 \\
\hline
\end{tabular}

\begin{tabular}{|c|c|c|c|c|c|}
\hline \multirow[t]{3}{*}{$\begin{array}{l}\text { CaneGmen } \\
\text { Resounces: } \\
\text { lanilyl } \\
\text { Secial Suppon }\end{array}$} & 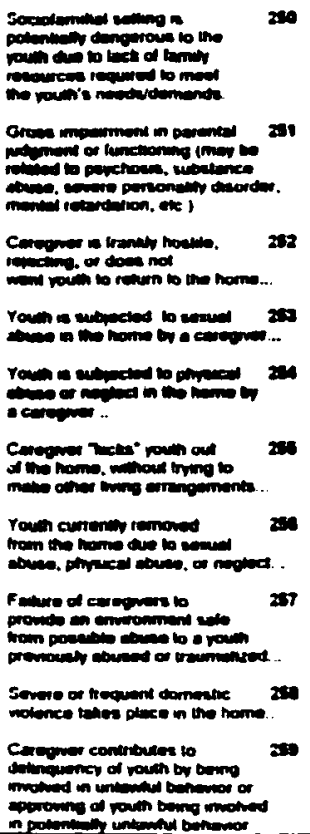 & 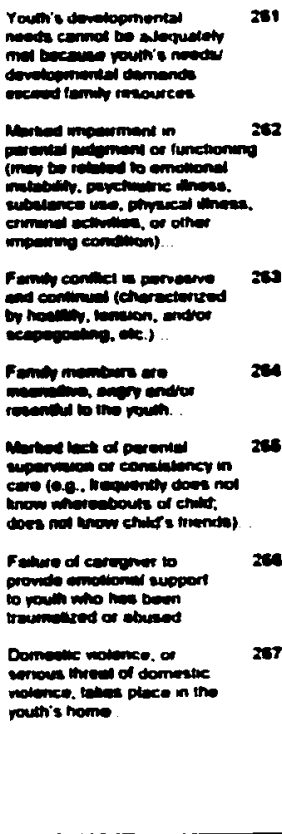 & 20 & 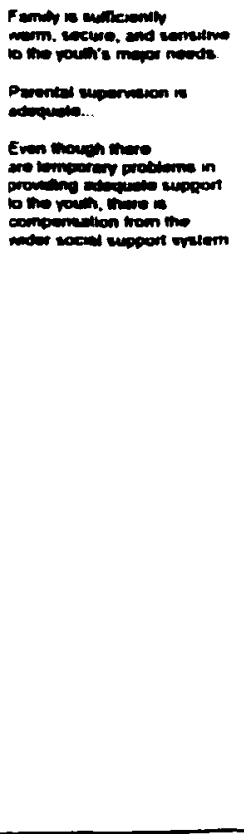 & $\begin{array}{l}275 \\
276\end{array}$ \\
\hline & Exception & EXCEPTION & EXCEPTION & EXCEPTION & $2 \pi$ \\
\hline & 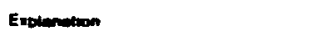 & & & Cound thot seme $27 \pi$ & \\
\hline
\end{tabular}

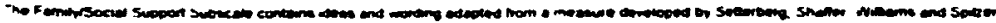

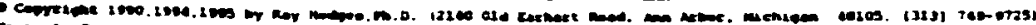


Yourn's Name

$10 \#$

CAREGIVER BEING RATED: SURROGATE CAREGIVER

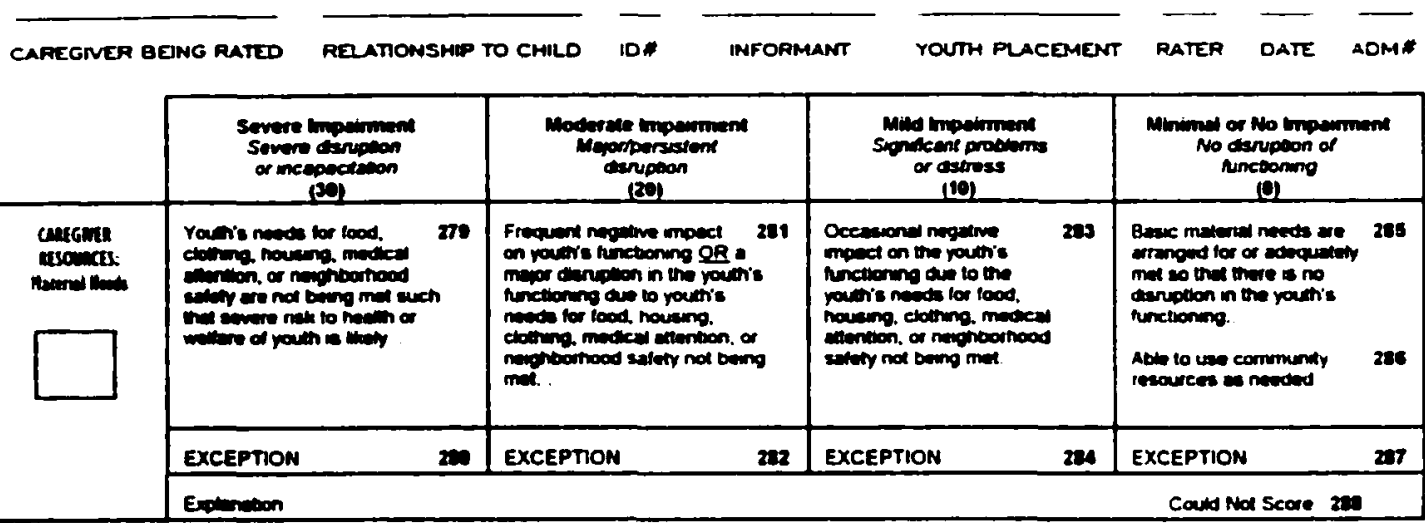

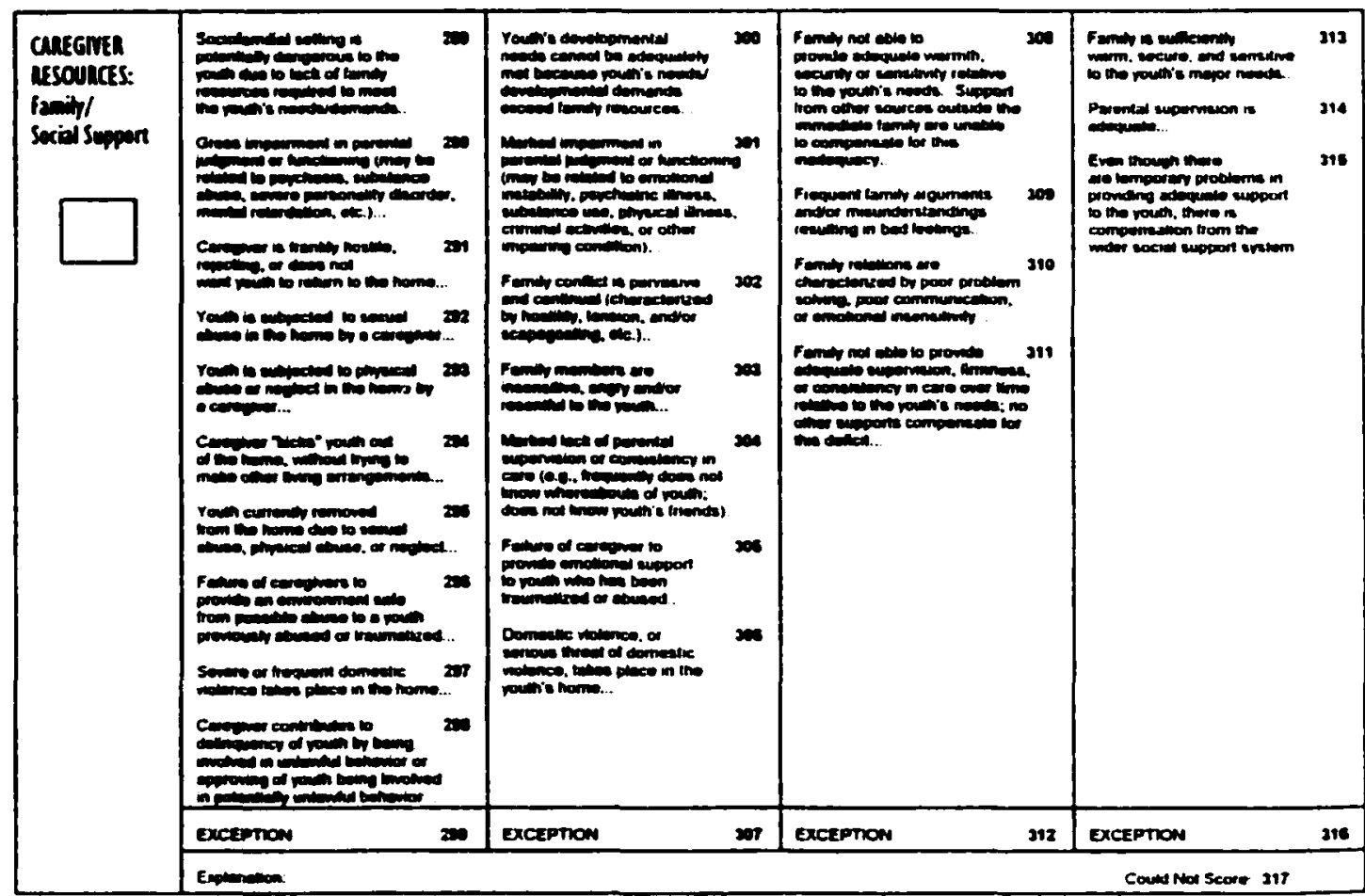

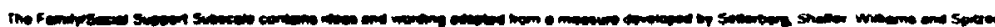

